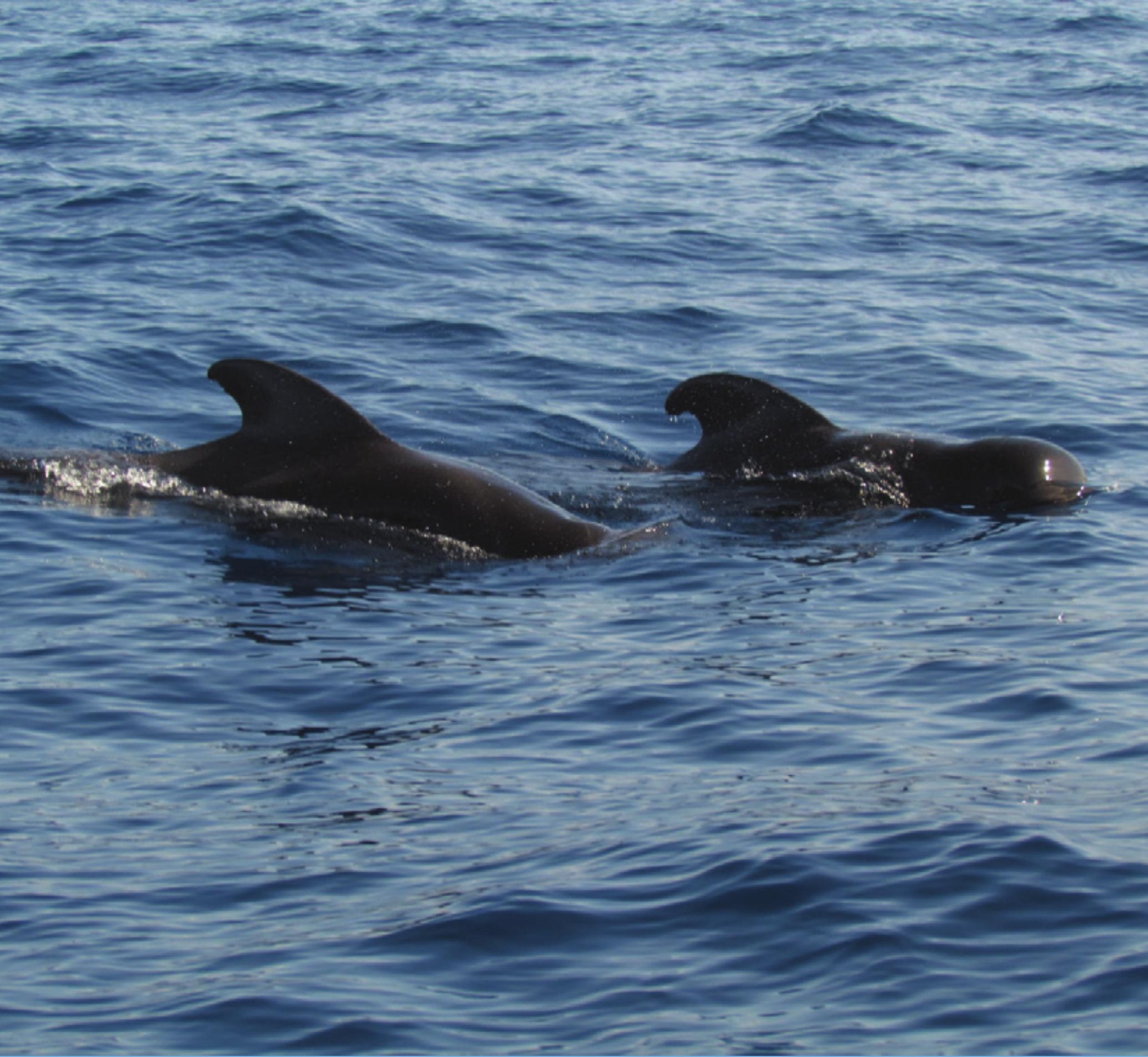

\title{
Defining and applying the concept of Favourable Reference Values for species and habitats under the EU Birds and Habitats Directives
}

Technical report

R.J. Bijlsma, E. Agrillo, F. Attorre, L. Boitani, A. Brunner, P. Evans, R. Foppen, S. Gubbay, J.A.M. Janssen,

A. van Kleunen, W. Langhout, R. Noordhuis, M. Pacifici, I. Ramírez, C. Rondinini, M. van Roomen,

H. Siepel \& H.V. Winter 



\section{Defining applying the concept of Favourable Reference Values for species and habitats under the EU Birds and Habitats Directives}

Technical report

Service contract No. 07.0202/2015/715107/SER/ENV.B.3 financed by the European Commission - contractor: Alterra, institute within the legal entity Stichting DLO (now: Wageningen Environmental Research)

R.J. Bijlsma ${ }^{1}$, E. Agrillo ${ }^{2}$, F. Attorre ${ }^{2}$, L. Boitani ${ }^{3}$, A. Brunner ${ }^{4}$, P. Evans ${ }^{5}$, R. Foppen ${ }^{6}$, S. Gubbay ${ }^{7}$, J.A.M. Janssen ${ }^{1}$, A. van Kleunen ${ }^{6}$, W. Langhout ${ }^{4}$, R. Noordhuis ${ }^{8}$, M. Pacifici $^{3}$, I. Ramírez ${ }^{9}$, C. Rondinini ${ }^{3}$, M. van Roomen ${ }^{6}$,

H. Siepel ${ }^{10}$ \& H.V. Winter ${ }^{11}$

1 Wageningen Environmental Research

2 Comunità Ambiente

3 Istituto Ecologia Applicata

4 Stichting BirdLife Europe

5 Sea Watch Foundation

6 Sovon Dutch Centre for Field Ornithology

7 Susan Gubbay

8 Deltares

9 BirdLife International

10 Radboud University Nijmegen

11 Wageningen Marine Research

Wageningen Environmental Research

Wageningen, January 2019

Report 2928

ISSN 1566-7197 


\section{)2}

Birdlife

\section{y2 \\ Birdlife

\section{Deltares}

Enabling Delta Life
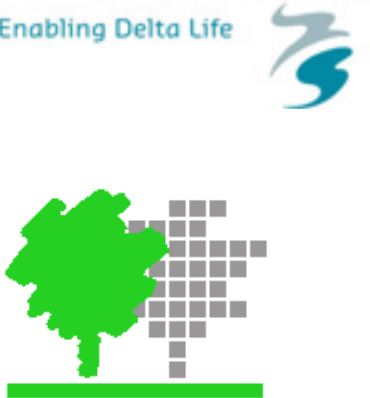

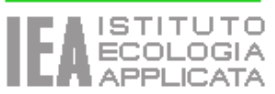

sea watch

FOU NDATION
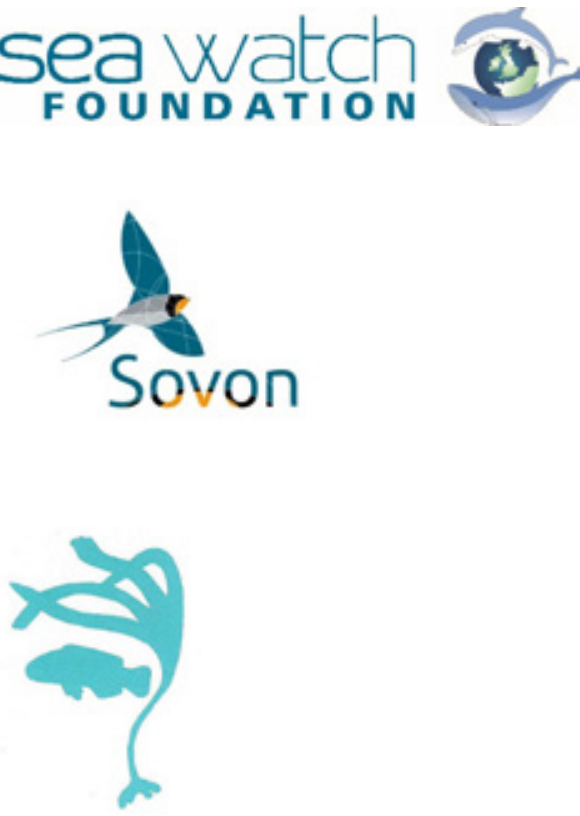

Susan Gubbay

Radboud University 
Bijlsma, R.J., E. Agrillo, F. Attorre, L. Boitani, A. Brunner, P. Evans, R. Foppen, S. Gubbay, J.A.M. Janssen, A. van Kleunen, W. Langhout, R. Noordhuis, M. Pacifici, I. Ramírez, C. Rondinini, M. van Roomen, H. Siepel \& H.V. Winter, 2019. Defining and applying the concept of Favourable Reference Values for species and habitats under the EU Birds and Habitats Directives; Technical report. Wageningen, Wageningen Environmental Research, Report 2928. 94 pp.

\section{Disclaimer}

The information and views set out in this report are those of the author(s) and do not necessarily reflect the official opinion of the European Commission. The Commission does not guarantee the accuracy of the data included in this report. Neither the Commission nor any person acting on the Commission's behalf may be held responsible for the use which may be made of the information contained therein.

The official guidelines on reporting under Article 17 of the Habitats Directive, including on setting Favourable Reference Values, are available from the Reporting Reference Portal (http://cdr.eionet.europa.eu/help/habitats_art17). They were adopted by the Habitats Committee and endorsed by the European Commission (DG Environment). Therefore, in case of conflicting definitions, approach or examples, the above-mentioned official guidelines take precedence.

The pdf file is free of charge and can be downloaded at https://doi.org/10.18174/469035 or via the website www.wur.nl/environmental-research (scroll down to Publications - Wageningen Environmental Research reports). Wageningen Environmental Research does not deliver printed versions of the Wageningen Environmental Research reports.

2019 Wageningen Environmental Research (an institute under the auspices of the Stichting Wageningen Research), P.O. Box 47, 6700 AA Wageningen, The Netherlands, $\mathrm{T}+31$ (0)317 4807 00, www.wur.nl/environmental-research. Wageningen Environmental Research is part of Wageningen University \& Research.

- Acquisition, duplication and transmission of this publication is permitted with clear acknowledgement of the source.

- Acquisition, duplication and transmission is not permitted for commercial purposes and/or monetary gain.

- Acquisition, duplication and transmission is not permitted of any parts of this publication for which the copyrights clearly rest with other parties and/or are reserved.

Wageningen Environmental Research assumes no liability for any losses resulting from the use of the research results or recommendations in this report.

Wageningen Environmental Research Report 2928 | ISSN 1566-7197

Photo cover: Short-finned pilot whales, Tenerife (Patty Bijlsma). 



\section{Contents}

$\begin{array}{ll}\text { List of abbreviations } & 7\end{array}$

$\begin{array}{ll}\text { Preface } & 9\end{array}$

$\begin{array}{ll}\text { Summary } & 11\end{array}$

$\begin{array}{ll}\text { Introduction and Member State approaches } & 15\end{array}$

$\begin{array}{lll}1.1 & \text { Background } & 15\end{array}$

$\begin{array}{lll}1.2 & \text { Objectives of the service contract } & 18\end{array}$

$\begin{array}{lll}1.3 & \text { The consortium } & 18\end{array}$

1.4 Reading guide $\quad 18$

1.5 Member State approaches: reporting context $\quad 19$

1.6 Summary of Member State approaches $\quad 21$

$\begin{array}{ll}\text { 1.6.1 General aspects } & 21\end{array}$

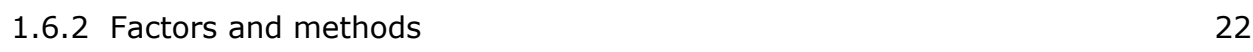

1.6.3 Spatial scale $\quad 24$

1.7 Documented approaches by Member States $\quad 25$

$\begin{array}{ll}\text { 1.7.1 Belgium - Flanders } & 26\end{array}$

$\begin{array}{ll}1.7 .2 \text { France } & 26\end{array}$

$\begin{array}{ll}1.7 .3 \text { Netherlands } & 27\end{array}$

$\begin{array}{ll}\text { 1.7.4 United Kingdom } & 27\end{array}$

2 Definitions and concepts for setting FRVs $\quad 29$

$\begin{array}{lll}2.1 & \text { Definitions } & 29\end{array}$

2.1.1 Conservation status 29

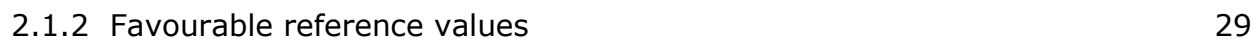

2.1.3 Current and Directive value, short and long term, recent and
historical past

2.1.4 Other terms and aspects of scale 30

2.2 Literature review of relevant concepts 30

2.2.1 Population viability analysis (PVA) 30

2.2.2 Minimum viable population (MVP) and generalised genetic rules 31

2.2.3 MVP-targets derived from body size relationships $\quad 32$

2.2.4 Potential range, habitat suitability and distribution modelling 32

2.2.5 Spatially structured populations: management units (assessment units) and flyway populations 33

3.1 General considerations

3.1.1 Guidance on the interpretation of FRVs, references and feasibility aspects

3.1.2 Relationships between CS parameters

3.1.3 Reference-based and model-based methods $\quad 36$

$\begin{array}{ll}3.1 .4 \text { A general approach for setting FRVs } & 37\end{array}$

3.2 The stepwise approach for species $\quad 39$

3.2.1 Step 1 - Gather information $\quad 39$

3.2.2 Step 2 - Set favourable reference values $\quad 45$

$\begin{array}{lll}3.3 & \text { The stepwise approach for habitat types } & 48\end{array}$

3.3.1 Step 1 - Gather information 48

3.3.2 Step 2 - Set favourable reference values 51 
4.1 Migratory species and species with large home ranges $\quad 55$

4.2 Marine mammals (cetaceans)

4.2.1 General remarks

4.2.2 Setting FRPs for cetaceans 56

4.2.3 Setting FRRs for cetaceans $\quad 58$

4.2.4 In summary $\quad 58$

$\begin{array}{lll}4.3 & \text { Birds } & 61\end{array}$

4.3.1 General remarks $\quad 61$

4.3.2 The MVP-concept in setting FRVs for birds $\quad 61$

4.3.3 The potential range method in setting FRVs for reproductive
populations

4.3.4 Migratory birds and setting FRVs for the staging and wintering populations $\quad 63$

$\begin{array}{lll}4.4 & \text { Migratory fish } & 68\end{array}$

4.4.1 General remarks 68

$\begin{array}{ll}4.4 .2 \text { Spatial scale of functioning } & 69\end{array}$

$\begin{array}{ll}4.4 .3 \text { Setting FRPs } & 69\end{array}$

4.4.4 Setting FRRs $\quad 70$

$\begin{array}{lll}4.5 & \text { Invertebrates } & 71\end{array}$

$\begin{array}{ll}\text { 4.5.1 General remarks } & 71\end{array}$

$\begin{array}{ll}\text { 4.5.2 Population categories for species groups } & 71\end{array}$

$\begin{array}{lll}4.6 & \text { Marine habitats } & 73\end{array}$

$\begin{array}{ll}\text { 4.6.1 General remarks } & 73\end{array}$

4.6.2 Setting FRR and FRA for marine habitats 73

$\begin{array}{ll}\text { General references } & 76\end{array}$

$\begin{array}{lll}\text { Annex } 1 & \text { Questionnaire sent to Member States } & 80\end{array}$

Annex 2 Lists of migratory species and species with large home ranges 82 


\section{List of abbreviations}

\begin{tabular}{|c|c|}
\hline \multicolumn{2}{|c|}{ Member State codes } \\
\hline Austria & AT \\
\hline Belgium & BE, BE-VLG (Flanders), BE-WAL (Wallonia) \\
\hline Bulgaria & BG \\
\hline Cyprus & $\mathrm{CY}$ \\
\hline Czech Republic & $\mathrm{CZ}$ \\
\hline Germany & DE \\
\hline Denmark & DK \\
\hline Estonia & $\mathrm{EE}$ \\
\hline Spain & ES \\
\hline Finland & FI \\
\hline France & FR \\
\hline Greece & GR \\
\hline Croatia & HR \\
\hline Hungary & HU \\
\hline Ireland & IE \\
\hline Italy & IT \\
\hline Lithuania & LT \\
\hline Luxembourg & LU \\
\hline Latvia & LV \\
\hline Malta & MT \\
\hline Netherlands & NL \\
\hline Poland & $\mathrm{PL}$ \\
\hline Portugal & PT \\
\hline Romania & RO \\
\hline Sweden & SE \\
\hline Slovenia & SI \\
\hline Slovakia & SK \\
\hline United Kingdom & UK \\
\hline
\end{tabular}

\section{Other abbreviations}

BD

CS

CV

EC

EEA

FCS

FRA

FRP

FRR

FRV

HD

DV

MS

MVP

PVA

SDM
Birds Directive

Conservation status

Current value. The value reported by the Member State for the present reporting period, which is to be compared to the favourable reference value

European Commission

European Environment Agency

Favourable Conservation Status

Favourable reference area (for habitats only)

Favourable reference population (for species only)

Favourable reference range (for habitats and species)

Favourable reference value (specified as FRA, FRP or FRR)

Habitats Directive

Directive value. Population size, area or range of a species or habitat at a time as close as possible to the date when the Directive came into force

Member State

Minimum Viable Population

Population Viability Analysis

Species Distribution Model 


\section{Preface}

The Birds and Habitats Directive ensure the conservation of a wide range of rare, threatened or endemic animal and plant species as well as characteristic habitat types in Europe. In reporting both directives use 'distance to target' measures regarding conservation status. The Habitats Directive considers explicit favourable reference values while the Birds Directive requires to maintain bird populations at a level which corresponds to their ecological, scientific and cultural requirements.

This report presents a common methodology for setting favourable reference values for features of both directives, in agreement with the Explanatory Notes and Guidelines for reporting under Article 17 of the Habitats Directive for the period 2013-2018 (http://cdr.eionet.europa.eu/help/habitats_art17).

The study was commissioned by the EC under the service contract 'Defining and applying the concept of favourable reference values for species and habitats under the EU Birds and Habitats Directives' (Service contract No. 07.0202/2015/715107/SER/ENV.B.3) and carried out by a consortium with the following partners: Wageningen Environmental Research, Wageningen Marine Research, Comunità Ambiente, Istituto Ecologia Applicata, Stichting BirdLife Europe, BirdLife International, Sea Watch Foundation, Sovon Dutch Centre for Field Ornithology, Susan Gubbay, Deltares and Radboud University Nijmegen.

The work was followed and reviewed by the Ad hoc group on 'favourable reference values' of the Expert Group on Reporting under the Nature Directives, and supported the general objective of the ad hoc group (chaired by EEA), namely to improve the guidance related to the setting and reporting of favourable reference values under the nature reporting, and contribute to further harmonise approaches between Member States. 


\section{Summary}

\section{Introduction}

In order to assess the conservation status under the Habitats Directive (HD) according to the agreed method used since the reporting period 2001-2006 under HD Article 17, it is necessary to determine favourable reference values (FRVs) for the range of habitat types and species (FRR), for area of habitat types (FRA) and for population size of species (FRP). FRVs are key reference levels to define when Favourable Conservation Status (FCS) is being achieved for individual species and habitats. Similar concepts apply to the Birds Directive (BD) even though they are spelled out less clearly and different terms are used.

Despite the fact that FRVs are essential elements to determine the distance to FCS, reporting has shown that they are still poorly developed and often inconsistently applied across Member States (MSs). Until now, the FRV was a concept to be applied at the level of a biogeographical region within a MS. However, for some species, it may be more relevant to set reference values at the scale of a biogeographical region or even larger. In the new bio-geographical process (Natura 2000 seminars), MS authorities have raised the need for streamlining and harmonisation of the concept behind assessing FCS, particularly establishing FRVs. In order to support this, the European Commission DG ENV issued a call for tenders for the service contract 'Defining and applying the concept of favourable reference values for species and habitats under the EU Birds and Habitats Directives'

(ENV.B.3/SER/2015/0009). The BD does not use FRVs but according to the tender specifications the terms and definitions used under the HD should be used for birds as well. The main objectives of the service contract were:

1. Support the development of methodologies and guidance on how to establish FRVs including testing of these methods;

2. Apply the resulting method (i.e. establishing FRVs) for a defined group of habitats and species.

\section{Member State approaches}

Primary input to the project was provided by questionnaires filled by Member State representatives involved in Article 12 (BD) and Article 17 (HD) reporting. The inquiry focused on methods for setting FRVs.

The database compiled by EEA from the Article 17 reports for the period 2007-2012 was used to find out for how many habitats and species FRVs have been reported by operators or real values. These data show that the current range is considered sufficient for $80 \%$ and $60 \%$ of the reported habitats and species respectively. For area and population size the corresponding figures are $55 \%$ and $30 \%$. Real values different from current values are only reported for $1 \%$ (FRR habitats), 2\% (FRR species), $6 \%$ (FRA) en $5 \%$ (FRP) of the habitats or species. Only a few Member States assessed real valued FRVs systematically.

Conclusions from the MS questionnaires include:

- Expert opinion is mentioned as one of the main ways of setting FRVs, in fact most if not all MSs somehow included expert opinion at some stage.

- About half of the MSs indicate that feasibility considerations have not been used in setting FRVs, whereas the other MSs included technical, social and/or financial aspects.

- Historical range and distribution have been used as important factors in setting FRVs by a majority of MSs, but specific historical references have much less been considered.

- Estimates of minimum viable population (MVP) size were not used by about $50 \%$ of the MSs. Some MSs used values from the literature while population viability analyses were only performed by a few MSs in special cases.

- Mobile species with dynamic ranges were explicitly considered only by a few MSs using expert opinion or in special cases (birds, large carnivores). 
- MSs suggest reference values above MS level for large carnivores, seals, marine migratory species, migratory fish, migratory bats and large birds with large home ranges.

\section{Definitions and concepts for setting FRVs}

Given the definitions of FRVs by the European Commission, setting FRP/FRA and FRR is interdependent and asks for an iterative process such that the FRR includes the extra distribution required for restoring the FRP/FRA in the natural range of the species/habitat as well as additional distribution in areas of the former range where the species/habitat has disappeared. The FRR acts as a geographical envelope for FRP and FRA.

In using historical information for setting FRVs, a broad historical perspective is needed by considering the recent past, including about 50 years before the relevant Directive came into force, and the historical past, up to the last two or three centuries, depending on occurrences of major impacts on distribution, population size or area.

Several concepts from the literature are summarized: population viability analysis (PVA), minimum viable populations (MVPs), MVP-targets derived from body size relationships, distribution modelling including habitat suitability and potential range, and the concepts of management unit and flyway as examples of spatially structured populations.

\section{Setting FRVs}

\section{General considerations}

Setting FRVs is presented as a stepwise approach which starts by selecting an appropriate spatial scale and historical perspective for the species or habitat type. This is necessary to understand how historical processes and major impacts shaped current ranges, areas and numbers and what can be considered as ecologically and technically feasible. Feasibility considerations should include irreversibility of large scale developments e.g. major infrastructure and urban development. Socioeconomic considerations such as availability of funding should be left out but are relevant when planning for operational conservation targets/milestones.

Two basic approaches are presented for setting FRVs: reference-based and model-based. The reference-based approach considers the historical distribution/area of a habitat type or the historical distribution/population size of a species in a period when the habitat type or species was supposed to be in a (stable) favourable condition. A special case of the reference-based approach applies to setting FRVs for non-reproductive 'populations' such as passing or wintering bird populations. Model-based approaches use species-specific information on required viable population size or species-specific or habitat type-specific features such as habitat suitability or required area for proper functioning. Three model-based methods are discussed. Firstly, the population-based method uses PVA or more often literature sources to estimate a MVP size, followed by upscaling to FRP level. Therefore, translating MVPs to the FRP and FRR level inevitably requires knowledge of reference conditions for ecological/genetic variations in the species' natural range. Generally, several 'long-term viable populations' will be necessary to represent all the significant ecological variations of the species within its range. Secondly, the potential-range method uses distribution modelling or habitat suitability measures to constrain the FRP/FRA and FRR within the potential range. Next, FRVs are determined by identifying and applying favourable reference densities (for FRPs) or environmental conditions (for FRAs) in 'optimal' and 'average' habitats within the potential range. Thirdly, the area-based method uses assumptions on the area requirement of a good functioning habitat at the landscape level, followed by upscaling to FRA level by considering risk spreading and ecological variations within the natural range. This approach is based on the 'minimum dynamic area' concept.

A combination of approaches is possible as well. Setting FRRs is inherently reference-based. This means e.g. that a population-based approach needs reference-based considerations to scale a MVP up to the FRP- and FRR-level accounting for 'all significant ecological variations within the natural range'.

In applying MVPs we assume 'genetic MVPs' i.e. accounting for evolutionary potential or other concept related to long-term viability. Most MVP-values in the literature refer to 'demographic MVPs' which 
require upscaling by some factor to account for long-term viability. In setting FRVs an additional kind of upscaling is nearly always necessary to ascertain that all significant variation within the natural range of a species is represented by the FRP.

The general approach for setting FRVs for both species and habitat types is presented by a flow chart which considers the following steps: 1 Gather information and 2 Set favourable reference values. The first step includes the gathering of biological/ecological information, selecting a spatial scale of functiong of the species or habitat type and the presentation of a narrative for the historical perspective. Next, the historical and current distribution and trends are analysed. When negative trends in distribution and/or population size/area are found, FRVs must be set explicitly (step 2). Otherwise, FRP/FRA and FRR are set at current value and at least the value when the Directive came into force. This approach is further elaborated for species and habitats separately.

\section{Setting FRVs for species}

For species, extensive guidance is provided to assess a proper scale of functioning of populations. For the identification of reproductive populations for birds and mammals, allometric relationships are used to estimate median dispersal distance. As a rule of thumb, we assume that populations more than five times the median dispersal distance apart can be considered as isolated. Next, populations are classified as reproductive or non-reproductive (e.g. wintering/staging 'populations'), sedentary/resident or migratory, and classified based on mobility considerations (e.g. home range, isolation) which result in six sedentary population categories (S1-6), six categories for reproductive populations of migratory species (MR1-6) and four for non-reproductive 'population' categories of migratory species (MNR1-4). For each category is indicated whether it applies to animals and/or plants and if FRV assessment is at the national or supra-national level. Boxes are provided as guidance on using a population-based or reference-base method.

We conclude that supranational assessment must be considered for species when 1) sustainable population size at the population level is not or only just met and $2 a$ ) the biology of the species allows for long-distance exchange (large home range or large dispersal distance) or 2b) individuals have small home ranges and occur in only one or a few isolated populations at supranational level.

\section{Setting FRVs for habitat types}

For habitat types, guidance on an assessment of the spatial scale of functioning is provided as well. Two basic categories are distinguished: macro- and meso-habitats. Macro-habitats represent ecosystems with broad abiotic ranges and natural dynamics, comprising a diversity of vegetation types and successional stages. They function from 10 s to 100 s of hectares. Examples are $\mathrm{H} 1330$ (Atlantic salt meadows), H7110 (Active raised bogs) and H9160 (Sub-Atlantic and medio-European oak or oakhornbeam forests of the Carpinion betuli). Meso-habitats are restricted to narrow and specific abiotic ranges, often determined by historical land use (semi-natural) and with simple structure due to specific management of localized conditions. The minimum area for functioning is several to 10 s of hectares. Examples are H4030 (European dry heaths), H6510 (Lowland hay meadows) and H9330 (Quercus suber forests). For both categories 'component' habitats are distinguished, defined by specific parts of the abiotic range or by a few dominant species. E.g. H5130 (Juniperus communis formations on heaths or calcareous grasslands) is considered as a macro-component and $\mathrm{H} 7210$ (Calcareous fens with Cladium mariscus and species of the Caricion davallianae) as a mesocomponent. Generally, these categories require different (combinations of) methods to assess FRVs. Clearly, semi-natural habitats (meso-habitats) require reference-based methods whereas habitats with extensive natural dynamics can be assessed using a minimum-area method. A special box is provided as guidance for assessing the level of restoration needed when using a reference-based-approach for habitats and species. Moreover, an additional box is devoted to spatial habitat modelling for setting FRVs of habitat types.

The requirement that a FRA must be sufficiently large to include the ecological variations in the natural range does not necessarily imply that supranational FRVs have to be considered. In fact, this requirement is met already when, in setting FRVs for habitats, each MS includes all ecological conditions resulting from geological, altitudinal, climatic variation and historical land use, within its national boundaries. For species considered at the supranational level, e.g. for large carnivores, a change in area or quality of the habitat in one MS will affect the functioning of the supranational 
population and that's why this scale level makes sense in setting FRPs. For habitat types, changes in area or quality in a particular MS mostly won't affect the functioning of that habitat type in an adjacent MS. Therefore, we propose to set FRAs for all marine and terrestrial habitat types at the national level only.

\section{Additional guidance}

The report gives additional guidance for selected groups of species and habitats: marine mammals (cetaceans), birds, migratory fish, invertebrates and marine habitats. An appendix with lists of migratory species and species with large home ranges is given as well. 


\section{Introduction and Member State approaches}

\section{$1.1 \quad$ Background}

Conservation status (CS) is a key concept in European nature conservation laws and policy, because the aim of Habitats Directive (HD) is to restore or maintain a favourable conservation status (FCS) for all species and habitats included in the Annexes of the HD. In order to assess the conservation status under this Directive according to the agreed method used since the reporting period 2001-2006 under Article 17 of the Habitats Directive, it is necessary to determine favourable reference values (FRVs) for the range of habitat types and species (FRR), for area of habitat types (FRA) and for population size of species (FRP). FRVs are key reference levels to define in specific terms when FCS is being achieved for individual species and habitats. However, FRVs are not the only aspect when assessing conservation status (see Table 1.1 and 1.2). Similar concepts apply to the Birds Directive (BD) even though they are spelled out less clearly and different terms are used.

Despite the fact that FRVs are essential elements to determine the 'distance to target' (i.e. the distance to FCS), the latest reporting under Article 17 has shown that they are still poorly developed and often inconsistently applied across Member States (MS). This is considered problematic, as it could lead to very different interpretations as to the overall goal to be achieved under the nature directives. Until now, the FRV was a concept to be applied at the level of a biogeographical region within a Member State. However, for some species, it may be more relevant to set reference values at the geographical scale of a biogeographical region or even larger scale. These types of inconsistencies have also become increasingly obvious in the new bio-geographical process (Natura 2000 seminars), where Member State authorities have raised the need for streamlining and harmonisation of the concept behind assessing FCS, particularly establishing FRVs as a priority issue for the coming years.

In order to support a more coherent way to establish FRVs amongst Member States and, where appropriate, develop such FRVs at the biogeographic level, the European Commission DG ENV issued a call for tenders for the service contract 'Defining and applying the concept of favourable reference values for species and habitats under the EU Birds and Habitats Directives' (ENV.B.3/SER/2015/0009). The BD does not use FRVs but requires Member States to take measures to maintain bird populations at a level which corresponds to their ecological, scientific and cultural requirements and to ensure sufficient extent and quality of habitat for all species of birds. According to the tender specifications the terms and definitions used under the HD should be used for birds as well.

The project closely cooperated with the Ad hoc group 'favourable reference values' of the Expert Group on Reporting under the Nature Directives, consisting of experts from Member States, the European Environment Agency (EEA), the European Topic Centre on Biological Diversity (ETC-BD), the Bern Convention, NGOs and the European Commission. 
Table 1.1 General evaluation matrix for species (from the Report format for the period 2013-2018: http://cdr.eionet.europa.eu/help/habitats_art17)

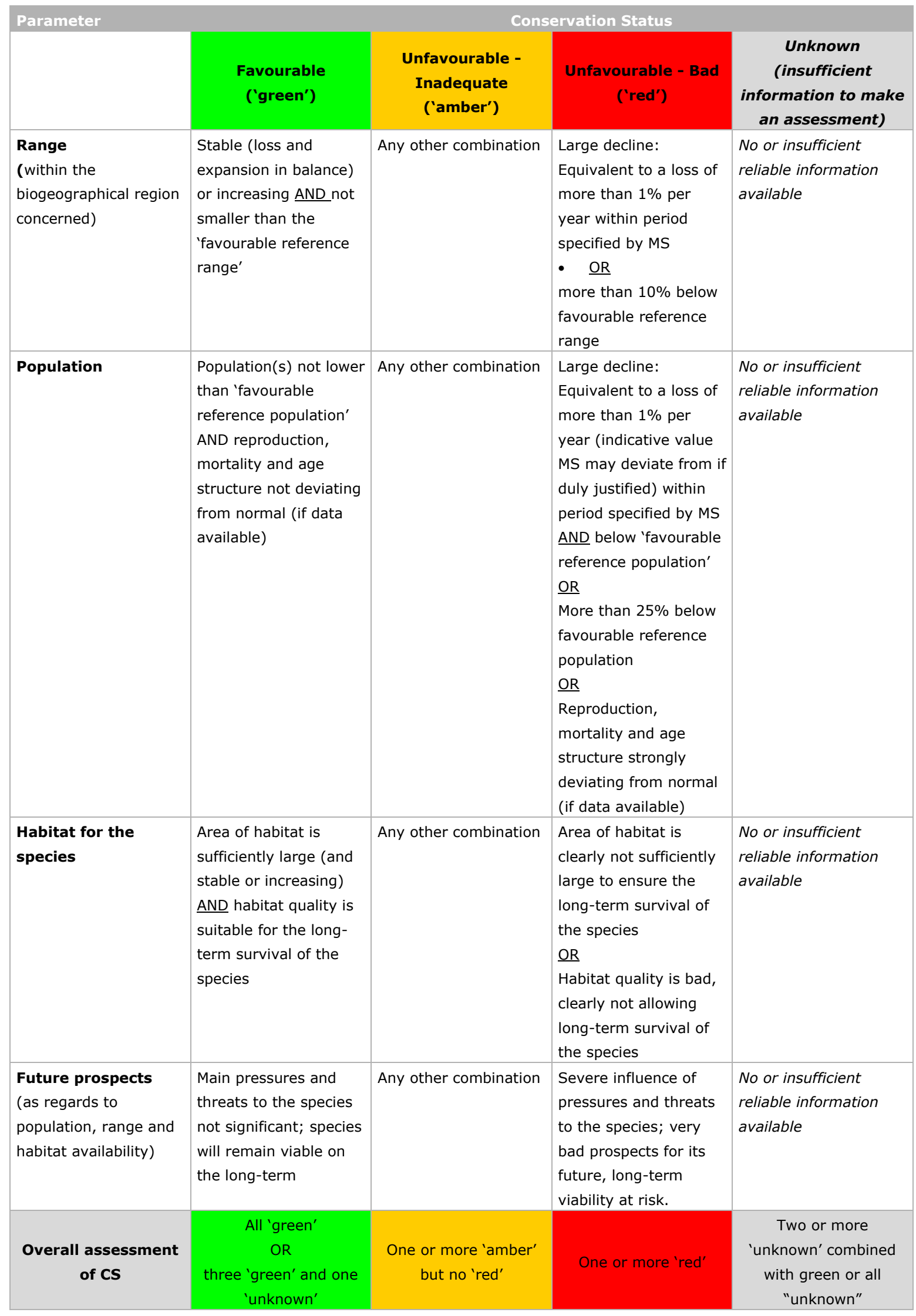


Table 1.2 General evaluation matrix for habitat types (from the Report format for the period 20132018: http://cdr.eionet.europa.eu/help/habitats_art17)

\begin{tabular}{|c|c|c|c|c|}
\hline Parameter & \multicolumn{4}{|c|}{ Conservation Status } \\
\hline $\begin{array}{l}\text { Range } \\
\text { (within the } \\
\text { biogeographical/marine } \\
\text { region concerned) }\end{array}$ & $\begin{array}{l}\text { Stable (loss and } \\
\text { expansion in } \\
\text { balance) or } \\
\text { increasing AND not } \\
\text { smaller than the } \\
\text { 'favourable } \\
\text { reference range' }\end{array}$ & Any other combination & $\begin{array}{l}\text { Large decrease: } \\
\text { Equivalent to a loss of } \\
\text { more than } 1 \% \text { per } \\
\text { year within period } \\
\text { specified by MS } \\
\underline{\text { OR }} \\
\text { More than } 10 \% \text { below } \\
\text { 'favourable reference } \\
\text { range' }\end{array}$ & $\begin{array}{l}\text { No or insufficient } \\
\text { reliable information } \\
\text { available }\end{array}$ \\
\hline $\begin{array}{l}\text { Specific structure and } \\
\text { functions (including } \\
\text { typical species }{ }^{2} \text { ) }\end{array}$ & $\begin{array}{l}\text { Structures and } \\
\text { functions (including } \\
\text { typical species) in } \\
\text { good condition and } \\
\text { no significant } \\
\text { deteriorations / } \\
\text { pressures }\end{array}$ & Any other combination & $\begin{array}{l}\text { More than } 25 \% \text { of the } \\
\text { area is unfavourable } \\
\text { as regards its specific } \\
\text { structures and } \\
\text { functions (including } \\
\text { typical species) }^{3}\end{array}$ & $\begin{array}{l}\text { No or insufficient } \\
\text { reliable information } \\
\text { available }\end{array}$ \\
\hline $\begin{array}{l}\text { Future prospects } \\
\text { (as regards range, area } \\
\text { covered and specific } \\
\text { structures and functions) }\end{array}$ & $\begin{array}{l}\text { The habitats } \\
\text { prospects for its } \\
\text { future are excellent } \\
\text { / good, no } \\
\text { significant impact } \\
\text { from threats } \\
\text { expected; long-term } \\
\text { viability assured }\end{array}$ & Any other combination & $\begin{array}{l}\text { The habitats prospects } \\
\text { are bad, severe impact } \\
\text { from threats expected; } \\
\text { long-term viability not } \\
\text { assured. }\end{array}$ & $\begin{array}{l}\text { No or insufficient } \\
\text { reliable information } \\
\text { available }\end{array}$ \\
\hline $\begin{array}{c}\text { Overall assessment of } \\
\text { CS }\end{array}$ & $\begin{array}{l}\text { All 'green' } \\
\text { OR } \\
\text { three 'green' and } \\
\text { one 'unknown' }\end{array}$ & $\begin{array}{l}\text { One or more 'amber' } \\
\text { but no 'red' }\end{array}$ & One or more 'red' & $\begin{array}{c}\text { Two or more } \\
\text { 'unknown' combined } \\
\text { with green or all } \\
\text { 'unknown' }\end{array}$ \\
\hline
\end{tabular}

\footnotetext{
1 There may be situations where the habitat area has decreased as a result of management measures to restore another Annex I habitat or habitat of an Annex II species. The habitat could still be considered to be at 'Favourable Conservation Status' but in such cases give details in the Complementary Information section ('Other relevant information') of Annex D. 2 See definition of typical species in the Explanatory Notes and Guidelines.

3 E.g. by discontinuation of former management, or is under pressure from significant adverse influences, e.g. critical loads of pollution exceeded.
} 


\subsection{Objectives of the service contract}

The main objectives of the service contract are:

1. Support the development of methodologies and guidance on how to establish FRVs including testing of these methods;

2. Apply the resulting method (i.e. establishing FRVs) for a defined group of habitats and species. The project must provide relevant input for the:

- EU review of the reporting procedures (in particular to the reporting guidelines via the ad-hoc group on FRVs) and thereby into the next reporting round under the nature directives (reports due by mid/end 2019);

- New biogeographic process (Natura 2000 seminars) providing concrete recommendations and examples on how to set and harmonise FRVs at local, regional, national and/or bio-geographical level across the EU.

\subsection{The consortium}

\begin{tabular}{|c|c|c|c|}
\hline Organisation & Country & Representative & Role in the project \\
\hline Wageningen Environmental & NL & Rienk-Jan Bijlsma & Project manager (PM) and deputy PM \\
\hline Research & & John Janssen & Experts terrestrial habitat types, flora \\
\hline \multirow[t]{2}{*}{ Comunità Ambiente } & IT & Emiliano Agrillo & Experts terrestrial habitat types \\
\hline & & Fabio Attorre & \\
\hline Deltares & & & Framework Directive \\
\hline \multirow[t]{3}{*}{ Istituto di Ecologia Applicata (IEA) } & IT & Michela Pacifici & Experts terrestrial mammals \\
\hline & & Carlo Rondinini & \\
\hline & & Luigi Boitani & \\
\hline Radboud University Nijmegen & NL & Henk Siepel & Expert invertebrates \\
\hline \multirow[t]{2}{*}{ Ornithology } & & Roomen & \\
\hline & & Ruud Foppen & \\
\hline \multirow[t]{2}{*}{ Stichting BirdLife Europe } & NL & Wouter Langhout & Experts Birds \& Habitats Directive \\
\hline & & Ariel Brunner & \\
\hline Susan Gubbay & UK & Susan Gubbay & $\begin{array}{l}\text { Expert marine environment and } \\
\text { marine habitat types }\end{array}$ \\
\hline Wageningen Marine Research & NL & Erwin Winter & Expert migratory fish \\
\hline
\end{tabular}

\subsection{Reading guide}

This Technical report presents the findings of the project under the service contract and provides elaborated methods and guidance which support the Explanatory Notes and Guidelines for Reporting under Article 17 of the Habitats Directive (period 2013-2018), in particular the sections on favourable reference values (see http://cdr.eionet.europa.eu/help/habitats_art17/index_html).

This chapter 1 includes the review of Member State approaches for setting FRVs (task A) based on questionnaires filled by the MS. The questionnaire itself is included in Annex 1.

Chapter 2 presents the definitions of FRVs and summarizes literature and documented methods used for setting FRVs.

Chapter 3 presents a general analysis of opinions and methods for setting FRVs and introduces a stepwise approach for setting FRVs at different spatial scales and for different kinds of populations and habitat types. Further guidance is provided by tables and boxes. 
Chapter 4 elaborates on guidance for particular groups of species and habitats. Annex 2 presents lists of migratory species and/or species with large home ranges.

A set of FRV sheets (worked out examples) have been completed by experts of the consortium to serve as inspiring examples of how to apply the stepwise approach in setting FRVs. The examples comprise habitat types and species groups (including birds) differing greatly in life histories, biological functioning and spatial requirements. A selected set of examples is available on the reference portal for Art.17 reporting under the Habitats Directive (http://cdr.eionet.europa.eu/help/habitats_art17).

Minutes from the meetings of the Ad hoc group can be found on the CIRCABC-website: https://circabc.europa.eu/w/browse/951a6763-c409-4f66-9fce-c7e9b6ed80c2

This report is referenced in the Explanatory Notes and Guidelines for the period 2013-2018 of Reporting under Article 17 of the Habitats Directive. See Reference portal for reporting under Article 17 of the Habitats Directive (http://cdr.eionet.europa.eu/help/habitats_art17).

\subsection{Member State approaches: reporting context}

Primary input to the project was provided by questionnaires filled by Member State representatives involved in Article 12 (Birds Directive) and Article 17 (Habitats Directive) reporting. The inquiry focused on methods for setting FRVs. The questionnaire format is given in Annex 1.

The response rate was high: 23 out of 27 Member States replied. Croatia was not addressed because of its recent EU membership and BG, PL, PT and RO didn't respond. Apart from insight in approaches used by Member States, the filled questionnaires gave many valuable suggestions and references.

The Article 17 reporting format and guidelines for the period 2007-2012 allowed reporting of FRVs as unknown (' $x$ ') or using operators (using the symbols $\approx,>,>>$; see Table 1.3) apart from providing real values in $\mathrm{km}^{2}$ for FRR and FRA and number of individuals/agreed exceptions/other units for FRP. The questionnaires sent to the MS asked among others for criteria used to report FRVs as ' $x$ ' or with operators.

This paragraph shows how MS actually reported these categories, based on a documented database compiled by EEA from the Article 17 reports for the period 2007-2012 ${ }^{4}$. This database was used to find out for how many habitats and species FRVs have been reported as ' $x$ ', by operators or real values (Figure 1.1). Table 1.3 explains the different categories used in this figure.

\footnotetext{
${ }^{4}$ http://www.eea.europa.eu/data-and-maps/data/article-17-database-habitats-directive-92-43-eec-1
} 
current value range relative to FRR (habitats)

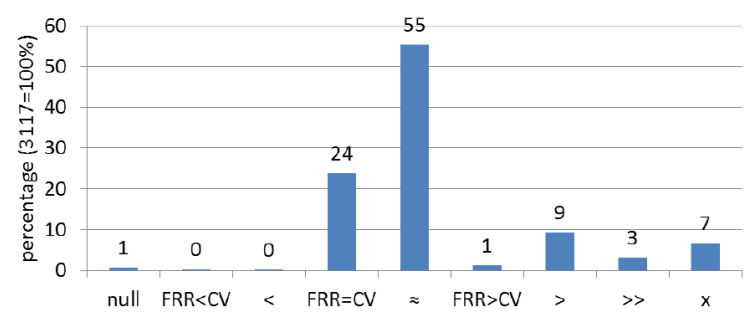

current value area relative to FRA

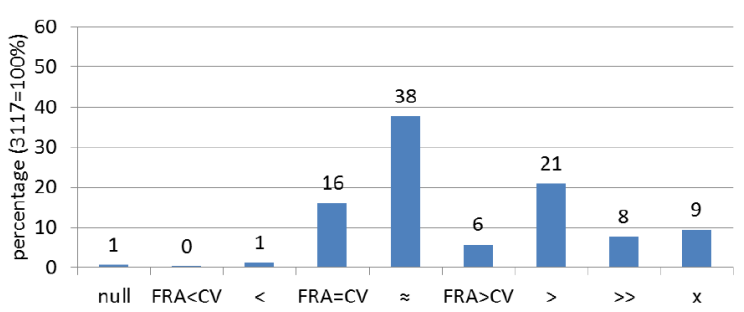

current value range relative to FRR (species)

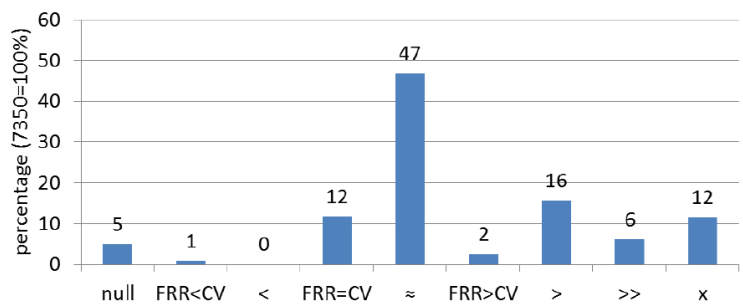

current value minimum population size relative to FRP

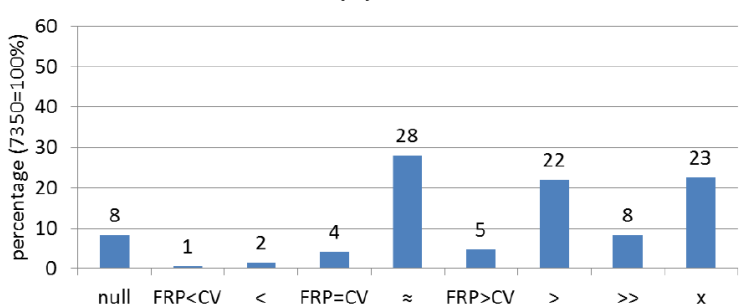

Figure 1.1 Categories of FRVs reported for habitats (3117 records in EU27) and species (7350 records). See Table 1.3 for explanation

Table 1.3 Explanation of FRV-categories used in Figure 1.1 as extracted from the database of Article 17 reports for the period 2007-2012. CV (current value) is the reported value for the range, area or minimum population size

The operator symbols mean: "approximately equal to", > "more than", >> "much more than". If the operator is ' $>>$ ', the current value is very likely to be more than $10 \%$ below FRV. The operator 'less than' $^{(<)}$can be used only in exceptional circumstances and an explanation of the reasoning why this operator has been used should be given

\begin{tabular}{ll} 
category & explanation \\
null & current value not reported and no operator reported \\
\hline FRV $<$ CV & real value for FRV $<$ current value (only in exceptional cases) and no operator reported \\
\hline$<$ & $<$ operator reported (idem) \\
\hline FRV $=$ CV & real value for FRV $=$ current value and no operator reported \\
\hline$\approx$ & $\approx$ operator reported \\
\hline FRV $>$ CV & real value for FRV $>$ current value and no operator reported \\
\hline$>$ & $>$ operator reported \\
\hline$>>$ & $>>$ operator reported \\
\hline$x$ & FRV reported as unknown \\
\hline
\end{tabular}

The figure shows that the current range is considered sufficient (FRR=CV or FRR $\approx$ ) for $80 \%$ and $60 \%$ of the reported habitats and species respectively. For area and population, the corresponding figures are about $55 \%$ and $30 \%$. Real values different from current values (mostly FRV $>C V$ ), are only reported for $1 \%$ (FRR habitats), 2\% (FRR species), 6\% (FRA) and 5\% (FRP) of the habitats or species.

For the project, reported real values different from current values provide the most interesting information, because these values are the result of explicit considerations about reference values relative to current numbers and areas. Table 1.4 presents the number of habitats and species reported as real values. 
Table 1.4 Number of habitats ( $n h a b$ ) and species (nspec) reported with real-values for FRA $>C V$ and/or real-values for FRP $>C V$ and as percentage of total numbers. Empty fields mean that MS didn't report values as indicated. MS not in this table didn't report this kind of real values

\begin{tabular}{|c|c|c|c|c|c|c|}
\hline country & tothab & $\begin{array}{c}\text { nhab with } \\
\text { FRA>CV }\end{array}$ & \%hab & totspec & $\begin{array}{c}\text { nspec with } \\
\text { FRP>CV }\end{array}$ & \%spec \\
\hline $\mathrm{BE}$ & 59 & 25 & 42 & 85 & & \\
\hline $\mathrm{CY}$ & 43 & & & 56 & 3 & 5 \\
\hline $\mathrm{DE}$ & 92 & 19 & 21 & 199 & 10 & 5 \\
\hline EE & 60 & & & 99 & 1 & 1 \\
\hline ES & 117 & 5 & 4 & 425 & 17 & 4 \\
\hline $\mathrm{FR}$ & 132 & & & 312 & 6 & 2 \\
\hline IE & 58 & 10 & 17 & 69 & 8 & 12 \\
\hline PL & 81 & 5 & 6 & 187 & 5 & 3 \\
\hline SE & 89 & 44 & 49 & 166 & 102 & 61 \\
\hline SK & 66 & 1 & 2 & 195 & 8 & 4 \\
\hline UK & 83 & 22 & 27 & 133 & 13 & 10 \\
\hline
\end{tabular}

The table shows that only a few other Member States than SE assessed real-valued FRVs systematically. Apparently, species are more often assessed this way than habitats; BE is a notable exception.

\subsection{Summary of Member State approaches}

\subsubsection{General aspects}

\section{Documented methodology for setting FRVs}

The Article 17-reporting format includes entries to describe the methods used to set reference values and this information is available from the database compiled by EEA (see $\S 1.5$ ). However, general considerations and methodology used to set FRVs have been documented by a few Member States only: BE, FR, NL and UK. Their approaches are summarized in § 1.7. Some MS didn't determine FRVs explicitly (DK, FI). Expert opinion is mentioned as the main basis for setting FRVs e.g. by ES, GR, HU, LT and SI, but in fact most if not all MS somehow included expert opinion in considering and weighting factors in setting FRVs.

\section{Using 'unknown' and operators}

The Guidelines (DG Environment, 2017) state: 'The use of operators should help to reduce the use of 'unknown' to a minimum'.

Most MS use 'unknown' as expected: in the case of lack of data, mostly actual distribution data but sometimes historical data. Particular situations or species groups include marine caves and several marine species (IE) and Cladonia spp./Lycopodium spp. of HD Annex V (NL, SE). Some MS use 'unknown' in case of occasional findings (EE) or new arrivals (BE-VLG, CZ, MT). Another reason for using 'unknown' is discussion about the occurrence or definition of a feature (AT). 
The use of operators is far less harmonised and occurs in several unrelated cases:

1. As a result of expert opinion and sufficient confidence despite the lack of proper data. This is the situation envisaged in the Guidelines.

2. Several MS reported only operators (see Table 1.4). Reasons are uncertainty about methods for the assessment of real values and/or uncertainty about the interpretation and (political) consequences of real values. For species, BE-VLG uses general population ecological (genetic) rules which 'give a good indication whether or not the actual population has a FCS (= meets the $F R P$ ), but do not allow a quantitative approach to set a real value for FRP (or such values are subject to important scientific discussions)'. NL didn't report population figures for common, widespread species occurring in 'the whole of the Netherlands'. Some MS consider the use of operators 'balanced', 'sufficient' or 'adequate' for the final assessment of CS (e.g. DK, GR).

3. Specific interpretations: ' $>$ ' has been used for habitats with restoration potential (EE); ' $\approx$ ' for species and habitats confined in range due to physical constraints (MT).

\section{Values when the HD came into force}

A FRV must be at least the value (range, surface area, population size) when the HD came into force (DG Environment, 2017) but will often be larger than this value.

As stated implicitly or explicitly by several MS, this requirement is not very relevant for the process of setting FRVs. Some MS note that increased knowledge and better data resulted in adjusted (including smaller) FRV estimates in 2013 (GR, NL, UK) compared to 2007. Some MS remark that exact values when the HD came into force are and will remain poorly known (AT, BE-VLG).

\section{Feasibility}

About half of the MS indicates that feasibility considerations have not been used in setting FRVs (AT, BE-VLG, CZ, DK, ES, FI, FR, GR, HU, IT, LV, SI, SK), whereas the other MS somehow included technical, social and/or financial aspects. It is noted that potential habitat can be irreversibly destroyed, e.g. by cities, land reclamations or closing of sea arms, resulting in substantial technical constraints on restoration and that this kind of feasibility inevitably must be included in setting FRVs $(N L, U K)$. Some MS emphasise that more guidance on feasibility is needed (BE-WAL, IT, LT).

Concerns about including or not feasibility aspects might be the result of uncertainty about the interpretation and consequences of FRVs. IE states: 'it is more important to demonstrate that efforts are being made to move towards an ecological/conservation target rather than setting a lower target for financial and social reasons'.

\subsubsection{Factors and methods}

\section{FRR and factors to be considered}

The 2007-2012 Guidelines (Evans \& Arvela, 2011, III.a.i) mention the following factors which should be considered in setting a FRR: 1 Current range; 2 Potential extent of range; 3 Historic range and causes of change; 4 Area required for viability of habitat type/species including consideration of connectivity and migration issues; 5 Variability including genetics.

Most MS (AT, BE-WAL, CZ, DE, EE, ES, FR, GR, HU, IE, IT, LT, LU, LV, MT, NL, SE, SI, SK, UK) consider both current and historical range. Potential extent (BE-VLG, BE-WAL, CZ, EE, ES, FR, GR, HU, IE, IT, LT, LU, LV, MT, NL, SE, UK) and area required for viability (BE-VLG, BE-WAL, CZ, EE, ES, FR, GR, IE, LT, MT, SE) are used less, and variability only by DE, EE, ES, GR, IE, MT, SE. The latter factor was explicitly rephrased by $\mathrm{DE}$ as plant-sociological, altitudinal and regional variation based on natural landscape units. NL includes the requirement that FRP/FRA must be covered by the FRR.

Connectivity and viability issues emerge in the assessment of FRP as well and require more guidance on setting FRVs (see also the paragraph Connectivity aspects).

\section{FRP and factors to be considered}

The former Guidelines mention the following factors which should be considered in setting a FRP (Evans \& Arvela, 2011, III.a.ii): 1 Population should be sufficiently large to accommodate natural 
fluctuations and allow a healthy population structure ; 2 Potential range; 3 Historic distribution and abundances; 4 Biological and ecological conditions; 5 Migration routes and dispersal ways; 6 Gene flow or genetic variation including clines (slightly re-ordered to show correspondence with factors mentioned under FRR).

Historical distribution is used by most MS. Only BE-VLG, CY, DK and FI didn't use this factor. Next comes the requirement that populations must be sufficiently large (BE-F, BE-W, CZ, DE, EE, FR, HU, IE, IT, LU, MT, NL, SE, SI, SK, UK). Potential range (BE-WAL, CZ, EE, FR, GR, HU, IE, IT, LT, LU, LV, $M T, N L, S E$ ), Biological and ecological conditions (BE-VLG, BE-WAL, CZ, DE, EE, ES, FR, GR, HU, IE, IT, LT, LV, MT, NL, SE) and Migration routes and dispersal ways (BE-VLG, BE-WAL, CZ, DE, EE, FR, GR, IE, LT, LU, LV, MT, NL, SE) are used by $60-70 \%$ of the MS. Gene flow or genetic variation only by BE-VLG, EE, GR, IE implicitly, SE.

BE-WAL considers connectivity as well (number of linked populations, colonies, grid cells). Likewise NL includes considerations on current population size, the number of metapopulations needed and/or the population density for more common species (see also the paragraph Connectivity aspects).

\section{FRA and factors to be considered}

The former Guidelines (Evans \& Arvela, 2011, III.a.iii) mention the following factors which should be considered in setting a FRA: 1 Actual distribution and actual variation (including quality of habitat); 2 Potential natural vegetation; 3 Historic distribution and causes of change; 4 Requirements of typical species (including gene flow); 5 Dynamics of the habitat type; 6 Natural variation (slightly re-ordered to show correspondence with factors mentioned under FRR).

The first three factors correspond to those already considered for setting the FRR. MS used these factors likewise in setting the FRA. 'Natural variation' for FRA resembles 'variability' for FRR and was used by about $40 \%$ of the MS (BE-VLG, BE-WAL, DE, EE, ES, FR, GR, IE, MT, NL, SE, UK) as was 'Dynamics of the habitat type' (BE-WAL, CZ, EE, ES, FR, GR, IE, LT habitat 7120 only, LV, MT, NL, SE, UK). 'Requirements of typical species' was far less used (DE, HU, IE implicitly, MT, NL, SE, UK) despite the primary importance of this factor apparent from the Guidelines. BE-VLG and NL considered the Red List status of typical species.

\section{Connectivity aspects}

The questionnaire asked What method(s) did you use in the assessment of connectivity aspects of FRP and/or FRR? More than $40 \%$ of the MS didn't use specific methods. Seven MS (BE-VLG, EE, ES, FR, LT, LU, MT) used GIS-analyses of habitat coverage in the landscape, and just a few (BE-VLG, EE, LU, $\mathrm{SE}$ ) used direct or indirect genetic methods or dispersal studies. Expert opinion is mentioned as well. SE notes that connectivity is related to both the area and quality of the habitat (barriers to dispersal). In fact, this dual role of connectivity, 1) as factor to be considered in setting FRVs and 2) to be assessed as a component of the CS parameter 'structure and functions' or 'habitat for the species', is implied in the Guidelines as well (see above, FRA and factors to be considered).

Whether, at which level (FRR or FRA/FRP) and how connectivity aspects are relevant in setting FRVs need more guidance, including the marine environment where connectivity is even less understood than on land.

\section{Use of historical references}

Although historical range and distribution have been used as important factors in setting FRVs by a majority of MS (see above), specific historical references have much less been considered. Some MS use more or less fixed reference years or periods: BE-VLG, BE-WAL, EE, ES, FR, LT, LU, NL (habitat types), SE, SI (mostly) and SK. DE uses fixed reference values with Red Lists (derived from trends considering historical values) as orientation. Specific references, such as a period when a feature was supposed to have FCS, are used (as well) by BE-VLG (only for birds), CZ, EE, ES, GR, IE, IT, LU, MT, $\mathrm{NL}$ (some habitat types and species) and SE. Five MS indicate that they didn't use historical references: DK (species), FI, HU, LV, UK. Some countries (BE-WAL, IE, NL) elaborate on the decision rules used. Several MS included questions or suggestions on the use of references in general and more particular on reference periods. Clearly these aspects need more guidance. 


\section{Use of trend data}

The use of trend data for setting FRVs is highly diverse across Member States. AT, CZ, DE, DK (HDspecies), ES, FI, LT, LV, MT, SI and SK didn't use trend data. BE-WAL only for bats, BE-VLG only for species with large dispersal rates and DK only for habitats; EE, FR, GR, HU, IT, LU, NL, SE and UK for habitats and HD-species while EE, GR and LU mention birds as well.

\section{Use of estimates of MVP}

The questionnaire asked Did you use or include estimates of minimum viable population size? The following MS didn't use MVPs for establishing FRVs: AT, CZ, DE, DK, EE, FI, HU, IT, LT, SE, SI and SK. For DK this answer is remarkable considering Box 3.4 in McConville \& Tucker (2015) devoted to the use of MVPs by Denmark. BE-VLG, GR, LU, LV and NL use MVP-values from literature. Some MS applied specific analyses: CY (PVA: birds), ES (handful of species), GR, LU, MT (special cases e.g. Aphanius fasciatus), LV and UK (special cases, e.g. Fisher's estuarine moth).

\section{Differentiation in methods}

BE-VLG, CZ (for groups of species/habitats), DE, EE, FR, LU, LV, SK and UK performed standardized approaches in setting FRVs for species and habitats; NL only for terrestrial habitats. GR and IT used different approaches depending on the taxonomic group.

Other species-related contrasts resulting in different methods are: marine vs. terrestrial (IE, LT, MT, $\mathrm{NL})$, Annex V vs. other annexes (BE-VLG), migratory vs. non-migratory species (BE-VLG, LT, NL), colonial vs. non-colonial birds (CY), common widespread vs. other species (NL) and population units, e.g. individuals vs. tree trunks (SE).

Data-driven differentiation results from differences in monitoring programmes e.g. dune habitats, saltmarsh, upland etc. (IE, SE), data quality (SE, SI) and availability of historical data (MT).

\subsubsection{Spatial scale}

\section{FRVs for mobile species}

The questionnaire asked How did you assess references values for mobile species with dynamic ranges crossing national boundaries or going beyond EU territories?

This species group was not considered explicitly by AT (but lynx in discussion), CY (island situation), CZ (despite cross border exchange), DK, ES, FI, FR, HU, LT (mostly reported as unknown), MT (island situation; most marine species reported as unknown) and SK. Although there may be movement of several terrestrial fauna across the border with Northern Ireland, IE considers it unlikely that the conservation status of most of these species are impacted by activities outside Ireland.

BE-WAL, EE, LU and SI (taking into account adjacent countries) did assess mobile species explicitly using expert opinion. GR considers only bird species with dynamic ranges crossing national boundaries as mobile; in setting FRVs the conservation status at the national and European level are taken into account. SE sets FRVs for large carnivores based on data in neighbouring countries. For mobile species DE assumes that an appropriate minimum share of the population must be present/maintained and that migration routes must be kept viable (e.g. fish migration) irrespective of the location of the reproduction/spawning sites. For some marine species, UK utilised data from large-scale international population surveys, cut to UK boundaries.

BE-VLG applies generalised genetic rules for mobile species: 'For mobile species with more widespread migration patterns, the real meta population could occur within a region much larger than FLanders. In these cases it is not always possible to reach the FRP in Flanders alone; if there are less than 5,000 individuals within Flanders, and the population is not decreasing, then it can still be considered in FCS. This system was used for several of the bat species' (from McConville \& Tucker, 2015). The whole of Flanders is considered as FRR for mobile widespread species. For migratory fish, NL calculated a FRP based on estimates of how many fish should reach the spawning sites (outside the country) taking mortality rates into account; for bats, only wintering in the Netherlands, FRVs are based on the wintering populations only; for cross border populations of Euplagia quadripunctata NL 
calculated its national FRV assuming that the neglected part of the population also would contribute to the survival of the species (compare assumptions used by DE above); for common widespread species $\mathrm{NL}$ assesses the FRR as the whole country and FRP as $\approx$ (operator).

\section{Features requiring reference values above MS-level}

The tender specifications for the Service contract acknowledge that 'for some habitats and species FRVs might best be set on national (-biogeographic) level, for others the level of the EU-biogeographic region might be more appropriate and again for others (e.g. large carnivores) the population level might be considered the most relevant one to set FRVs'.

The filled questionnaires suggest reference values above MS level for large carnivores, seals, marine migratory species (sea turtles, some cetaceans), migratory fish, migratory bats and large birds (of prey) with large home ranges. Apart from considerations about individual behaviour, methods above the MS level are motivated to avoid double counting and to recognise all parts of a species life cycle (IE).

Small countries (BE, LU, NL) note that many species and habitats inherently show relevant transboundary dynamics but don't suggest FRVs above MS level in this case (see also FRVs for mobile species, above).

Population-based FRVs are suggested for small, isolated populations by FR (for species occurring in one biogeographic region), GR (e.g. Vipera ursinii), HU, and IT and in principle for all HD-species with small dispersal capacity (e.g. amphibians) by BE-VGL.

SE proposes to reconsider the calculation of FRVs for biogeographic regions within Member States (a point raised by BE-WAL as well):

- A FRV should be calculated for a biogeographic region part of the MS for 1) species with regionally important populations, 2) species or habitats with regionally differentiated management or 3 ) when threats and pressures are different between different biogeographic regions.

- One FRV for the entire MS (covering several biogeographic regions) is appropriate for species which are migrating throughout the MS and between the regions, and where a separation of subpopulations is not meaningful. This can also apply to habitats where conditions in the previous point are not met.

For habitats, the questionnaires present no arguments for considering trans-boundary FRVs, except (BE-WAL) when a habitat is supposed to host very mobile species or if a habitat has a small, transboundary distribution. Examples for these cases are not given. BE-WAL further notes that 'a huge issue is the lack of homogeneity for habitats definitions, between MS or between regions. Even for forest habitats or heaths, the definition may be very different from one MS to another'.

\subsection{Documented approaches by Member States}

McConville \& Tucker (2015) already reviewed practices and underpinning assumptions used by Member States in interpreting FCS and setting FRVs, in particular with regards to widespread species with extensive populations outside Natura 2000-sites.

This paragraph summarizes explicitly documented approaches for setting FRVs by Member States. Table 1.5 provides references to this documentation (extracted from the MS questionnaires). 
Table 1.5 References to documentation on defining and setting FRVs by Member States. For full references: see General references

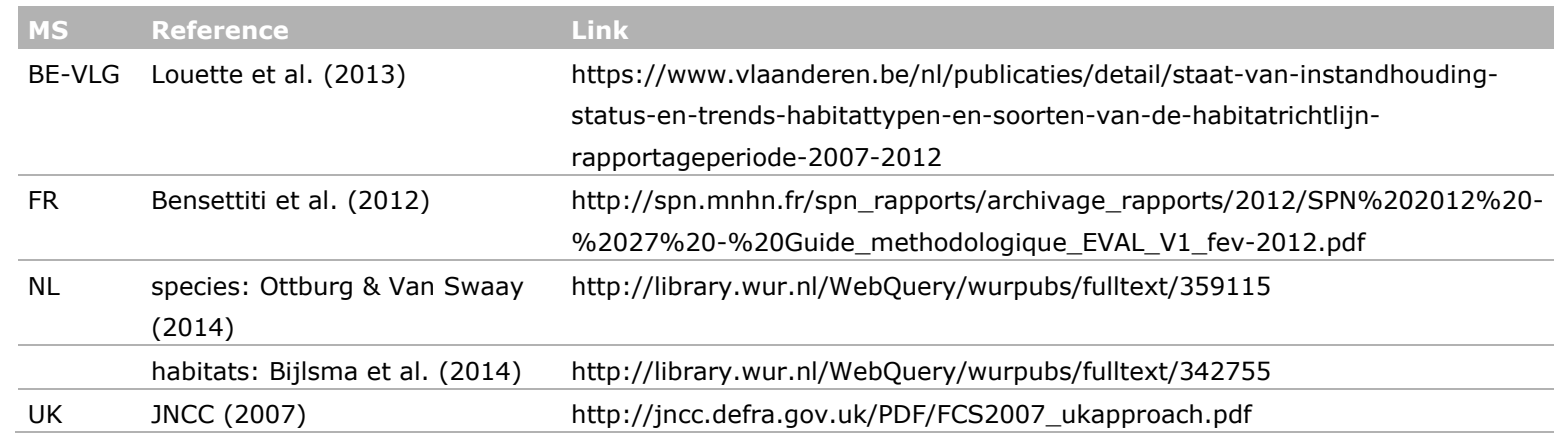

\subsubsection{Belgium - Flanders}

Louette et al. (2011) describe the stepwise approach used by Flanders to derive its conservation objectives. The first step is the assessment of the current conservation status at the regional level (i.e. both within and outside the SCIs) which allows an evaluation of how it relates to reference conditions. These reference conditions are drawn from knowledge of the current conservation status, as well as indicative, but not yet allocated nature development potentials in the landscape. Setting up reference conditions is furthermore supported by historical and actual distribution and abundance data of habitats and species, ecological characteristics of habitats and species, complemented with expert judgment. These reference conditions were further fine-tuned with socio-economical considerations, via a participation process with stakeholders. Louette et al. (2013) describe the setting of FRVs in more detail.

FRR for habitats were set by adding critically evaluated historical locations to the current distribution; for some habitats locations of site-specific, future conservation targets were added as well. Likewise, FRA includes current area and the area corresponding to decided future targets at the protected site level.

FRR for species was often taken as the area when the HD came into force (1994) or to correspond to federal conservation objectives (see above). FRPs were mainly based on generalised genetic rules provided by Mergeay (2012) who recommends a minimum effective population size $\mathrm{N}_{\mathrm{e}}=500$ corresponding to a census population of at least 5000 adult individuals, possibly distributed outside Flanders and across several metapopulations. For the conservation of one metapopulation, the objective is to conserve $95 \%$ of the genetic diversity in 100 years, with required population numbers given by Mergeay (2012). Apart from these recommendations, FRPs resulted from site-specific objectives for isolated populations near range limits as well.

\subsubsection{France}

Bensettiti et al. (2012) discuss the approaches for setting FRVs, explored and applied by France. As a general strategy, information from species or habitat specific survival and viability studies is preferred over historical data.

In setting FRR for species and habitats a minimum value of $100 \mathrm{~km}^{2}$ is assumed, corresponding to the threshold of IUCN Criterion D Vulnerable (Rodríguez et al., 2010). Historical data are used to estimate a sufficiently large potential range.

In the absence of complete demographic and abundance data, several alternatives for setting FRP are considered, based on Sanderson (2006), often including a historical approach. Reported FRPs can be the sum of FRPs for individual, more or less isolated populations. The use of a single, universal minimum population size, e.g. derived from Traill et al. (2007), is considered not satisfactory. 
FRA is considered the most difficult FRV to estimate. Different approaches are used depending on the extent of the habitat. For localised habitats mainly determined by physical conditions, such as caves, spring areas, bogs and lakes, the area of occurrence of the particular conditions is used as FRA, generally corresponding to the actual area, and sometimes adjusted using historical data from the period 1950-60, e.g. for bogs. For widespread habitats, the FRA depends on the natural variation judged from the number of defining phytosociological associations. In this case they suggest a FRA of $2000 \times$ the number of associations, based on the threshold of $2000 \mathrm{~km}^{2}$ for the area of occupancy corresponding to IUCN Criterion C Vulnerable, as given by Rodríguez et al. (2010). In any case, values can be adjusted by expert judgement. For (unspecified) special cases they suggest to derive the FRA from the FRPs of key species of the habitat.

\subsubsection{Netherlands}

The process of setting FRVs for species in the Netherlands has been reported by Ottburg \& Van Swaay (2014). First, the FRP was determined, based on the minimum number of adult individuals necessary to ensure the long-term survival of the species. This was achieved by applying the MVP-concept, based on Traill et al. (2007), and by taking risk spreading into account. The latter consideration generally required several viable population core areas, i.e. with their own reference values, distributed over the (historical) range. Secondly, the FRR was determined, derived from the actual distribution and the requirement to encompass the FRP.

Bijlsma et al. (2014) derived FRVs for habitats in the Netherlands. Again, first the FRA was set using a stepwise approach based on (1) area trends relative to the historical surface area (i.e. stable or increasing, $<1 \%$ decrease, $>1 \%$ decrease), (2) current structure and function (in three classes) and (3) current Red-List status of typical species and the threat to qualifying vegetation types (in two classes). The reference year for the historical surface area is usually 1950, the year that is also used for Red Lists. For habitat types with a negative trend, this approach results in an expansion requirement for current area, expressed as a percentage of the 'area lost', i.e. the historical area minus the current area. Appendices of the report present estimates of the historical surface areas of heaths, drift sands, raised bogs and a few grassland types in the Netherlands around 1950. Secondly, setting the FRR involved assessing whether there was a negative trend and whether the historical geographic diversity and required spatial connectivity in distribution were accounted for.

\subsubsection{United Kingdom}

The methodology used by the UK in setting FRVs is documented by the Joint Nature Conservation Committee (JNCC, 2007). The documentation clearly describes how the general instructions for setting FRVs in the Guidelines were interpreted and structured into practical approaches with inherent shortcomings and uncertainties. This description probably applies to the approach of many Member States and therefore is reproduced here for the case of setting FRRs for habitats: 'The EC Guidance did not provide a definitive method by which viability of habitat range could be assessed, e.g. by specifying metrics and the thresholds for judgements. Nor was there a widely accepted 'off the shelf' method that could be applied. To overcome this problem, some key factors and questions were identified to take into account in determining viability. These factors were not necessarily exclusive, nor did they absolutely prove or disprove viability. They were used to give a reasonable indication of viability, based on expert judgement as to the significance of particular factors and the general weight of evidence. The approach relied on expert opinion, trends and general knowledge'.

In setting FRRs for species, '1994 was used as a preliminary baseline. Where 1994 data were not available the nearest, most recent alternative was considered. No presumptions have been made as to whether range was favourable or not at that time, but consideration was given to whether the range was sufficiently large to support a long-term viable population of the species. In the absence of detailed modelling, defining favourable reference values at a UK level has been problematic. To help overcome this, current trend data were used as an indicator and have been transposed into a decision tree to assist in setting favourable reference range values'. 
In setting FRPs 'due to time and resource constraints, population viability analyses were not carried out. Instead, current trend data were used as an indicator for determining viability and, as for FRR, transposed into a decision tree. Long-term has been interpreted by the UK as 12 -15 years or three generations (whichever is longer)'.

Applying the concept of viability to habitats was considered problematic. In setting FRRs for habitats 'the approach relied on expert opinion, trends and general knowledge. In most cases this approach did not precisely define the FRR, but it did help to clarify if the current range was more or less than $10 \%$ below the FRR, i.e. if the range should be judged as inadequate or bad'. 'Two main factors were considered: (i) the total range area; and (ii) how fragmented the range appeared to be (by way of the number and size of each range block, and how well each block was filled). The view taken was that habitats which covered a large part of the UK, or which had a relatively compact range were generally more likely to be viable. Habitats that had only a limited range or which had a fragmented range were less likely to be viable. A number of other factors were also considered. A recent decline in range triggered some concern, especially if the decline had been rapid (>1\% per annum) and extensive. Allowance was made for habitats that are naturally scarce or have been scarce for many centuries, i.e. their current scarcity was not necessarily taken as a cause for concern'.

In setting FRAs two main factors were considered. 'Firstly, total habitat area. As a crude guide, habitats covering less than about 3,000 ha were taken as 'scarce' and therefore at possible 'risk'. The second main factor was the area of individual habitat patches. The view taken was that larger patches of habitats are generally more likely to be viable than smaller ones and provide some interior conditions'. Regarding habitat loss and fragmentation 'it was judged that fragmentation and isolation were unlikely to lead to a conclusion that the current habitat area need to be increased by more than $10 \%$ to ensure viability, i.e. the current area was not more than $10 \%$ below the favourable reference area'. This conclusion results from the consideration that 'fragmentation and isolation are most likely to result in impoverishment (rather than actual habitat loss). They can be remedied (at least in part) without increasing the actual habitat area (but by way of buffer zones, which could be of another habitat, or improving agricultural practices)'. 


\section{Definitions and concepts for setting FRVs}

\section{$2.1 \quad$ Definitions}

\subsubsection{Conservation status}

The Habitats Directive (article 1i) considers the conservation status of a species as 'favourable' when:

- population dynamic data on the species concerned indicate that it is maintaining itself on a longterm basis as a viable component of its natural habitats, and

- the natural range of the species is neither being reduced nor is likely to be reduced for the foreseeable future, and

- there is, and will probably continue to be, a sufficiently large habitat.

Likewise (HD article 1e), the conservation status of a natural habitat will be taken as 'favourable' when

- its natural range and areas it covers within that range are stable or increasing, and

- the specific structure and functions which are necessary for its long-term maintenance exist and are likely to continue to exist for the foreseeable future, and

- the conservation status of its typical species is favourable as defined in (i).

In the context of the Habitats Directive, the concept of Conservation Status applies to species and habitats at the national/regional scale and not to sites, the condition of a site or the condition of a species or habitat in a site. At the site level the concept of Degree of conservation is used.

The Birds Directive requires that Member States shall take the requisite measures to maintain the population of the species (referred to in BD Article 2) at a level, which corresponds in particular to ecological, scientific and cultural requirements, while taking account of economic and recreational requirements, or to adapt the population of these species to that level. Article 3 also includes the equivalent of the concept of favourable reference value for range ('area and diversity of habitat'), with diversity understood in the geographical extent. For the purpose of this report when defining and applying FRVs the terms and definitions used under the HD are being used for birds as well (see Preface of this report).

Regarding the concept of typical species, the Guidelines state (DG Environment, 2017): 'Although the Directive uses the term 'typical species', it does not give a definition, either for use in reporting or for use in impact assessments under Article 6. As it would mean a considerable increase in the necessary work to undertake an assessment of the conservation status of each typical species using the methodology used for species of Annexes II, IV and V, the assessment of typical species is included as part of the assessment of the Structure and functions parameter'.

\subsubsection{Favourable reference values}

Favourable reference values are not directly mentioned in the legal text of the HD but they are a tool to deal with the consideration of long-term viability of a species or habitat in their natural range including ecological variations. FRVs are one element among others in assessing the conservation status of a habitat or species and help to define the distance to a favourable situation. Definitions are given in Table 2.1 . 
Table 2.1 Definitions of favourable reference values by the Habitats Committee in 2004 (European Commission, 2005)

\begin{tabular}{|c|c|}
\hline FRV & Definition \\
\hline FRR & $\begin{array}{l}\text { Range within which all significant ecological variations of the habitat/species are included for a given } \\
\text { biogeographical region and which is sufficiently large to allow the long term survival of the habitat/species; } \\
\text { favourable reference value must be at least the range (in size and configuration) when the Directive came } \\
\text { into force. }\end{array}$ \\
\hline FRP & $\begin{array}{l}\text { Population in a given biogeographical region considered the minimum necessary to ensure the long-term } \\
\text { viability of the species; favourable reference value must be at least the size of the population when the } \\
\text { Directive came into force. }\end{array}$ \\
\hline FRA & $\begin{array}{l}\text { Total surface area of habitat in a given biogeographical region considered the minimum necessary to ensure } \\
\text { the long-term viability of the habitat type; this should include necessary areas for restoration or } \\
\text { development for those habitat types for which the present coverage is not sufficient to ensure long-term } \\
\text { viability; favourable reference value must be at least the surface area when the Directive came into force. }\end{array}$ \\
\hline
\end{tabular}

\subsubsection{Current and Directive value, short and long term, recent and historical past}

The term 'current value' (CV) is the value for range, population size or area covered by habitat reported by the Member State for the present reporting period, which is to be compared to the favourable reference value as part of the assessment of conservation status. A favourable reference value must be at least the value when the Habitats Directive came into force (i.e. the Directive value DV) (see Table 2.1) and this holds for the Birds Directive as well. When CV is used in setting FRVs (e.g. in statements like FRP $=\mathrm{CV}$ ) we assume that this requirement has been considered such that a FRV is at least the value when the Directive came into force.

In reporting under Art.17 of the HD, short term has been defined as 12 year (two reporting periods) and long term as at least 24 year (four reporting periods). In using historical information for setting FRVs, we need a broader historical perspective and consider the recent past, including about 50 years before the relevant Directive came into force, and the historical past, up to the last two or three centuries, depending on occurrences of major impacts on distribution, population size or area.

\subsubsection{Other terms and aspects of scale}

The HD articles which define a FCS for species and habitats use terms and phrases which in their turn need definitions and guidance, such as 'long-term basis' and 'viable'. Clearly, defining FRVs will depend on the interpretation of these terms and we include literature on this subject in $\S 2.2$.

Another important aspect in defining FRVs is selecting an appropriate spatial scale for the assessment of the conservation status of features. However, this is much less discussed because until now all FRVs have been defined at the biogeographic level within Member States. The concepts of spatial management unit (or assessment unit) and flyway population are included in the literature review but a more detailed view on spatial aspects is presented in chapter 3.

\subsection{Literature review of relevant concepts}

\subsubsection{Population viability analysis (PVA)}

PVA is a quantitative model-based method that uses genetic, demographic and abundance data of species and incorporates identifiable threats to population survival to estimate the probability of extinction and/or loss of genetic variation (Beissinger \& McCullough, 2002). PVA uses models of population dynamics which incorporate causes of fluctuations in population size in order to predict probabilities of extinction and maintenance of genetic variation, and to help identify the processes which contribute to a population's vulnerability. Which of the various deterministic and stochastic factors are important to consider in a PVA will depend on the species biology, the present population size and distribution, and the threats a population faces. Several software packages perform PVA, such 
as Vortex (www.vortex10.org/Vortex10.aspx). Sjögren-Gulve \& Ebenhard (2001) give examples of PVAs used in conservation planning.

Linnell et al. (2008) discuss the use of PVA in the context of management plans for large carnivores and explicitly include its relationship with defining FRPs. They 'strongly recommend that FRP be defined at significantly higher levels than the minimum levels predicted by a PVA. This recommendation is based both on the best available science and on the intention of the Habitats Directive as clarified in (1) the various guidance documents that underline that FCS is intended to represent a positive goal, not just a minimum, (2) that true long term consideration requires attention to genetic issues, and (3) the Directive's statement that species should be viable components of their habitat, which implies some degree of ecological functionality'.

PVA requires a lot of biological data which are not only species specific but necessarily site specific as well. Radchuk et al. (2016) conclude that 'for threatened and poorly-known species, there is no shortcut when developing models: investments to collect appropriately detailed data are required to ensure PVA models can assess extinction risk under complex environmental conditions'. Linnell et al. (2008) note that many PVAs, instead of field data, use a range of 'reasonable values', or values taken from other study sites or from captive animals. Despite these objections and its demanding nature, PVA is an important tool in exploring and planning population management including setting FRVs when data are available or can be obtained.

Some recent examples of applied PVA are available for Scandinavian wolf, bear, lynx and wolverine (Nilsson, 2013; Bruford, 2015; Puranen-Li et al., 2014). Brambilla et al. (2011) provided FRPs based on PVA for populations of Italian breeding birds with less than 2,500 pairs. For species with more than 2,500 pairs and a wide, more or less continuous range, the FRP was expressed in terms of breeding density at different spatial scales for non-colonial species. Out of the 88 species considered, they were able to formulate PVA-based FRPs for 47 populations belonging to 21 species, and breeding density for 15 further species. This approach was modified by Tye et al. (2014).

The use of PVA in plant conservation is reviewed by Harrison \& Ray (2002), Brigham \& Schwartz (2003) and Zeigler et al. (2013). The relative importance of genetic factors in driving extinction of plant species is discussed by Kim et al. (2015).

\subsubsection{Minimum viable population (MVP) and generalised genetic rules}

'The idea of a MVP has its foundation in efforts to capture, in population viability analyses (PVA), the many and interacting determinants of extinction risk. In this original context, MVP is defined as the smallest number of individuals required for a population to persist in its natural environment. The likelihood of success is measured on a probability scale (0-1), and projections into the future can be scaled to years or generations' (Traill et al., 2010).

Generalised genetic rules, derived from population genetic analysis and PVA, recommend general thresholds for viable population sizes. A much used and debated generalisation is the '50/500-rule' which states that an effective population size $\mathrm{N}_{\mathrm{e}}>50$ is sufficient to prevent inbreeding depression in naturally outbreeding species in the short term ('demographic MVP'), and $\mathrm{N}_{\mathrm{e}}>500$ to retain evolutionary potential ('genetic MVP'). A 'genetic MVP' refers to the population size required at equilibrium to balance the loss of quantitative genetic variation with the gain from mutation (Traill et al., 2010).

Example ${ }^{5}$ : The 'demographic MVP' obtained from a well-programmed PVA of wolverine in Scandinavia (Nilsson, 2013) is 320, which corresponds to $<1 \%$ risk of extinction in 100 years. A 'genetic MVP' based on $\mathrm{N}_{\mathrm{e}}>500$ using the same software and based on the same population and demography is 1380 .

\footnotetext{
5 Provided by Per Sjögren-Gulve, Swedish Environmental Protection Agency.
} 
MVP size refers to the minimum population size at which a population is likely to persist over some defined period of time with a given probability of extinction (Jamieson \& Allendorf, 2012). Based on the meta-analysis by Traill et al. (2007), the MVP for $99 \%$ persistence for 40 generations for a typical outbreeding species is of the order of several thousand (N) (Frankham et al., 2014: 6.3).

Frankham et al. (2014) give a recent review on this subject, including discussion on how $\mathrm{N}_{\mathrm{e}}$-values relate to census population sizes N and MVPs. Palstra \& Fraser (2012) and Wang et al. (2016) discuss the $\mathrm{N}_{\mathrm{e}} / \mathrm{N}$-relationship in more detail. The observed ratio $\mathrm{N}_{\mathrm{e}} / \mathrm{N}$ has been found to be about $10-20 \%$ on average in meta-analyses across many species and populations. This means that 'genetic MVPs', based on $\mathrm{N}_{\mathrm{e}}>500$, are on average greater than $2500-5000$ individuals. However, this average $\mathrm{N}_{\mathrm{e}} / \mathrm{N}$ ratio may be an overestimate, as marine species are under-represented in these analyses and can have extremely low $\mathrm{N}_{\mathrm{e}} / \mathrm{N}$ ratios (Wang et al., 2016). As noted by Brook et al. (2011) the genetic arguments alone are sufficient to embrace MVP generalisations, because there is substantial evidence that inbreeding does indeed matter profoundly for extinction risk. Frankham et al. (2014) further present revised recommendations including a '100/1000-rule' and thresholds for population size used by the IUCN red List criterion C: Critically Endangered <500, Endangered $<5000$ and Vulnerable $<20,000$ (instead of 250, 2500 and 10,000).

Generalised genetic rules have been applied in setting FRPs e.g. by BE-VLG and NL (see $\S 1.8$ ) and further analysed e.g. by Laikre et al. (2016) for the Fennoscandian wolf.

\subsubsection{MVP-targets derived from body size relationships}

Hilbers et al. (2016b) present an approach to estimate MVP targets which differs from the PVA-based method in being context independent i.e. based only on intrinsic characteristics of the species. Furthermore, these targets differ from fixed nonspecific targets ('generalised rules', see previous paragraph) in being tailored to a species' biology. They found that body mass is a good predictor of a number of life-history traits related to survival, reproduction and spatial behaviour. The influence of environmental stochastic effects on animal populations is related to body mass as well, with larger species being less susceptible to fluctuations in environmental conditions. Given that animal demographic rates and their susceptibility to environmental stochasticity depend on body size, it can be expected that MVP targets are, at least partly, dependent on body size too. These targets have been derived for a range of body masses of mammals, from $2 \mathrm{~g}$ to $3825 \mathrm{~kg}$, by using allometric relationships for intrinsic growth rate and stochastic effects in models of population dynamics (for more guidance see Box 3.4).

\subsubsection{Potential range, habitat suitability and distribution modelling}

The potential range of a species or habitat type reflects relationships between the spatial distribution of species or plant communities and required environmental variables. Information on the potential range of a species or habitat can be used to constrain the reference range and the area and population size within this range. Several sophisticated approaches are available to estimate the potential range of species and habitats, based on statistical relationships between distribution and physical, climatological and other conditions. Species distribution models (SDMs) now include former niche models and habitat suitability models and are used to understand the relationship between a species and its (a)biotic environment and to predict the occurrence of a species for locations where survey data are lacking (Franklin, 2010).

Most studies rely on a few methods (MaxEnt, Generalized Additive Methods, Boosted Regression Trees; Franklin, 2010) which model distribution patterns using presence-absence, presence-only or relative abundance data. Methodological issues concerning these models are much debated (e.g. Yackulic \& Ginsberg, 2016). False absences (detection bias) reduce the predictive accuracy of conventional SDMs. (Dynamic) occupancy modelling is used to avoid this bias (e.g. Comte \& Grenouillet, 2013).

Di Marco et al. (2016) use habitat suitability models to scale up population targets to the species level. They test their approach in a case study on the European ground squirrel (Spermophilus citellus) and 
identify three main steps to be followed: (i) definition of a population target, (ii) characterisation of the species' populations by means of a habitat suitability model, and (iii) definition of a scaled species target. An up-scaled species target should include multiple conditions reflecting species persistence (number, size, location of the populations to be protected), uniqueness (e.g. evolutionary potential) and representativeness (e.g. presence in different ecosystems).

Bonelli et al. (2018) present FRVs for Apollo (Parnassius apollo) in the Alpine biogeographical region in Italy, based on habitat suitability modelling using MaxEnt, followed by a procedure to identify discrete patches of suitable habitat at a $1 \times 1 \mathrm{~km}$ scale. Information on species dispersal ability was included to select patches satisfying the minimum area requirement of the species. Next, the current distribution of these patches was verified with respect to the natural range and FRVs were derived by identifying the number of patches necessary to completely cover the environmental variation.

Álvarez-Martínez et al. (2017) demonstrate how the potential ranges of habitat types can be modelled with abiotic variables related to topography and climate and how these estimates can be downscaled to local, realized distributions with remote sensing. In addition, Agrillo et al. (2018) propose the use of large vegetation databases to explore the compositional and distributional patterns of habitat types (e.g. Quercus suber woodlands) across European biogeographical regions. These approaches can support setting FRVs for habitat types as well (elaborated in Box 3.6).

\subsubsection{Spatially structured populations: management units (assessment units) and flyway populations}

In defining appropriate spatial scales for FRVs, sometimes a species range needs to be spatially stratified within or across Member States, based on ecological criteria. The concept of management unit is important in this respect. Management units (MUs) are functionally independent populations or population segments i.e. exhibit distinct demographic processes and show reduced exchange (migration/dispersal) rates over a few generations. MUs can be characterized by genetic markers, life history parameters, distribution, behaviour, movements (i.e. connectivity) and morphology, and are appropriate elements for conservation. The concept is used in conservation management (e.g. Olea \& Mateo-Tomás, 2014) but especially well-developed for migratory or otherwise mobile, marine species such as turtles, cetaceans and seals (Palsbøll et al., 2007; Evans \& Teilmann, 2009; Wallace et al., 2010; Olsen et al., 2014; Sveegaard et al., 2015). Managers commonly use the term 'assessment unit' as equivalent to management unit.

Another important spatial stratification of populations results from the flyway approach, welldeveloped for migratory birds. A flyway encompasses the entire range of a migratory population, including the breeding and wintering areas and the resting and feeding sites in between, as well as the area within which a bird migrates. The flyway approach to conservation requires that all key sites/habitats along a flyway are in good condition and are able to carry out their functional role in the migratory cycle (Dodman \& Boere, 2010). In fact, the definition of a range ${ }^{6}$ includes this concept. Guidelines for reporting under Article 17 ask to consider "migration issues" and "migration routes" in setting FRVs (Evans \& Arvela, 2011: 16,18) and explicitly include the "complete migration route" for migratory fish and lampreys (Explanatory Notes and Guidelines for the period 2013-2018: 123). Therefore the flyway approach is not only relevant for birds but for migratory fish and bats as well. The stepwise approach for setting FRVs for species ( $\$ 3.2$ ) explicitly deals with FRVs for nonreproductive 'populations' occurring in wintering or passing areas.

\footnotetext{
6 "The natural range includes however, areas that are not permanently used: for example for migratory species "range" means all the areas of land or water that a migratory species inhabits, stays in temporarily, crosses or overflies at any time on its normal migration" (European Commission, 2005).
} 


\section{Setting FRVs}

This chapter presents the considerations and building blocks used to construct the general approach for setting FRVs as given in the Explanatory Notes and Guidelines for the period 2013-2018. The approach is based on the MS questionnaires (chapter 2), an overview of literature and methods (chapter 3) and opinions and reviews by the authors of this report as well as discussions with the Ad hoc group on FRVs.

\subsection{General considerations}

\subsubsection{Guidance on the interpretation of FRVs, references and feasibility aspects}

'Establishing favourable reference values must be distinguished from establishing concrete targets: setting targets would mean the translation of such reference values into operational, practical and feasible short-, middle- \& long-term targets/milestones. This obviously would not only involve technical questions but be related to resources and other factors' (European Commission, 2005).

This clearly stated relationship between FRVs and conservation targets can be summarized as follows:

- FRV = ecologically determined threshold value for the assessment of a FCS;

- FRV = amount/number required for a viable conservation of the habitat type/species;

- $F R V \geq$ value when the Directive came into force;

- FRP > minimum viable population (MVP);

- $\mathrm{FRV}$ = linked to a fixed reference year (taking into account that an FRV should not be smaller than the value in the year when the Directive came into force);

- FRVs are not necessarily the same as historical values, but in certain cases this may well be possible;

- FRV is not necessarily the same as potential value; in any case potential values can be used to understand restoration possibilities and constraints;

- FRVs can be broken down into specific conservation targets and milestones; depending how far FRVs are from current values, such targets can be milestones on the way to FRVs, but also be equivalent to FRVs or even go beyond.

The presented stepwise approach for setting FRVs (see § 3.1.4) starts by selecting an appropriate spatial scale and historical perspective for the species or habitat type. This is necessary to understand how historical processes and major impacts shaped current ranges, areas and numbers and, based on this, what can be considered as ecologically and technically feasible. Feasibility considerations should include irreversibility of large scale developments e.g. major infrastructure and urban development. Socio-economic considerations such as availability of funding should be left out but are relevant when planning for operational conservation targets/milestones.

Historical considerations and major impacts on the distribution and population size of species groups and habitat types differ between environments and often between species groups and land use categories as well. Some major historical changes and impacts are given below:

- For coastal environments the main period of land claim/enclosure and therefore habitat loss was in the 18th century. Some offshore habitats also significantly depleted long before this time period e.g. oyster reefs in the southern North Sea.

Baleen whales like blue, fin, and humpback whale were first hunted intensively from 1850s onwards, with the most intense period (in eastern North Atlantic) being between 1900 and 1960s. Protection became widespread in mid-1980s. Bottlenose dolphin appears to have been more widespread (particularly in estuaries and semi-enclosed bays) before 1900, and may also have experienced declines between 1960s and 1980s. Harbour porpoise also appear to have experienced declines during the twentieth century, particularly the latter half (1960s-1980s). In both cases, increased 
pollution may have played a role; in the latter case, additionally, by-catch almost certainly has done, whilst prey depletion from over-exploitation of fish stocks may well have a role as well.

- The regulation of river systems and lakes started already in the 19th and early 20th century with large river works e.g. dams, weirs, summer dykes. Important pressures in the fresh water environment are water pollution, strong overfishing, habitat loss, invasive alien species and diseases (e.g. in crayfish, amphibians).

- Severe wetland loss started in the same period and still continues, caused by the same drivers: changes in land use (increase in agriculture and grazing animals); water diversion through dams, dikes and canalization; infrastructure development, particularly in river valleys and coastal areas.

- Semi-natural habitats depending on extensive agricultural management experienced severe declines in quantity and quality and in numbers of associated species in most parts of Europe after World War II due to cultivation, hydrological 'improvement', agricultural intensification including ammonia emissions, water pollution, fragmentation and urbanisation (e.g. Fuller, 1987; Cousins et al., 2007; Ridding et al., 2015).

- Forest cover steadily declined in most parts of Europe to very low values, starting from 1000 BC up to about 1850, a process linked to increasing population density (Kaplan et al., 2009). After this low, forest cover generally increased as a result of plantation forestry (often with non-native tree species). Therefore, historical values for area and viability of native forest ecosystems can generally not be used as reference in setting FRVs.

- Industrialisation starting in the mid-19th century resulted a.o. in high (acidifying) $\mathrm{SO}_{2}$ emissions in the first half of the 20th century with maximum levels in the 1970s and 1980s; since 1990 a strong reduction in $\mathrm{SO}_{2}$ emissions has been achieved by a combination of measures. Many acid-sensitive species (e.g. lichens, bryophytes) and habitat types (e.g. 6230, Species-rich Nardus-grasslands) were already in severe decline before 1950 (Van den Berg et al., 2005).

- For countries in which urbanisation caused large declines, the second half of the 20th century may be the period of main losses in coastal dune areas.

\subsubsection{Relationships between CS parameters}

\section{The iterative process of setting of FRR and FRP/FRA}

In setting FRP and FRA, requirements on the viability of a species/habitat type in its natural range will result in constraints on densities/numbers/areas and on spatial aspects such as exchange, connectivity, (meta)population structure and risk spreading. This means that data on the spatial configuration of populations and habitats (spatial distribution) will be necessary to set FRP and FRA. Next, setting FRP/FRA and FRR is interdependent and asks for an iterative process because the FRR must not only encompass the FRP/FRA but often requires additional distribution to restore significant ecological variations of the habitat/species in areas of the former range (see FRR definition in Table 2.1). In this case the FRP/FRA must include additional population size/habitat area to represent the additional distribution.

\section{Other CS parameters}

Setting FRVs for range, area and population should be independent from the assessment of the other CS parameters such as 'habitat for the species' for species, 'structure and functions (incl. typical species)' for habitats and 'future prospects' for species and habitats. However, requirements e.g. on spatial configuration, connectivity, (meta)population structure and population density used for setting FRVs, will probably be assessed as aspects of habitat quality as well. Therefore, a clear separation of the assessment of the different parameters will not always be possible nor meaningful.

The FRV definitions given in Table 2.1 include requirements of connectivity, population density and ecological and genetic variations in setting FRP and FRA and this will have consequences for the methodology used to assess the other parameters. In fact, this procedure will contribute to a better understanding of the conservation status of quality parameters. For example, in the case of assumptions on population density in setting FRPs, an environment must provide the conditions which enable such a density; quality indicators are needed to evaluate these conditions. Another subtle relationship exists between FRA and the 'structure and functions' of habitats regarding the conservation status of typical species. It seems logical to include requirements of characteristic species of a habitat in setting a FRA; however, the evaluation of typical species is part of the 
assessment of Art 17 'structure and functions' and both uses of characteristic/typical species need to be independent and consistent.

\subsubsection{Reference-based and model-based methods}

This paragraph introduces two basic methods for setting FRVs, reference-based and model-based, and discusses combined approaches as well. See $\S 3.2 .2$ (step 2.1 FRP assessment) or $\S 3.3 .2$ (step 2.1 FRA assessment) for further implementation.

\section{The reference-based method}

The reference-based approach for setting FRVs considers the historical distribution/area of a habitat type or the historical distribution/population size of a species in a period when the habitat type or species was supposed to be in a (stable) favourable condition. Empirical numbers, areas or densities corresponding to a particular historical baseline are used to set FRVs.

The selection of a reference period generally depends on occurrences of major impacts on distribution and population size/area of the particular species or habitat (see § 3.1.1 for examples). Since such impacts might often be irreversible from a technical/ecological point of view, conditions before these impacts will not be ecologically feasible as reference values. In the absence of clear breaking points in the occurrence and function of populations/habitat types, we suggest to examine the recent past, i.e. up to about 50 years before the relevant Directive came into force (see $\S 2.1 .3$ ).

Using the reference-based approach, the FRA/FRP is derived from a historical reference (baseline). The question is: How much of the baseline needs to be restored to represent a favourable area or population size? This process is elaborated in Box 3.5. Setting the FRR is inherently reference-based because it requires to consider all significant ecological variations within the range (Table 2.1).

A special case of the reference-based approach applies to setting FRVs for non-reproductive 'populations' such as passing or wintering bird populations (see $\S 4.4 .4$ ).

\section{Model-based methods}

The functional unit that responds to environmental changes and human pressures is the population for species and the vegetation (or corresponding 'stand' in marine environments) and its corresponding species composition, typical species, structure and functions/processes for habitats.

Model-based approaches use species-specific information on required viable population size or speciesspecific or habitat type-specific features such as habitat suitability or required area for proper functioning. The following methods can be used:

The population-based method uses population viability analysis (PVA) or more often literature sources to estimate a minimum viable population (MVP) size, followed by upscaling to FRP level (Box 3.1). Therefore, translating MVPs to the FRP and FRR level inevitably requires knowledge of reference conditions for ecological/genetic variations in the species' natural range. Generally, several 'long-term viable populations' will be necessary to represent all the significant ecological variations of the species within its range.

\section{Box 3.1. Applying MVPs in setting FRVs}

In applying MVPs we assume 'genetic MVPs' i.e. accounting for evolutionary potential or other concept related to long-term viability. Most MVP-values in the literature refer to 'demographic MVPs' which require upscaling by some factor to account for long-term viability (compare '50-500 rule' in § 3.2.3).

In setting FRVs an additional kind of upscaling is nearly always necessary to ascertain that all significant variation within the natural range of a species is represented by the FRP (as required in setting the FRR, see Table 2.1). This kind of upscaling therefore depends on conditions within the Member State. See Box 3.3 for additional guidance. 
- The potential-range method uses distribution modelling or habitat suitability measures to constrain the FRP/FRA and FRR within the potential range (see $\S 2.2 .5$ ). Box 3.6 provides guidance for Spatial Habitat Modelling using Maxent. Next, FRVs are determined by identifying and applying favourable reference densities (for FRPs) or environmental conditions (for FRAs) in 'optimal' and 'average' habitats within the potential range, given considerations on ecological and technical feasibility (see $\S 3.1 .1$ ). See $\S 4.4 .3$ for using the potential range method in setting FRVs for birds.

- The area-based method uses assumptions on the area requirement of a good functioning habitat at the landscape level, followed by upscaling to FRA level by considering risk spreading and ecological variations within the natural range. This approach is based on the 'minimum dynamic area' concept (e.g. Poiani et al., 2000) and is valid for 'macro habitats' (see § 3.3.1 Table 3.2).

\section{Combining methods}

As already mentioned above, setting FRRs is inherently reference-based. This means e.g. that a population-based approach needs reference-based considerations to scale a MVP up to the FRP- and FRR-level accounting for 'all significant ecological variations within the natural range' (see Box 3.1). Therefore, a purely model-based approach to set FRPs ensuring long-term viability and survival of species will only be used if there is absolutely no knowledge of the historical distribution.

In using the potential-range or reference-based method for species, a useful combination of methods starts by identifying the proper minimum viable population (MVP) size (see e.g. § 4.4).

Setting FRVs for habitat can combine a reference-based approach with distribution modelling to define the FRAs. While reference-based and model-based methods are very different in their approach, they are not mutually exclusive and practical examples and testing have shown that combining these methods is useful (see $\S 2.2 .4$ ).

\subsubsection{A general approach for setting FRVs}

The most obvious general conclusion emerging from chapter 2 is the need for defining and structuring criteria and indicators for setting FRVs at appropriate spatial and temporal scales into practical methods. The criteria and scales to be considered must have an ecologically relevant relationship with the long-term viability of the features.

Chapter 2 presented definitions and available concepts, building material and methods relevant for the structuring of criteria into practical methods. The previous paragraphs provide guidance on general aspects in setting FRVs. Now, all these elements are brought together in a stepwise approach for setting FRVs. Apart from guiding the process, this approach enables careful early decisions about data deficiency (FRV is unknown) or clearly favourable conditions (FRV is current value) after which the process is finished. Figure 3.1 presents the necessary steps (and see Figure 10 in Explanatory Notes and Guidelines for the period 2013-2018). These steps are elaborated in $\S 3.2$ for species and in $\S 3.3$ for habitat types.

In setting FRVs we consider three levels of data availability and knowledge:

- low: sparse data on actual distribution and ecological requirements; hardly historical data;

- moderate: good data on actual distribution and ecological requirements but limited historical distribution data (only trends);

- high: good data on actual distribution and ecological requirements and good historical data and trends.

These levels will determine which approach (reference-based and/or model-based) can be used and how confident FRVs can be presented: as unknown, by expert opinion, as operator or real valued. 
1 Gather information
1.1 Biology/Ecology of the species/habitat

1.2 Spatial scale of functioning

1.3 Historical perspective

1.4 Analysis of historical versus current distribution and trends

\begin{tabular}{|c|c|c|}
\hline $\begin{array}{c}\text { 1.4a Are data or proxies available } \\
\text { for distribution and trends? }\end{array}$ & No & $\begin{array}{c}\text { FRP/FRA/FRR is unknown } \\
\text { or CV for common and }\end{array}$ \\
& & widespread species \\
\hline
\end{tabular}

Yes

1.4b Negative trends in distribution or population size/area?

No

1.4c Other problems which can be tackled by increasing population size/area? or

Positive trends due to natural recovering?

2 Set favourable reference values

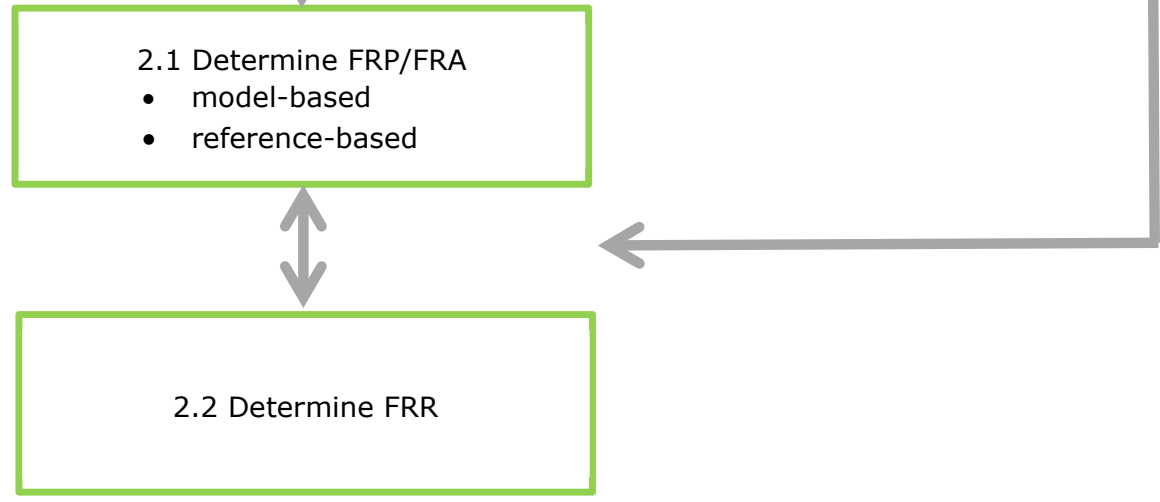

model-based

reference-based

2.2 Determine FRR

Figure 3.1 Flowchart for the stepwise process of setting FRVs for species and habitat types 


\subsection{The stepwise approach for species}

Refer to Figure 3.1 for the overall process of setting FRVs and its relationship with the steps elaborated below.

\subsubsection{Step 1 - Gather information}

\section{Step 1.1 - Biology of the species}

Differences in species attributes and requirements will result in different population processes and different methods for setting FRVs. Consider:

- Life history strategies; body size; dispersal capacity

- Genetic structure of the population: subpopulations, meta-populations, management units

- Geographical variation (differentiation) in habitat requirements, migration routes

- Habitat requirements for reproduction, foraging, resting, migration, wintering

- Potential range (based on species requirements and attributes)

- Unit for defining population size including proxies (e.g. occupancy)

\section{Step 1.2a - Spatial scale of functioning: how many populations?}

For a given species, the first question is how many isolated (meta)populations have to be considered. Next the viability of each population must be assessed at an appropriate spatial scale (step 1.2b).

The identification of reproductive populations for which it is very likely that they are isolated, i.e. have insufficient exchange of individuals with neighbouring populations to consider them part of one coherent population network or metapopulation, requires region-specific data and knowledge and therefore is only feasible for a limited number of already well-studied species. We propose a shortcut by considering the distribution of a species, e.g. from national atlases, and defining separate 'populations' only in the case of clearly disjunct distributions. In order to work this out, information is needed on:

- the species' current distribution in Europe or the distribution of management units;

- the species' distribution in Europe in a reference period and/or a species' potential distribution to evaluate the possible impact of historical pressures and to identify possible relict occurrences;

- the species' reproductive dispersal distance (see step 1.1 Biology of the species); Box 3.2 provides guidance on estimating the median dispersal distance for birds and mammals and in using this distance to decide whether populations are isolated or not.

Generally, we expect distinct populations for habitat specialists which naturally occur only locally, e.g. in mountain areas or calcareous regions, or for species with island or relict populations. On the other hand common and widespread species can form just one large population.

Although a population approach formally does not apply to non-reproductive populations, we propose to use the same procedure as for reproductive populations: separate non-reproductive populations which are supposed not to exchange individuals. With respect to waterbirds and several terrestrial bird species and seabirds, considering their flyway populations is useful for this purpose, also in linking wintering and passage populations to breeding populations. 
Although distribution patterns of clearly disjunct species suggest isolated populations, this must at least be evaluated relative to the species' dispersal distance. The distribution of (natal) species dispersal distance (dispersal density) can be used for this purpose. This density describes the probability of settling (breeding, reproducing) at a particular distance from the site of origin (birth, parent). Several authors discuss relationships between dispersal distance and species traits, such as adult body mass (e.g. Sutherland et al., 2000; Santini et al., 2013; Whitmee \& Orme, 2013).

Hilbers et al. (2016a) provide allometric relationships for birds and mammals between body mass and size of home range and between the latter and median dispersal distance which can be used to evaluate whether a species is likely to colonize distant habitat or not. We assume that habitat at larger distance than five times the median dispersal distance will not be colonized and therefore that populations more than five times the median dispersal distance apart can be considered as isolated.

The allometric relationships for given body mass $\mathrm{m}$ (in $\mathrm{kg}$ ) are as follows (from Hilbers et al. 2016a, Table 1):

\begin{tabular}{|c|c|c|c|c|}
\hline \multirow[t]{2}{*}{ Variable \& unit } & \multicolumn{4}{|c|}{ Estimate } \\
\hline & $\begin{array}{l}\text { carnivorous } \\
\text { birds }\end{array}$ & $\begin{array}{l}\text { non- } \\
\text { carnivorous } \\
\text { birds }\end{array}$ & $\begin{array}{l}\text { carnivorous } \\
\text { mammals }\end{array}$ & $\begin{array}{c}\text { non- } \\
\text { carnivorous } \\
\text { mammals }\end{array}$ \\
\hline HR home range size $\left(\mathrm{km}^{2}\right)$ & $2.1 \times 10^{2} \times \mathrm{m}^{1.13}$ & $3.7 \times 10^{1} \times \mathrm{m}$ & $3.8 \times 10^{-1} \times \mathrm{m}^{1.13}$ & $5.4 \times 10^{--2} \times m$ \\
\hline $\begin{array}{l}d_{m} \text { median natal dispersal distance } \\
(\mathrm{km} / \text { generation })\end{array}$ & \multicolumn{2}{|c|}{$12 \times \mathrm{HR}^{0.5}$} & \multicolumn{2}{|c|}{$5.6 \times \mathrm{HR}^{0.5}$} \\
\hline
\end{tabular}

Example: The smew (Mergellus albellus), a diving duck, has body mass $\mathrm{m} 0.5-0.9 \mathrm{~kg}$, an estimated home range size $\mathrm{HR}=37 \times 0.9=33 \mathrm{~km}^{2}$ and an estimated median dispersal distance $\mathrm{d}_{\mathrm{m}}=12 \times 33^{0.5}=69 \mathrm{~km}$ per generation. This means that populations more than about $350 \mathrm{~km}$ apart can be considered as isolated.

\section{Step 1.2b - Spatial scale of functioning: population categories}

Species are highly diverse in their mobility and spatial requirements and dynamics. Therefore, FRVs only make sense when the appropriate spatial scale is explicitly taken into account. Populations functioning at different spatial scales may require different methods in setting FRVs. This step determines an appropriate spatial scale for setting FRVs by considering different population categories related to the behaviour of individuals and features of species groups.

The following aspects have been used to define population categories (and see Table 3.1a en 3.1b):

\section{- Sedentary (resident) versus migratory reproductive populations}

This distinction is useful in setting FRVs because sedentary (resident) and migratory populations face different pressures and threats and generally require different measures to maintain or reach a favourable conservation status. Migratory populations are defined here as having individuals showing large cyclic (seasonal), directed movements between reproductive and non-reproductive areas. Despite this high mobility, reproductive populations can be small and confined to specific locations (predictable) or large and more or less continuous and dynamically responding to variations in available habitat (covered by the categories MR1-MR4).

Most migratory species to be considered belong to birds, cetaceans and turtles; fish and mammals include migratory species as well and even some insects do (some butterflies, moths and dragonflies). Annex 2 presents lists of the migratory species of the Birds and Habitats Directive.

\section{- Reproductive versus non-reproductive populations}

Several migratory species including birds, several whales, turtles and some bats have nonreproductive (wintering, staging) populations separated from their reproductive populations in space and/or time. Sometimes the non-reproductive and reproductive population occur close to each other within the same Member State. In this case a population can be considered as resident and reproductive at the national level.

Setting FRVs for these non-reproductive populations (nrFRVs) requires other approaches and methods than for reproductive populations, e.g. MVPs and population-based methods can't be used. 
The categories MNR1-MNR4 characterize non-reproductive populations for resident and migratory species analogously to the categories MR1-MR4 for reproductive populations.

\section{- Home range, mobility and predictability of habitat}

Species with large home ranges, e.g. large carnivores and several cetaceans, require FRVs at the supranational level (categories S4, MR4).

For small, more or less immobile invertebrate species often occurring in locally high densities (category S6), both population numbers and historical references are not or hardly available and in this case an area-based approach or potential-range based method can be used.

Some invertebrates (e.g. butterflies) use several types of habitat during their life span which must lie within the mobility range of the species during one generation. Other small and mobile species require extra attention as well in terms of metapopulation dynamics and/or required combinations of habitats (see § 4.5). For these cases population category S5 applies.

\section{- Animal versus plant species}

Most population categories apply to animals to describe their diversity in spatial behaviour. Only three categories are used for plants as well to differentiate between more or less continuous distributions often crossing Member State boundaries with exchange by seeds or pollen (S1), clearly disjunct distributions of uncommon species with isolated or genetically differentiated populations (S2) and an intermediate category with scattered (often fragmented) distribution (S6).

\section{- National versus supranational assessment}

Many species have large sustainable populations above member state level for which supranational FRVs have no added value for the assessment of conservation status. Therefore, we assume that for widespread species with more or less continuous distributions (often crossing national boundaries) and populations (assessment units) with more or less exchange at or below national level, setting FRVs at the national level within biogeographic regions is appropriate when sustainable population size is clearly exceeded in the current situation. This corresponds to category S1 for resident species and MR1 for migratory species. In this case, define a FRP at MS level only, e.g. by considering the potential range and its ecological variation within the MS.

In summary: supranational assessment must be considered for species when

1) sustainable population size at the population level (corresponding to a properly scaled MVP, see Box 3.1) is not or only just met and

2a) the biology of the species allows for long-distance exchange (large home range or large dispersal distance)(categories S4, MR4) or

2b) individuals have small home ranges and occur in only one or a few isolated populations at supranational level (categories S3, MR3).

In the case when more than one population must be considered, FRPs can be defined for each population separately, resulting in partial FRPs (pFRPs; see Table 3.1 categories S2 and MR2) within a Member State. The overall FRP (at national level) results from adding all pFRPs. However, the evaluation of current value must consider all pFRPs on a one-out-all-out basis: overall population size will be favourable (FV) only when all partial population sizes are favourable.

For small countries, species with populations showing substantial transboundary dynamics, the same reasoning applies. In this case it is important to decide between categories S1/MR1 (sustainable population to be assessed at national level), S3/MR3 (isolated population to be assessed at supranational level) and S4/MR4 (species with individuals with large home ranges).

From an ecological point of view, distinct FRVs may be necessary or not at the biogeographic regionlevel within the national level. Likewise, the supranational level might be above the biogeographic region-level, especially for bird species and large carnivores. Therefore, FRVs should be set at the most appropriate scale (often national, sometimes supranational). However, for the purpose of reporting under Article 17, FRVs must be reported at the national-biogeographical level, e.g. using a proportion based on distribution and/or size or area within the biogeographical region. 
Table 3.1a Population categories for sedentary/resident species and migratory species (reproductive populations) of the habitats and birds directive with reproductive populations in one or more Member States (MS a-d). See Table 3.1b for the legend

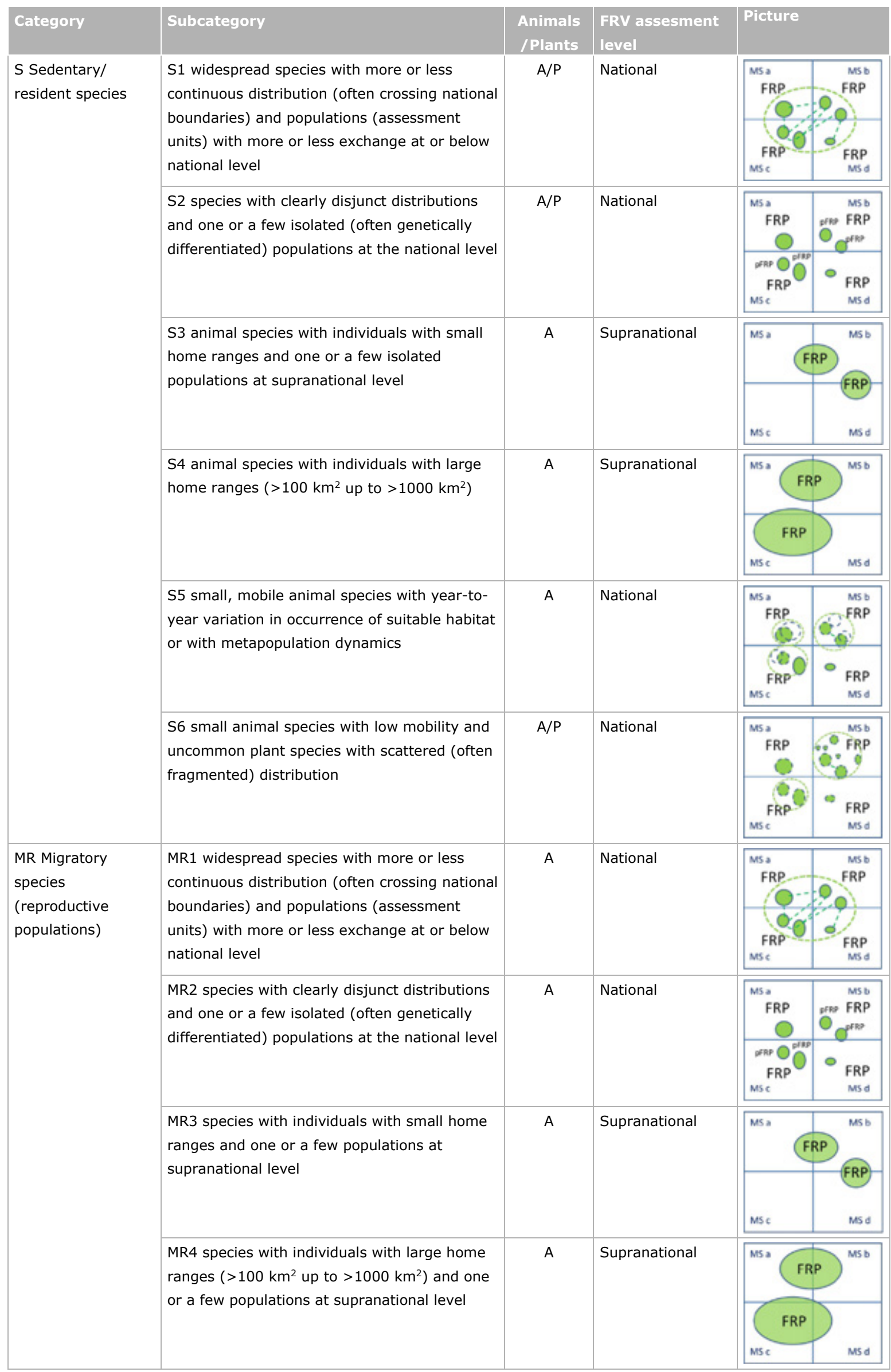


Table 3.1b Population categories for migratory species of the habitats and birds directive with nonreproductive populations in one or more Member States (MS a-d)

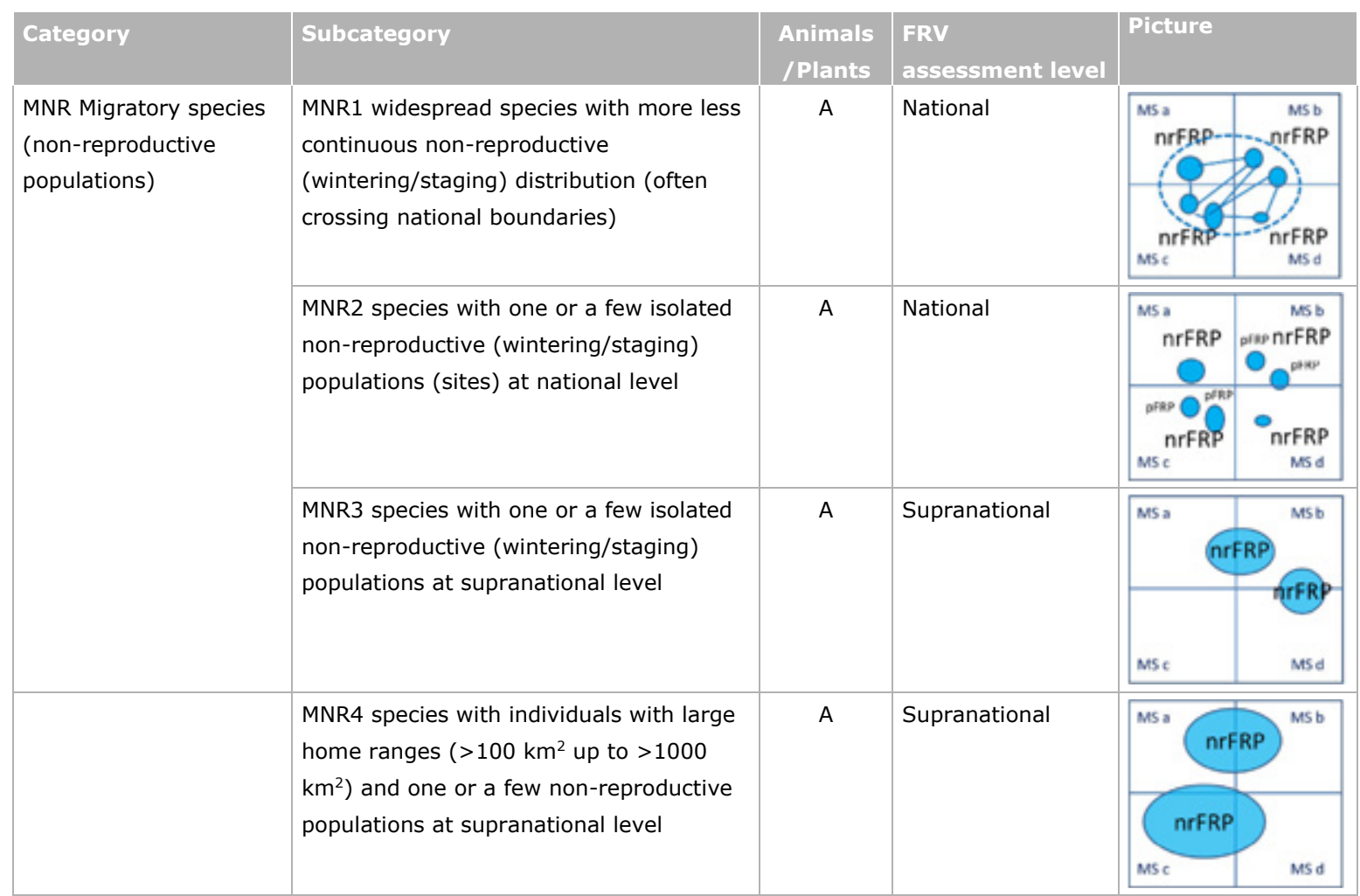

\section{Population categories for setting FRVs at the national and supranational level}

\section{Legend}

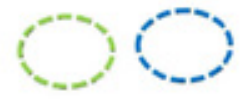

Effective populations resulting from more or less exchange between reproductive populations (green) or movements between non-reproductive populations (blue)

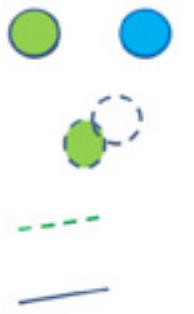

Reproductive (green) and non-reproductive (wintering, staging, passing) population (blue), more or less clearly delimited

Reproductive population with local year-to-year variation in location of suitable habitat, often not clearly delimited

Exchange between reproductive populations

Movement between non-reproductive populations

FRP: (reproductive) Favourable Reference Population

nrFRP: non-reproductive FRP

pFRP: partial FRP for disjunct populations within MSs

\section{Step 1.3 - Historical perspective: what happened to the species?}

Current size and configuration of a species' range are strongly shaped by historical factors. The viability of populations within their range can only be understood and evaluated from a broad historical perspective on FCS. However, while many populations and habitats were more abundant in the past than nowadays, this does not necessarily have direct implications on their probability to persist and play their role in the environment. This step must provide a proper historical perspective.

Deducing this perspective could involve the generation of a narrative of what happened to a species, for example by looking at pre-industrialisation or pre-agricultural intensification levels of human 
impact. This could cover a timespan of anything up to the last ice age (e.g. for identifying relic distributions or considering species that could be reintroduced) but with much more recent time scale for considering the potential and relevance of restoration.

Present a narrative about what happened to the species. Consider:

- Recent and historical distribution and population size

- Distribution and population size when the relevant Directive came into force

- Major impacts on overall distribution and population size; when did they occur? See § 3.1 .1 for an overview of major historical changes

- Changes in configuration of the range (connectivity, fragmentation)

- Loss of ecological variations in habitat of the species, e.g. in particular regions

- Main causes of trends - pressures \& threats

- Restoration potential; (ir)reversibility of major impacts and measures

\section{Step 1.4 - Analysis of historical versus current distribution and trends}

Given an appropriate spatial scale and historical perspective, step 1.4 proceeds with the analysis of distribution (and therefore range) and trends based on historical and recent data. If current population numbers are below or just reach MVP size and/or when negative trends in numbers or areas are found or can be inferred from the historical perspective, subsequent analyses must reveal the causes of low viability or decline, e.g. decreased connectivity, land use change or overexploitation. Generally this results in setting FRVs greater than CV. If this kind of signals is not found or can't be inferred, we assume that FRV $=\mathrm{CV}$ and the process of setting FRVs is finished. Step 1.4 is also meant to decide about data deficiency and to avoid the process of setting FRVs in the case of a clearly favourable conservation status.

Step 1.4a - Are data or proxies available for distribution and trends?

Only in the case of a total lack of data or proxies on current distribution or any indications of historical distribution and trends, FRVs are considered as data deficient $(\mathrm{X})$. For common widespread species $\mathrm{FRV}=\mathrm{CV}$ is more appropriate in this situation.

Step $1.4 b$ - Negative trends in distribution or population size?

This step requires an appropriate historical perspective and estimates or indications of a species' historical range including spatial configuration. The relevant time scale depends on historical impacts specific to the particular environment (step 1.3). References from before such impacts are not feasible ecologically. Trends must be assessed for both the recent and historical past (see § 2.1.3). The spatial resolution in marine environments is generally $50 \times 50 \mathrm{~km}$ (but preferably lower), on land below $10 \times 10 \mathrm{~km}$, preferably $1 \times 1 \mathrm{~km}$. Factors/indicators to consider are grid-based presence/occupancy and spatial configuration.

If any negative trend in distribution or population size is found, proceed with step 2.1 (FRP assessment).

Step $1.4 \mathrm{C}$ - Other problems which can be tackled by increasing population size or Positive trends due to natural recovering?

This extra step is to ensure first, that small and isolated populations with apparently stable distributions (ranges) and population sizes are indeed viable in the long term. When this is not evident (e.g. regarding reproduction) a FRP must be assessed according to step 2.1, probably corresponding to population category S2 (species with clearly disjunct distributions and one or a few isolated populations at the national level; see Table 3.1a).

Secondly, the situation where range and population show positive trends due to natural recovering needs explicit consideration. For several species population sizes in the recent and even historical past were very low due to overexploitation, hunting etc. As a result of changes in land use or legislation, some of these species now recolonize their natural range spontaneously, e.g. cetaceans and some large carnivores. This process needs to be assessed relative to the natural (potential) range including ecological variations according to step 2.2 (FRR assessment). 
Otherwise, FRV = CV and the process of setting FRVs has been finished. Note that this decision is only made when 1) the historical distribution is smaller than or similar to the actual distribution in size and configuration, and 2) trends in distribution and in size are not negative in the recent and historical past, and 3) after evaluating two special, apparently favourable cases.

\subsubsection{Step 2 - Set favourable reference values}

\section{Step 2.1 - FRP assessment}

Setting the FRP and FRR is an iterative process (see Figure 3.1), but since the FRR must at least contain the FRP, step 2 starts with the FRP assessment. The FRP is assessed in two cases detected in step 1.4:

1. Negative trends in current and/or historical distribution and/or population numbers;

2. Positive trends in current distribution and/or population numbers for species recovering from a deep low, e.g. after cessation of hunting or whaling or as a result of legislation, land use change or improvement of air or water quality. Although in this case current population size can be (much) higher than when the Directive came into force, it needs to be determined what values for population size and range are sufficient for long-term viability.

In both cases a population-based method can be used to asses the FRP (see Box 3.3). When a population-based approach can not be performed, e.g. for species with other population units than individuals or when proxies have been used (such as occupancy), a reference-based or another modelbased approach can be applied (see Box 3.5). For species with a more or less stable or still decreasing population size all these approaches depend on considerations about restorable suitable habitat. Note that the use of historical information does not mean that the FRP must or will be restored up to the historical population size. See $\S 3.1 .3$ for a discussion of reference-based and model-based methods including combined approaches.

In case 2 , when a species is already recolonizing its natural range successfully, instead of using the outcome of a population-based analysis, we suggest to use operators until population size and distribution have been stabilized for a sufficient long time ('wait-and-see'). This is particularly useful for naturally expanding, (formerly) threatened species. In this case FRP > CV (or FRP >> CV) and generally FRR > CV (or FRR >> CV) as well, depending on how much the species expanded already in its (former) natural range.

After a FRP has been determined, including the additional range necessary to restore population size up to FRP-level, proceed with step 2.2 FRR assessment. Note that the FRP possibly has to include additional population size to restore ecological variations within the range as well (see Step 2.2 FRR assessment).

\section{Step 2.2 - FRR assessment}

The iterative FRP/FRR-assessment includes considerations to restore ecological variations and configuration within the natural range of the species (see $\S 3.1 .2$ ). Therefore, the FRR can be derived by considering $\mathrm{CV}$, additional range to include the FRP in the case FRP > CV and additional range to restore ecological variations within the range. 


\section{Box 3.3. Guidance on using a population-based method in setting FRPS}

A. Determine or infer the minimum viable population size (MVP) corresponding to a genetic MVP or similar concept (see Box 3.1)

- high data quality: perform Population Viability Analysis (PVA) for a given population and context (see $\S 2.2 .1)$

- moderate/low data quality: use MVP-estimates from

- species (and context) specific literature, accounting for differences in genetic and demographic MVPs; the latter requires upscaling (see Box 3.1)

- generalised genetic rules corresponding to an effective population size $\mathrm{N}_{\mathrm{e}} \geq 500$ ('genetic MVP'; see $\S 2.2 .3)$

- (for mammals) body size relationships (see Box 3.4 for further guidance)

- (for birds) body size relationship with 'rule of thumb' (see § 4.4.2).

B. Find a scaling factor to translate MVP-size to the FRP-level

Additional population size and/or the number of required (minimum viable) populations will at least depend on ecological variations within the natural range of the species and often on trends as well. This requires to take into account 1 ) ecological/genetic variations within the (historical) natural range i.e. geographical, climatological, geological and altitudinal gradients as well as significant differences in historical land use, 2) trends (from step 1.4) and 3) ecological and technical feasibility.

Approaches:

- moderate data quality: use models for potential range and habitat suitability (see § 2.2 .5 ) or available estimates of population density, amount of suitable area and maximum dispersal distance to constrain the number of required populations or the spatial extent of one mixing population

- low data quality: consider ecological/genetic variations within the historical range and find the minimum number of populations needed to cover this variation

- for migratory species and species with large home ranges: consider structured populations according to management units (marine mammals and turtles) or flyway populations of migratory birds (see $\S 2.2 .6$ )

C. Determine the FRP

- if the scaling factor can be estimated with sufficient confidence:

$\mathrm{FRP}=\mathrm{MVP} *$ scaling factor (derived from the number of required populations or the required additional population size)

if this FRP $<$ CV then FRP $=\mathrm{CV}$

- if the scaling factor can only be estimated qualitatively, use operators:

if $M V P<<C V$ then FRP $=C V$

if $M V P \sim$ or $>C V$ and the scaling factor is relatively low: FRP $>C V$

if $\mathrm{MVP} \sim$ or $>\mathrm{CV}$ and the scaling factor is relatively high: FRP $>>\mathrm{CV}$

Note: Refer to § 2.1 .3 for using 'current value' (CV) in setting FRVs.

D. Consider consequences for setting the FRR

In case of FRP $>$ CV or FRP > > CV determine how much additional range is necessary (or not) to include the FRP.

Note that the assessment of FRP/FRR is an iterative process and that the FRR-assessment can result in required additional population size to restore all ecological variations within the range. 


\section{Box 3.4. Guidance on calculating MVP targets according to Hilbers et al. (2016b)}

Refer to $\S 2.2 .4$ for the rationale behind estimating minimum viable population targets based om body size relationships (and see Hilbers et al. 2016b).

MVP targets related to the body mass ( $\mathrm{m}$ in $\mathrm{kg}$ ) of mammals for six different intrinsic growth rates ( $\mathrm{rm}$ of $80 \%, 60 \%, 40 \%, 20 \%$, and $0 \%$ of $\mathrm{rm}$ ) are obtained by the regression equation

$\log M V P=a-b * \log m+c * \log ^{2} m\left(\log _{10}\right.$-based $)$

with coefficients $\mathrm{a}, \mathrm{b}$ and $\mathrm{c}$ given in the table below.

\begin{tabular}{l|c|c|c|c|c|c|}
\multirow{2}{*}{ model } & \multicolumn{4}{|c|}{ Mean } & \multicolumn{3}{c}{ Mean + 2SD } \\
\cline { 2 - 7 } & a & b & $c$ & a & b & $c$ \\
\hline $100 \% \mathrm{rm}$ & 1.51 & 0.38 & 0.06 & 1.78 & 0.49 & 0.10 \\
\hline
\end{tabular}

The mean value corresponds to a population with $95 \%$ chance to withstand environmental stochasticity for 100 years.

The model is based on the assumption that threats are absent or abated by protection so that the target population has a mean growth rate $\geq 0$. The influence of alleged unfavourable conditions on the MVP targets, which represent habitats of relatively low quality or external factors (e.g., human pressures or predation) affects the growth rate of species, and can be quantified as fractions of the intrinsic population growth rate $\mathrm{rm}$. Since favourable reference values represent favourable conditions, we propose to use the $100 \% \mathrm{rm}$ model only. Refer to Hilbers et al. (2016b) for coefficients of regression models for fractions of $\mathrm{rm}$. They also present 'cautionary MVPs' using the upper bound at 2 SD of the estimates, for which coefficients have been included in the table above (Mean + 2SD)*

Example: For the Eurasian red squirrel with body mass $0.33 \mathrm{~kg}$, model mean gives $\mathrm{MVP}=51$ and the 'cautionary model' (mean + 2SD) MVP=109.

*Provided by Jelle Hilbers, Radboud University Nijmegen, the Netherlands 


\subsection{The stepwise approach for habitat types}

Refer to Figure 3.1 for the overall process of setting FRVs and its relationship with the steps elaborated below.

\subsubsection{Step 1 - Gather information}

\section{Step 1.1 - Ecology of the habitat}

Differences in species composition and requirements will result in different structures and functioning of habitat types and in different methods for setting FRVs. Consider:

- Physical, climatological and ecological conditions (including potential extent of range)

- Variation in species composition across geographical regions, environmental variables (e.g. altitude) and historical land use

- Stability and dynamics of area of occupancy, including units to define FRA (e.g. $\mathrm{km}^{2}$ or detailed distribution as a proxy)

- Features of a favourable 'structure and functions'

- Typical species and their range and conservation status

\section{Step 1.2 - Spatial scale of functioning}

Habitat types have been defined by each MS based on a common interpretation manual at the EU level (European Commission, 2013). National interpretations and definitions may therefore differ between countries.

The requirement that a FRA must be sufficiently large to include the ecological variations in the natural range (see Table 2.1) does not necessarily imply that supranational FRVs have to be considered. In fact, this requirement is met already when, in setting FRVs for habitats, each MS includes all ecological conditions resulting from geological, altitudinal and climatic variation and from historical land use, within its national boundaries. Indeed, many habitat types show considerable turnover in species composition along geographic gradients within their ranges. For species considered at the supranational level, e.g. for large carnivores, a change in area or quality of the habitat in one MS will affect the functioning of the supranational population and that's why this scale level makes sense in setting FRPs. For habitat types, changes in area or quality in a particular MS generally won't affect the functioning of that habitat type in an adjacent MS.

In conclusion, we propose to set FRAs for all marine and terrestrial habitat types at the national level only.

Habitat types differ considerably in extent and scale of ecological processes and therefore in requirements for proper functioning (viability). A useful distinction to address differences in functioning of habitat types including the spatial scale of key processes involved, is between a macroand meso-habitats as given in Table 3.2. According to this table each habitat type can be assigned to one out of four categories, exemplified by habitat types of group 31 'Standing waters':

- Macro-habitats (category 1a): e.g. 3160 Natural dystrophic lakes and ponds, $3170 *$ Mediterranean temporary ponds, 3180 *Turloughs, 3190 Lakes of gypsum karst;

- Macro-habitat components (category 1b): e.g. 3260 Rivers with muddy banks with Chenopodion rubri p.p. and Bidention p.p. vegetation

- Meso-habitats (category 2a): e.g. 3110 Oligotrophic waters containing very few minerals of sandy plains (Littorelletalia uniflorae), 3140 Hard oligo-mesotrophic waters with benthic vegetation of Chara spp.;

- Meso-habitat components (category 2b): 31A0 *Transylvanian hot-spring lotus beds. 


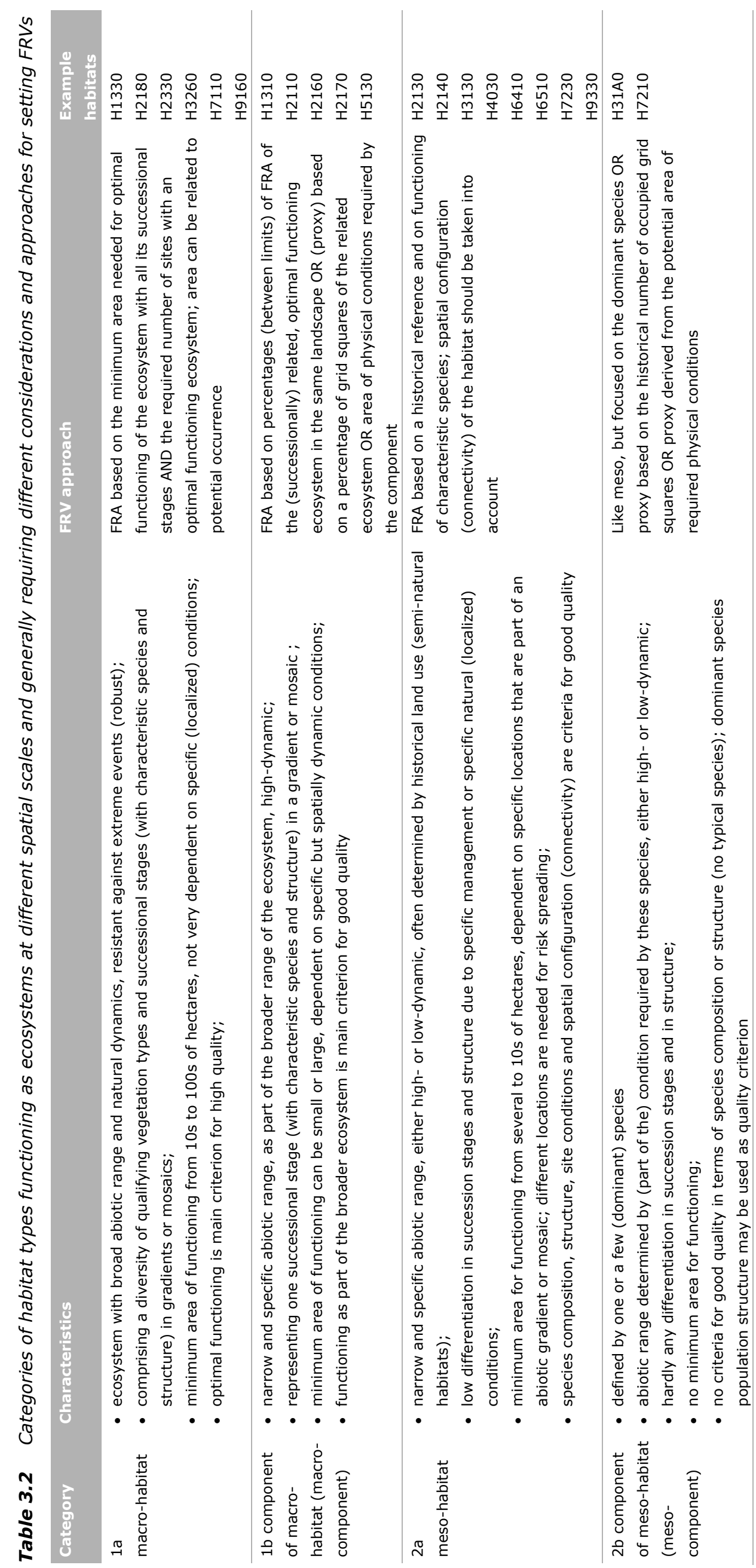


Considerations on gene flow, isolation and viability don't apply directly to habitat types (defined by abstract vegetation types), and therefore (meta)population theory can't be applied either. However, these theories can be used to describe requirements of the typical, diagnostic or key species of a habitat type. The HD requires that a habitat with FCS must have its typical species in favourable condition as well, and theoretically this may determine the area and spatial configuration of habitats, and therefore the FRA and FRR. So, although the reporting format evaluates typical species as part of the assessment of the Structures \& Functions parameter, this doesn't theoretically exclude using species and their FRPs in the process of setting FRAs. Note however the increasing insight into factors and species attributes which result in considerable extinction debts of characteristic species (e.g. Piessens \& Hermy, 2006; Cousins \& Vanhoenacker, 2011; Dullinger et al., 2013).

\section{Step 1.3 - Historical perspective: what happened to the habitat?}

Current size and configuration of a habitat's range are strongly shaped by historical pressures and viability of habitats within their range can only be understood and evaluated from a broad historical perspective on FCS (compare $\S 3.2 .1$ step 1.3 for species).

Present a narrative about what happened to the habitat. Consider:

- Recent and historical distribution and area

- Distribution and area when the HD came into force

- Major impacts on overall distribution and area; when did they occur?

- Changes in configuration of the range (connectivity, fragmentation)

- Loss of ecological variations, e.g. in particular regions

- Changes in species composition and 'structure and functions'

- Main causes of trends - pressures and threats

- Restoration potential; (ir)reversibility of major impacts and measures

Since setting FRVs for habitat types will often depend on reference-based methods, a historical perspective for a FCS is important. Although much literature exists on historical land use change which can be used to infer trends in area and quality of habitat types, direct data (surveys) on corresponding changes in species composition of the vegetation are scarce and at most available from the early $20^{\text {th }}$ century onwards. Modelled potential distribution (potential-range method; see Box 3.6) may help to assess historical area for climax habitats, like most forest types.

As for species, reference periods for setting FRVs for habitat types must be deduced by considering common threats and pressures in particular environments as well as major impacts resulting in irreversible changes in landscapes and seascapes (see § 3.1.1 for major changes and impacts).

\section{Step 1.4 - Analysis of historical versus current distribution and trends}

Given an appropriate spatial scale (macro- or meso-habitat or component) and historical perspective, step 1.4 proceeds with the analysis of distribution (and therefore range) and trends based on historical and recent data. If negative developments are found or can be inferred from a general historical perspective, subsequent analyses must reveal their nature and causes, e.g. decreased connectivity or land use change. Generally this results in setting FRVs greater than CV. If this kind of signals is not found or can't be inferred, we assume that FRV = CV and the process of setting FRVs is finished.

Step 1.4 is also meant to decide about data deficiency and to avoid the process of setting FRVs in the case of a clearly favourable conservation status.

Step 1.4a - Are data or proxies available for distribution and trends?

Only in the case of a total lack of data or proxies on current distribution or any indications of historical distribution and trends, FRVs are considered as data deficient $(\mathrm{X})$.

Step $1.4 b$ - Negative trends in distribution or area?

This step requires an appropriate historical perspective and estimates or indications of a habitat's historical range including spatial configuration. The relevant time scale depends on historical impacts specific to the particular environment (step 1.3). Trends are assessed for both the recent and historical past (see $\S 2.1 .3$ ). The spatial resolution in marine environments is generally $50 \times 50 \mathrm{~km}$ (but 
preferably lower), on land preferably below $10 \times 10 \mathrm{~km}$. Factors/indicators to consider are grid-based presence/occupancy and spatial configuration.

If a negative trend in distribution or area is found, proceed with step 2.1 (FRA assessment).

Step 1.4c - Other problems which can be tackled by increasing area or Positive trends due to natural recovering?

This extra step is to ensure first, that habitats with apparently stable distributions and areas are indeed viable in the long term regarding their structure and function. The special case where distribution and area appear more or less stable but favourable functioning requires additional area occurs in habitats showing large-scale aging and decline in typical species when large-scale suitable habitat for rejuvenation or pioneer stages is absent (e.g. salt marshes, drift sands). An area-based approach can be used to assess FRA (see step 2.1). Negative trends in the structure and/or function without clear relationship with area and distribution have to be assessed under the parameters 'structure and functions' and/or 'future prospects'.

Secondly, the situation where range and area show positive trends due to natural recovering needs explicit consideration. For some habitats areas in the recent and even historical past were very low caused by cultivation or overexploitation. As a result of changes in legislation or land use, some of these habitats now spread spontaneously into their natural range again, e.g. some forest types. This process needs to be assessed according to step 2.1 .

In all other cases, FRV = CV and the process of setting FRVs has been finished. Note that this decision is only made when 1) the historical distribution is smaller than or similar to the actual distribution in size and configuration, and 2) trends in distribution and in area are not negative in the recent and historical past, and 3) after evaluating two special, apparently favourable cases.

\subsubsection{Step 2 - Set favourable reference values}

\section{Step 2.1 - FRA assessment}

Setting the FRA and FRR is an iterative process (see Figure 3.1), but since the FRR must at least contain the FRA, step 2 starts with the FRA assessment. The FRA is assessed in two cases described in step 1.4:

1. Negative trends in current or historical distribution and/or area;

2. Positive trends in current distribution and/or area for habitats recovering from a deep low, e.g. as a result of legislation, land use change or improvement of air or water quality. Although in this case current area can be higher than when the Directive came into force, it needs to be determined what values for area and range are sufficient for long-term viability.

For habitats with a more or less stable or still decreasing area (case 1) FRA assessment depends on considerations about restorable suitable habitat. Note that the use of historical information does not mean that the FRA must or will be restored up to the historical area.

In case 2, when a habitat is already spreading into its (former) natural range successfully (e.g. 5230* Arborescent matorral with Laurus nobilis in Italy), we suggest to use operators until area and distribution have been stabilized for a sufficient long time ('wait-and-see'). This is particularly useful for naturally expanding, (formerly) threatened habitats such as forest types.

Alternatively, an area-based approach can be used: determine the minimum area (MA) needed for a good functioning habitat at the landscape scale and decide on the minimum number of locations in its natural range considering ecological variations. Then, FRA $=\mathrm{CV}+(\mathrm{MA} *$ number of locations needed). An area-based approach is relevant e.g. for natural forest types with only scattered remaining locations and for which a reference-based approach clearly makes no sense. Area requirements for the natural functioning of woodlands at the scale of gap dynamics can be derived from the concept of 'minimum structure area' (MSA; e.g. Bücking, 2003; Parviainen, 2005), based on the more general concept of 'minimum dynamic area' (e.g. Poiani et al., 2000). To allow large-scale disturbance events and functioning at the scale of stand dynamics (e.g. see Angelstam \& Kuuluvainen, 2005; Hahn et al., 2007) the MSA must be increased by at least a factor of five (Parviainen, 2005). This estimate does 
not include considerations about species composition. Generally, an even larger area is needed to obtain 'compositional equilibrium' (e.g. Busing \& White, 1993), which would be recommendable given the definition of favourable status of a habitat type in the Habitats Directive.

After a FRA has been determined, including the additional range necessary to restore area up to FRAlevel, proceed with step 2.2 FRR assessment. Note that the FRA possibly has to include additional area to restore ecological variations within the range as well (see Step 2.2 FRR assessment).

\section{Step 2.2 - FRR assessment}

The iterative FRA/FRR-assessment includes considerations to restore ecological variations and configuration within the natural range of the habitat type (see § 3.1 .2 and Box 3.5). Therefore, the FRR can be derived by considering CV, additional range to include the FRA in the case FRA > CV and additional range to restore ecological variations within the range.

\section{Box 3.5. Guidance for assessing the level of restoration needed when using a reference-based approach (habitats and species)}

Note: Refer to § 2.1 .3 for using 'current value' (CV) in setting FRVs.

A. Determine a reference value (RefValue)

- Find a historical reference period for which the habitat/species is supposed to be in favourable condition, based on the narrative of what happend to the habitat/species including considerations about major impacts (see stepwise approach). Estimate the corresponding area of habitat, population size or occupancy (=RefValue) for this period

- Alternatively (requiring high data quality and knowledge), use the potential-range method (§ 3.1.3), based on statistical relationships between occupancy and physical and climatological factors and underpin a desired minimum occupation threshold to infer a RefValue (e.g. by considering historical distribution). For species, use estimates of favourable density to find reference population size and for habitats use estimates of favourable conditions to find reference area within potential range.

Define 'distance to reference value' RV1 = RefValue - CV. Use min-max values to express confidence.

B. Determine how much of RV1 can be restored, considering ecological and technical feasibility and knowledge of suitable/potential habitat. This is the restorable amount RV2. Note that the magnitude of the negative trend determines the amount of RV2: the more negative, the larger RV2 will be.

C. Determine FRA/FRP

- if RV2 can be estimated with sufficient confidence:

- FRA/FRP $=\mathrm{CV}+\mathrm{RV} 2$ (or use min-max-values to express confidence)

- if RV2 can only be estimated qualitatively, use operators:

- FRA/FRP > CV when RV2 is relatively small

- FRA/FRP >> CV when RV2 is relatively large

D. Consider consequences for setting the FRR

When RV2 is relatively large due to loss of variations or configuration: determine how much additional range is necessary to include the FRA/FRP. 
Spatial distribution models are generally based on various hypotheses on how environmental factors control the distribution of species and communities (Guisan \& Zimmermann, 2000; Guisan et al., 2017). Habitat types are identified by plant communities considered as proper synthetic indicators for the conservation status of a habitat type (Maciejewski et al., 2000; Poncet et al., 2014).

Spatial Habitat Modeling (SHM) predicts the distribution of habitats across the landscape (ie. potential range) using relationships between the spatial distribution of plant communities and environmental variables as does Species Distribution Modeling (SDM; Franklin, 1995, 2010). This approach requires georeferenced habitat vegetation plots and environmental predictors covering the target area (e.g. topographic, climatic or land cover variables). When habitat plots are classified a priori with respect to its vegetation type (Brzeziecki et al., 1993; Miller \& Franklin, 2002; Maggini et al., 2006; Poncet et al., 2014), approaches and statistical methods for spatial vegetation modeling are conceptually similar to those commonly used in species distribution modelling, such as regression methods (e.g. generalized linear models, generalized additive models) or machine learning systems (e.g. maximum entropy models, decision trees) (Guisan \& Zimmermann, 2000; Guisan et al., 2017; Franklin, 2010). Irrespective of the method used, the results of spatial modelling, especially for plant communities, are always predictions of the habitat distribution. However, a dynamic perspective might support the habitat assessment sensu Habitats Directive by repeating the modelling process for qualifying vegetation types, especially in cases where there is lack of data for robust assessment of the conservation status (e.g. for the range parameter).

The next steps can be followed to estimate a habitats potential area in its actual range (considered equal to FRA if the habitat type is in favourable conservation status) by spatial modeling analysis:

\section{Selection of habitat type plots}

The vegetation plots with characteristic/diagnostic/key species (refering to national and European habitat interpretation manuals) must be selected from available national georeferenced vegetation databases (e.g. European Vegetation Archive and/or Global Index Vegetation Database). A further selection has to be performed taking into account the variation in structure of the habitat such as relative cover of the diagnostic/ characteristic species (e.g. equal or higher than $50 \%$ relative to other tree species cover or layers). Furthermore, depending on the vegetation classification system (De Cáceres et al., 2015), a consistent plant assemblage of the habitat types can be detected by supervised or unsupervised classification of the vegetation plots.

2. Spatial modelling

Spatial predictive modelling estimates the geographic extent of the natural range of the habitat and its correlation with major environmental factors. To obtain a valuable result the following issues must be considered (and see Table 1):

a. choose environmental variables (measured directly or indirectly) pertinent and significant, for defining the spatial ecological niche of the habitat type;

b. identify a proper spatial resolution of the environmental variables, usually provided in grid cells, in relation to the analyzed habitat (e.g. topographic factors, climatic factors, land use factors etc.);

c. spatial distribution modeling can only be performed analyzing one habitat at a time.

We use MaxEnt as SHM software, because it allows "presence-only" data (Guisan \& Zimmermann, 2000), generally available from national vegetation archives linked to habitat code. Table 1 gives examples of predictor variables used in SHM. Our approach, which is based on the composition of plant communities, has been shown as a useful method for understanding distribution patterns of natural habitats (Potts et al., 2013; Álvarez-Martínez et al., 2017). The habitat suitability models computed with MaxEnt gave the spatial pattern of the habitat types with a high performance after 10 -fold cross-validation as measured by the AUC ("area under the curve", a performance indicator). The models did not show overfitting, suggesting that the restricted distributions were determined by climatic and topographic conditions rather than just by spatial autocorrelation.

The resulting model produces a suitability map (with probabilities ranging from 0 to 1 ) for the habitat analyzed across the territory investigated (i.e. "wider potential range") and using a probability threshold value to exclude the lower suitability values. This threshold value can be provided by Maxent (e.g. values less than the "Equate entropy of thresholded and original distributions value"). Furthermore, territories occupied by patches of land that are not compatible with the existence of a natural habitat (i.e. urban areas, intensive and extensive agricultural areas etc.) or patches not compatible with the habitat under examination (i.e. forest habitats, dunes, rivers etc.) must be excluded. Therefore, the final result is a more refined map of habitat (i.e. "narrower potential range"). 
Box 3.6. Spatial habitat modelling (SHM) for settings FRVs of habitat types (continued)

Suitability maps can be used to estimate range parameters (i.e. environmental driver) as well, such as the area of occupancy, useful for assessing the conservation status at both regional (Álvarez-Martínez et al., 2017) and continental (Jiménez-Alfaro et al., 2018; Agrillo et al., 2018) scales.

Table 1 Predictor variables used for the Spatial Habitat Modeling with MaxEnt.

\begin{tabular}{|c|c|c|c|c|}
\hline Family & Variable & Resolution & Units & Source \\
\hline \multirow[t]{3}{*}{ Topography } & Altitude & 20 meters & meter asl & Digital Terrain Model \\
\hline & Slope & 20 meters & degrees & Digital Terrain Model \\
\hline & Aspect & 20 meters & adimensional & Digital Terrain Model \\
\hline \multirow[t]{7}{*}{ Climate } & Annual Mean & 30 arc-second & degrees Celcius $\times 10$ & WorldClim \\
\hline & Temperature & & & \\
\hline & $\begin{array}{l}\text { Temperature } \\
\text { Seasonality }\end{array}$ & 30 arc-second & $\begin{array}{l}\text { degrees Celcius } \times 10 \\
\text { (values standard } \\
\text { deviation } * 100 \text { ) }\end{array}$ & WorldClim \\
\hline & $\begin{array}{l}\text { Mean Temp of Wettest } \\
\text { Quarter }\end{array}$ & 30 arc-second & degrees Celcius x 10 & WorldClim \\
\hline & Annual Precipitation & 30 arc-second & millimetres & WorldClim \\
\hline & $\begin{array}{l}\text { Precipitation } \\
\text { Seasonality }\end{array}$ & 30 arc-second & millimetres & WorldClim \\
\hline & $\begin{array}{l}\text { Precipitation of } \\
\text { Warmest Quarter }\end{array}$ & 30 arc-second & millimetres & WorldClim \\
\hline
\end{tabular}

\section{References}

Agrillo, E, N. Alessi, B. Jiménez-Alfaro, L. Casella, P. Angelini, O. Argagnon, G. Crespo, F. FernándezGonzález, T. Monteiro-Henriques, C.S. Neto \& F. Attorre. 2018. The use of large databases to characterize habitat types: the case of Quercus suber woodlands in Europe. Rend. Fis. Acc. Lincei https://doi.org/10.1007/s12210-018-0703-x.

Álvarez-Martínez, J.M., B. Jiménez-Alfaro, J. Barquín, B. Ondiviela, M. Recio, A. Silió-Calzada \& J.A. Juanes. 2017. Modelling the area of occupancy of habitat types with remote sensing. Methods Ecol. Evol., doi: 10.1111/2041-210X.12925.

Brzeziecki, B., F. Kienast \& O. Wildi. 1993. A simulated map of the potential natural forest vegetation of Switzerland. J.Veg.Sci. 4: 499-508.

De Cáceres, M. et al. 2015. A comparative framework for broad-scale plot-based vegetation classification. Applied Vegetation Science, 18(4), 543-560.

Franklin, J. 1995. Predictive vegetation mapping: geographic modelling of biospatial patterns in relation to environmental gradients. Progress in physical geography 19(4): 474-499.

Franklin, J. 2010. Mapping species distributions: spatial inference and prediction. Cambridge University Press.

Guisan, N.E. \& Zimmermann. 2000. Predictive habitat distribution models in ecology. Ecol. Model. 135: 147-186.

Guisan, A., W. Thuiller \& N.E. Zimmermann. 2017. Habitat Suitability and Distribution Models: With Applications in R. Cambridge University Press.

Ichter, J., D. Evans \& D. Richard. 2014. Terrestrial habitat mapping in Europe: an overview. Eur. (Joint MNHN--EEA report). EEA Technical report No $1 / 2014$.

Jiménez-Alfaro, B. et al. 2018. Modelling the distribution and compositional variation of plant communities at the continental scale. Diversity and Distributions (accepted).

Maciejewski, L., F. Lepareur, D. Viry, F. Bensettiti, R. Puissauve \& J. Touroult. 2000. Etat de conservation des habitats : propositions de définitions et de concepts pour l'évaluation à l'échelle d'un site Natura 2000. Revue d'Ecologie (Terre et Vie), 71(1): 3-20.

Maggini, R., A. Lehmann, N.E. Zimmermann \& A. Guisan. 2006. Improving generalized regression analysis for the spatial prediction of forest communities. J.Biogeogr.33: 1729-1749.

Miller, J. \& J. Franklin. 2002. Modeling the distribution of four vegetation alliances using generalised linear models and classification trees with spatial dependence. Ecol. Model. 157: 227-247.

Poncet, L, R. Spyropoulou \& I. Pereira Martins(eds.) 2014. Terrestrial habitat mapping in Europe: an 212 overview. EEA Technical report No 1/2014. ISSN 1725-2237.

Potts, A.J., T.A. Hedderson, J. Franklin \& R.M. Cowling. 2013. The Last Glacial Maximum distribution of South African subtropical thicket inferred from community distribution modelling. Journal of Biogeography 40: 310-322. 


\section{$4 \quad$ Additional guidance for selected groups of species and habitats}

\subsection{Migratory species and species with large home ranges}

Annex 2 lists all migratory species and species with large home ranges of the Habitats and Birds directives:

- terrestrial mammals (Table A2.1);

- seals and turtles (Table A2.2);

- cetaceans (Table A2.3);

- fishes and lampreys (Table A2.4);

- birds (Table A2.5).

Additional guidance on setting FRVs is provided for selected species groups and habitats in the next paragraphs.

\subsection{Marine mammals (cetaceans)}

\subsubsection{General remarks}

Thirty-eight species of cetaceans have been recorded in European seas (Table 4.2.1), representing more than $40 \%$ of the 90 species currently recognised in the world. Of those thirty-eight species, 15 are common or regular, whilst the remaining 23 are rare or vagrant.

Table 4.2.1 List of cetacean species recorded in Europe

\begin{tabular}{|c|c|}
\hline Common or Regular Species & Rare or Vagrant Species \\
\hline Harbour Porpoise Phocoena & Rough-toothed Dolphin Steno bredanensis \\
\hline Short-beaked Common Dolphin Delphinus delphis & Spinner Dolphin Stenella longirostris \\
\hline Atlantic White-sided Dolphin Lagnorhynchus acutus & Fraser's Dolphin Lagenodelphis hosei \\
\hline Striped Dolphin Stenela coeruleoalba & Melon-headed Whale Peponocephala electra \\
\hline Risso's Dolphin Grampus griseus & Pygmy Killer Whale Feresa attenuata \\
\hline Long-finned Pilot Whale Globicephela melas & Short-finned Pilot Whale Globicephala macrorhynchus \\
\hline Killer Whale Orcinus orca & Beluga Delphinapterus leucas \\
\hline Northern Bottlenose Whale Hyperoodon ampullatus & Narwhal Monodon monoceros \\
\hline Cuvier's Beaked Whale Ziphius cavirostris & Sowerby's Beaked Whale Mesoplodon bidens \\
\hline \multirow[t]{8}{*}{ Humpback Whale Megaptera novaeangliae } & Gray's Beaked Whale Mesoplodon grayi \\
\hline & Pygmy Sperm Whale Kogia breviceps \\
\hline & Dwarf Sperm Whale Kogia sima \\
\hline & Blue Whale Balaenoptera musculus \\
\hline & Sei Whale Balaenoptera borealis \\
\hline & Bryde's Whale Baaenoptera edeni \\
\hline & Gray Whale Eschrichtius robustus \\
\hline & Bowhead Whale Balaena mysticetus \\
\hline
\end{tabular}


Species diversity is greatest for those countries bordering the Atlantic, and lowest for semi-enclosed seas like the Baltic and Black Seas (Evans, 2010, 2011; see Fig. 4.2.1). For a list of species by European country, see Waring et al. (2009).

All the species of cetaceans recorded in European seas are highly mobile, and none has a range confined to a single country or even to Europe. The only species with relatively restricted ranges are northern bottlenose whale, Atlantic white-sided dolphin and white-beaked dolphin, and all three of these occur across the North Atlantic. Although the status of particular species may vary between countries' EEZs, the majority of species are rare or vagrant, largely because their main distributions are outside European waters. It is therefore recommended that FRVs be assessed only for the 15 common or regular species. All European cetaceans are European Protected Species (requiring 'strict protection'), but only the harbour porpoise and bottlenose dolphin are listed on Annex II of the Habitats Directive, requiring Natura 2000 sites for their protection.

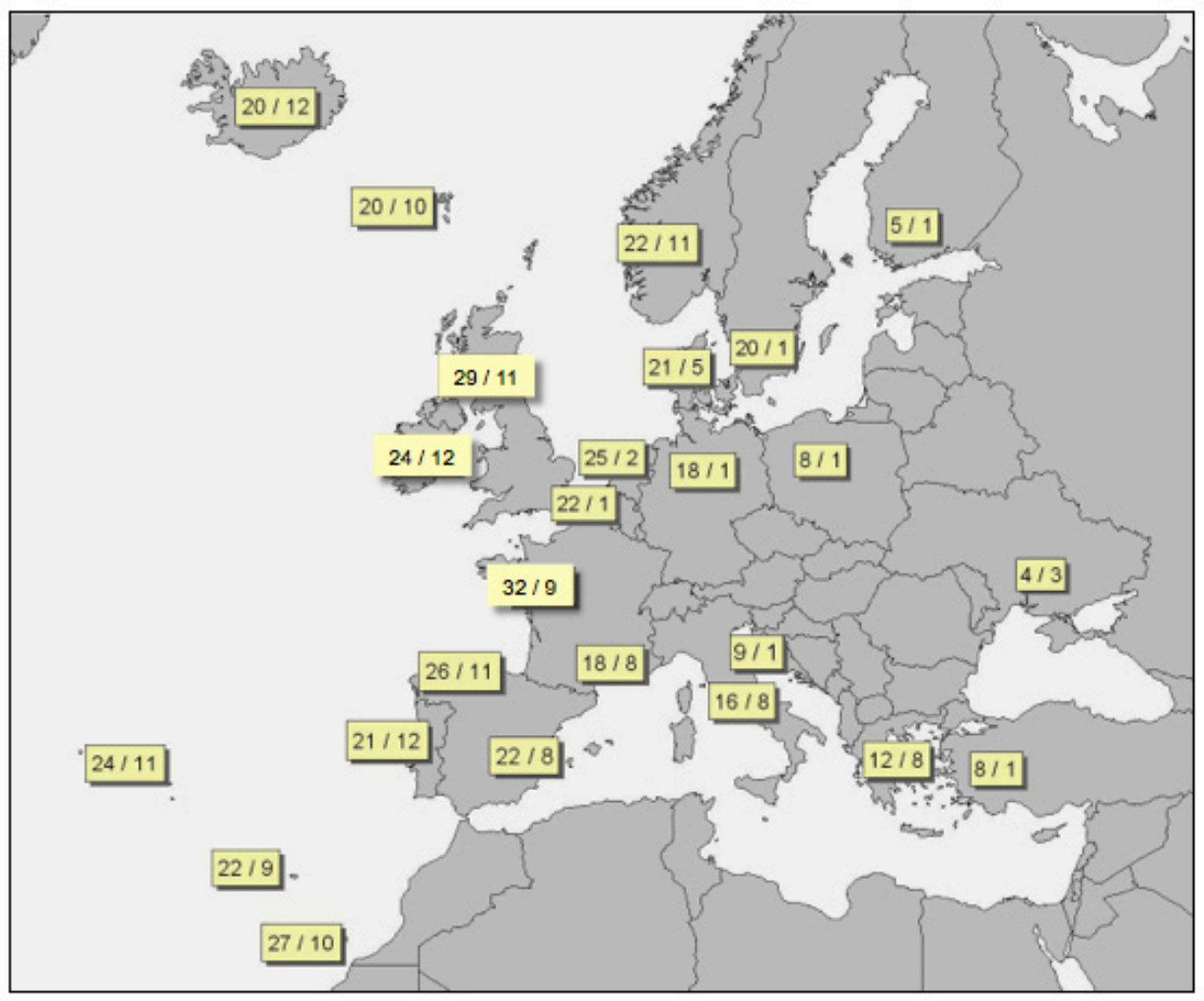

Figure 4.2.1 Cetacean species diversity by country. The first value is the total number of species recorded in that country; the second value is the number of regular species (adapted from Evans, 2010)

Building upon the criteria for identification of FRVs proposed by the Article 17 Reporting Guidelines the following are proposed for setting FRPs and FRRs for cetaceans.

\subsubsection{Setting FRPs for cetaceans}

Population trends. Large-scale systematic surveys to estimate cetacean abundance only started in the North Atlantic in the late 1980s. Part of the Northwest European continental shelf was surveyed in July 1994 (SCANS survey - Hammond et al., 2002) and a larger area of the shelf in July 2005 (SCANS II survey - Hammond et al., 2013), whilst there was a survey along and beyond the West European shelf edge in July 2007 (CODA, 2009). A third SCANS survey took place in July 2016. The SCANS surveys have allowed trends to be determined for harbour porpoise, white-beaked dolphin, and minke whale (abundance estimates exist also for bottlenose dolphin and common dolphin but these have not been sampled sufficiently widely in both years to determine trends). Tables of existing abundance estimates for different species in NW Europe may be found in ICES (2016b). North Atlantic 
Sightings Surveys have also been undertaken mainly to the north of Britain \& Ireland, involving Norway, Faroe Islands, Iceland, Greenland, and in the early years, Spain, with surveys occurring during the summers of 1987, 1989, 1995, 2001, 2007 and 2015, yielding population trends for blue, fin and minke whale as well as sperm whale (Lockyer \& Pike, 2009). Inshore populations of bottlenose dolphin are best monitored using photo-identification of individuals and capture-mark-recapture analytical techniques. However, for only six such populations (in the Sado Estuary, Moray Firth, Cardigan Bay, Shannon Estuary, Gulf of St Malo, and Ile de Sein) has it been possible to examine trends (over periods ranging from 5 - 29 years) (ICES, 2016a). Indices of abundance (as opposed to actual abundance estimates) exist for a number of species in UK waters, using data from a range of effort-based surveys extending back to the early 1980s (Evans et al., 2003; Paxton et al., 2016). Although some areas within the Mediterranean Sea have been surveyed systematically on occasions, there have not been surveys over the entire region, and no trends have been assessed (Notarbartolo di Sciara \& Birkun, 2010).

A recommended approach for cetacean species where there is little past information on population parameters is to use genetics as an indicator of population health and decline (see, for example, Hoban et al., 2014). With improved techniques for genetic analyses, it is now possible to examine entire genomes and, even with small sample sizes, to investigate genetic variability in space and time using RAD (restriction site associated DNA) sequencing. This can provide measures of effective population size ( $\mathrm{Ne}$ ) comparing that to the censused population size ( $\mathrm{Ne} / \mathrm{N}$ ratio), genetic diversity and variability (observed and predicted heterozygosities, haplotype and nucleotide diversities). These provide insights into the extent to which present day populations have experienced contractions in size and loss of genetic diversity. Genetic analysis enables one to estimate the effective population size $(\mathrm{Ne})$ for management units prior to major human impacts, as has been undertaken for large whale populations pre-whaling (Roman \& Palumbi, 2003; Alter \& Palumbi, 2009; Ruegg et al., 2013).

Because there tend to be fine-scale divisions among coastal populations (e.g. of the common bottlenose dolphin), regional populations are often less diverse (lower $\mathrm{Ne}$ ) than offshore, but coastal populations will also be the most impacted by human activities. Using metrics that reflect $\mathrm{Ne}$, connectivity, and population dynamics, one could establish FRPs that are diverse, connected and stable, the three key population parameters to aim to attain. For guidance on how to approach these issues, see the decision-making tools developed from the EU CONGRESS Project (http://www.congressgenetics.eu/Default.aspx).

Management Units (see also § 2.2.6). Cetacean species rarely exhibit obvious discontinuous distributions and yet populations may be demographically, if not genetically, distinct and thus should be treated separately where those differences can be detected. Management units have been tentatively defined for harbour porpoise and bottlenose dolphin (Evans \& Teilmann, 2009; ICES, 2013). Although generally difficult to determine with accuracy, there is scope to identify these for several species (Evans \& Teilmann, 2009) and to set FRVs at the level of management units (see FRVsheet common bottlenose dolphin).

Genetic Variation \& Diversity. With improved techniques for genetic analyses, it is now possible to examine entire genomes and, even with small sample sizes, to investigate genetic variability in space and time using RAD (restriction site associated DNA) sequencing. This can provide measures of effective population size ( $\mathrm{Ne}$ ) comparing that to the censused population size ( $\mathrm{Ne} / \mathrm{N}$ ratio), genetic diversity and variability (observed and predicted heterozygosities, haplotype and nucleotide diversities). These provide insights into the extent to which present day populations have experienced contractions in size and loss of genetic diversity, and can be calculated for harbour porpoise, bottlenose dolphin, common dolphin, Risso's dolphin, killer whale, and long-finned pilot whale, and possibly other cetacean species.

Life History Changes. Other approaches to assessing the characteristics of a favourable reference population include measures of life history parameters: age structure, age at sexual maturity, pregnancy rates, and calving intervals. These can then be compared over time or with populations in other geographical regions. Examples of their uses can be found for harbour porpoise (Murphy et al., 2015), common dolphin (Murphy et al., 2013) and bottlenose dolphin (Feingold and Evans, 2014). 
Population Viability Analysis. This has been conducted on a wide range of terrestrial birds and mammals but upon relatively few cetacean species because of lack of input data. One of the beststudied species is the bottlenose dolphin, and an example of a PVA analysis on the Moray Firth dolphin population can be found in Thompson et al. (2000).

\subsubsection{Setting FRRs for cetaceans}

Present Range. The present ranges of all fifteen cetacean species regularly occurring in European seas, are reasonably well known and have been described in a number of publications (see, for example, Reid et al., 2003; Culik, 2004; Jefferson et al., 2008; Notarbartolo di Sciara \& Birkun, 2010).

Historic Range. Historic ranges, on the other hand, are not known for any cetacean species, and there is only fragmentary information of range changes before the 1950s. Some evidence exists for historical reductions in the occurrence of bottlenose dolphins in a number of coastal estuaries and semi-enclosed bays around Europe (Evans \& Scanlan, 1989; ICES, 2016a), possibly as a result of pollution. And harbour porpoises appear to have experienced declines in several parts of Europe between the 1960s and 1990s (Evans, 1980, 1990, 2010).

Potential Range in Relation to Available Suitable Habitat. Through habitat modelling of present datasets it is now possible to determine the potential range of each of the fifteen common or regular species in relation to available suitable habitat, and to use this to better assess FRR.

Occupancy. Occupancy can be calculated, but only in the present and for the range of the fifteen common or regular species. Nevertheless, it would be useful to apply this to those species where robust estimates of population sizes and trends are not available. Occupancy-abundance relationships have been described in a number of taxa but have scarcely been investigated with cetaceans. This is an area of research that could usefully be developed further.

\subsubsection{In summary}

For cetaceans, some of the criteria proposed by the Article 17 Reporting Guidelines are more appropriate than others given their trans-boundary characteristics and for most species, relatively poor data on population sizes and trends, migration routes and dispersal. Some species (e.g. the great whales - blue, fin, sei, humpback, and northern right whale as well as sperm whale) have populations whose current sizes in the North Atlantic are clearly much diminished on what they were historically before commercial whaling, although pre-exploitation population size estimates are difficult to obtain, and both population modelling and genetic analytical attempts have given variable results (Roman \& Palumbi, 2003; Holt \& Mitchell, 2004; Punt et al., 2006; Alter \& Palumbi, 2009; Smith \& Reeves, 2010; Ruegg et al., 2013). However, new generation genetic approaches can address FRPs for the majority of cetacean species; they have the potential to provide a historical estimate before the bulk of anthropogenic related impacts, as well as various measures of genetic variability, and an estimate of migration rates.

\section{References}

Alter, S.E. and Palumbi, S.R. (2009) Comparing evolutionary patterns and variability in the mitochondrial control region and cytochrome $B$ in three species of baleen whales. Journal of. Molecular Evoution, 68, 97-111.

CODA (2009) Cetacean Offshore Distribution and Abundance in the European Atlantic (CODA), 43pp.

Culik, B. (2004) Review of Small Cetaceans. Distribution, Behaviour, Migration and Threats. Marine Mammal Action Plan/Regional Seas Reports and Studies no. 177, UNEP/CMS, Bonn, Germany. 343pp.

Evans, P.G.H. (1980) Cetaceans in British Waters. Mammal Review, 10, 1-52.

Evans, P.G.H. (1990) European cetaceans and seabirds in an oceanographic context. Lutra, 33, 95-125.

Evans, P.G.H. (2010) Review of Trend Analyses in the ASCOBANS Area. ASCOBANS AC17/Doc. 6-08 (S). 68pp.

Evans, P.G.H. (2011) Review of Trend Analyses in the ASCOBANS Area. ASCOBANS AC18/Doc. 6-05 (S). 12pp. 
Evans, P.G.H. and Scanlan, G. (1989) Historical Status Changes of Cetaceans in British and Irish waters. European Research on Cetaceans, 3, 51-57.

Evans, P.G.H. and Teilmann, J. (editors) (2009) Report of ASCOBANS/HELCOM Small Cetacean Population Structure Workshop. ASCOBANS/UNEP Secretariat, Bonn, Germany. 140pp.

Evans, P.G.H., Anderwald, P. and Baines, M.E. (2003) UK Cetacean Status Review. Report to English Nature and the Countryside Council for Wales. Sea Watch Foundation, Oxford. 160pp.

Feingold, D. and Evans, P.G.H. (2014) Bottlenose Dolphin and Harbour Porpoise Monitoring in Cardigan Bay and Pen Llyn a'r Sarnau Special Areas of Conservation 2011-2013. Natural Resources Wales Evidence Report Series No. 4. 124pp.

Hammond, P.S., Berggren, P., Benke, H., Borchers, D.L., Collet, A., Heide-Jørgensen, M.P., Heimlich, S., Hiby, A.R., Leopold, M.F. and Øien, N. (2002) Abundance of harbour porpoise and other cetaceans in the North Sea and adjacent waters. Journal of Applied Ecology, 39, 361-376.

Hammond, P.S., Macleod, K., Berggren, P., Borchers, D.L., Burt, M.L., Cañadas, A., Desportes, G., Donovan, G.P., Gilles, A., Gillespie, D., Gordon, J., Hiby, L., Kuklik, I., Leaper, R., Lehnert, K., Leopold, M., Lovell, P., Øien, N., Paxton, C.G.M., Ridoux, V., Rogan, E., Samarra, F., Scheidat, M., Sequeira, M., Siebert, U., Skov, H., Swift, R., Tasker, M.L., Teilmann, J., Van Canneyt, O. and Vázquez, J.A. (2013) Cetacean abundance and distribution in European Atlantic shelf waters to inform conservation and management. Biological Conservation, 164, 107-122.

Hoban, S., Amtzen, J.A., Bruford, M.W., Godoy, J.A., Hoelzel, A.R. Segelbacker, G., Vila, C., and Bertorelle, G. (2014) Comparative evaluation of potential indicators and temporal sampling protocols for monitoring genetic erosion. Evolutionary Applications, 7(9): 984-998. http://dx.doi.org/10.1111/eva.12197.

Holt, S.J. and Mitchell, E.D. (2004) Counting whales in the North Atlantic. Science, 303, 39-40.

ICES (2013). Report of the Working Group on Marine Mammal Ecology (WGMME), 4-7 February 2013, Paris, France. ICES CM 2013/ACOM:26. 117pp.

ICES (2016a) OSPAR request on indicator assessment of coastal bottlenose dolphins. ICES Special Request Advice Northeast Atlantic Ecoregion. ICES, Copenhagen. 14pp.

ICES (2016b) OSPAR request on indicator assessment of cetacean species other than coastal bottlenose dolphins. ICES Special Request Advice Northeast Atlantic Ecoregion. ICES, Copenhagen. 7pp.

Jefferson, T.A., Webber, M.A., and Pitman, R.L. (2008) Marine Mammals of the World. Academic Press/Elsevier, Amsterdam, London and New York.

Lockyer, C. and Pike, D. (editors) (2009) North Atlantic Sightings Surveys. Counting whales in the North Atlantic 1987-2001 NAMMCO Scientific Publications Volume 7. 244pp.

Murphy, S., Barber, J.L., Learmonth, J.A., Read, F.A., Deaville, R., Perkins, M.W., Brownlow, A., Davison, N., Penrose, R., Pierce, G.J., Law, R.J. and Jepson, P.D. (2015) Reproductive failure in UK harbour porpoises Phocoena: legacy of pollutant exposure? PLoS ONE, 10(7), e0131085. doi: 10.1371/journal.pone.0131085.

Murphy, S., Pinn, E.H. and Jepson, P.D. (2013) The short-beaked common dolphin (Delphinus delphis) in the north-eastern Atlantic: distribution, ecology, management and conservation status. Oceanography and Marine Biology: An Annual Review, 51, 193-280.

Notarbartolo di Sciara, G. and Birkun, Jr, A. (2010) Conserving whales, dolphins and porpoises in the Mediterranan and Black Seas. An ACCOBAMS status report, 2010. ACCOBAMS, Monaco. 212pp.

Paxton, C.G.M., Scott-Hayward, L., Mackenzie, M., Rexstad, E. and Thomas, L. (2016) Revised Phase III Data Analysis of Joint Cetacean Protocol Data Resources. JNCC Report No. 517. 196pp.

Punt, A.E., Friday, N.A. and Smith, T.D. (2006) Reconciling data on the trends and abundance of North Atlantic humpback whales within a population modelling framework. Journal of Cetacean Research \& Management, 8, 145-159.

Reid, J.B., Evans, P.G.H. and Northridge, S.P. (2003) Atlas of Cetacean Distribution in North-west European Waters. Joint Nature Conservation Committee, Peterborough. 76pp.

Roman, J., and Palumbi, S.R. (2003) Whales before Whaling in the North Atlantic. Science, 301: 508510.

Ruegg, K., Rosenbaum, H.C., Anderson, E.C., Engle, M., Rothschild, A., Baker, C.S. and Palumbi, S.R. (2013) Long-term population size of the North Atlantic humpback whale within the context of worldwide population structure. Conservation Genetics, 14, 103-114. 
Smith, T.D. and Reeves, R.R. (2010) Historical catches of humpback whales, Megaptera novaeangliae, in the North Atlantic Ocean: estimates of landings and removals. Marine Fisheries Review, 72, 143.

Thompson, P.M., Wilson, B., Grellier, K. and Hammond, P.S. (2000) Combining power analysis and population viability analysis to compare traditional and precautionary approaches to conservation of coastal cetaceans. Conservation Biology, 14(5), 1253-1263.

Waring, G.T., Palka, D.B. and Evans, P.G.H. (2009). North Atlantic Marine Mammals. Pp. 763-771. In: Encyclopedia of Marine Mammals (Editors W.F. Perrin, B. Würsig and J.G.M. Thewissen). 2nd edition. Academic Press, San Diego. 1,450pp. 


\subsection{Birds}

\subsubsection{General remarks}

Two methods are generally available for setting FRVs for reproductive populations (compare § 3.1.3):

- the combined population-based and reference-based method which starts by identifying the proper minimum viable population (MVP) size (see § 4.3.2) and by identifying the historical trend in numbers;

- the potential-range method which uses information on habitat requirements and suitability (see $\S 4.3 .3)$.

Both methods, as applied to reproductive populations of resident and migratory birds (Table 3.1a), require that the FRP must exceed a properly scaled MVP-value (see Box 3.1). Furthermore, the FRVs should not be smaller than the population size (for FRP) and range size (for FRR) at the start of the Birds Directive. Note that the potential-range method is constrained by MVP size as well (as applied to birds).

In setting FRVs for non-reproductive populations of migratory birds during the staging and/or wintering phase (compare Table 3.1b) reference based methods are used. (§ 4.3.4).

In the case of working with distribution or occupancy data as proxies for population numbers, a reference-based method should be used as well. Sovon has tested this approach in a case of the lapwing (Vanellus vanellus) in the province of Friesland (the Netherlands)(Teunissen et al., 2015) and this was supported by the State Attorney. They used distribution data (km-squares) to define a period in which this distribution was considered favourable and defined the regional favourable reference population as the population index in that period. If data on the exact rate of change are lacking because there is no yearly change index then operators can be used to describe the population status relative to the reference period.

\subsubsection{The MVP-concept in setting FRVs for birds}

Refer to $\S$ 2.2.2 (Population viability analysis) and 2.2.3 (Minimum viable populations and generalised genetic rules) for introductory information and compare $\S 2.2 .4$ (MVP-targets derived from body size relationships).

\section{A MVP-body size relationship for breeding populations of birds}

The number of bird species for which MVPs have been calculated is limited (Traill et al., 2007) and for many European breeding birds MVPs are not available. Following Hilbers et al. (2016b) who derived relationships between MVP and body size for terrestrial mammals using population modelling (see $\S 2.2 .4$ ), we investigated the simpler approach of a direct allometric relationship between MVP and body size in birds. Although there are some outliers, generally light weighed birds $(<1 \mathrm{~kg})$ have MVPs around 2500 individuals and heavy birds ( $>1 \mathrm{~kg}$ ) have MVPs around 500 individuals (Figure 4.3.1). 


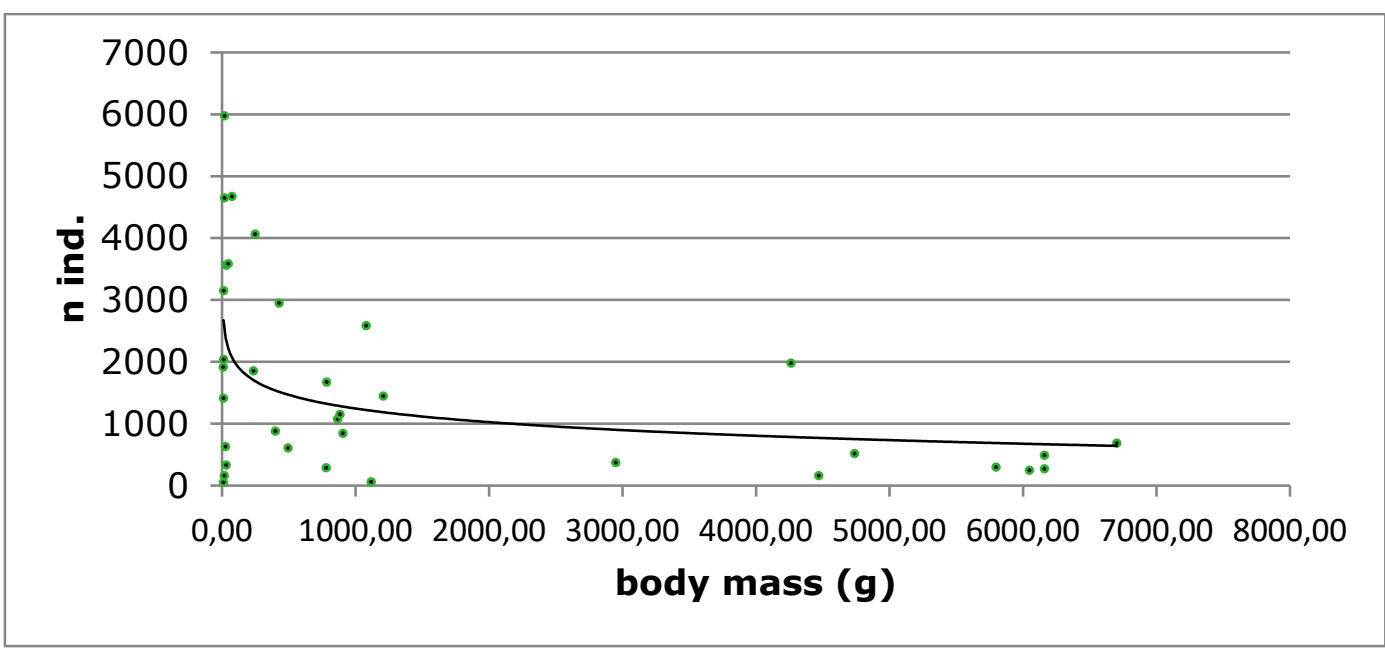

Figure 4.3.1 Relation between the MVP-values of birds (n individuals; based on Traill et al., 2007) and body mass ( $g$ ) (Foppen unpubl.)

\section{Guidance on setting FRPs for reproductive populations using MVPs and reference values}

Step 1. Setting and upscaling MVPs

1. Preferably use a published MVP (e.g. Traill et al., 2007) and see Box 3.1.

2. If a published MVP is not available use the relationship between MVP and body size presented in Figure 4.3.1.

3. Apply a multiplier to account for the risk of a large magnitude decline. This step is part of ongoing research by the Royal Society for the Protection of Birds (RSPB) and Durham University on defining favourable conservation status for birds in the UK ${ }^{7}$. Awaiting further guidance, we agreed to use a factor 10 as a rule of thumb (Table 4.3.1). The resulting value should be checked with historical values when available.

4. Continue the stepwise process by considering additional population possibly needed to account for ecological/genetic variations within the (historical) natural range (see Box 3.3).

Table 4.3.1 Rule of thumb values of upscaled MVPs (expressed as pairs) as dependent on body mass to be used in setting FRPs for birds

\begin{tabular}{cc} 
body mass $(\mathrm{g})$ & upscaled MVP (breeding pairs) \\
$\leq 1000$ & 12500 \\
\hline$>1000$ & 2500 \\
\hline
\end{tabular}

Step 2. Considering reference values

The Birds Directive requires that population numbers should not be lower than at the start of the Directive (DV, 'directive value'). Of course this does not necessarily mean that these numbers represent favourable conditions:

1. A species' population size might have declined before the BD came into force. In that case the upscaled MVP value always serves as a threshold to prevent setting a FRP that might lead to extinction. If the DV exceeds the MVP, the FRP should be at least equal to DV. A higher FRP value should be set if the species is known to have declined as a result of unnatural conditions that are reversible. In this case a more historical reference from about the last 50 years could be selected reflecting more natural conditions before the decline of the species.

2. A species' population size might have been above MVP level when the BD came into force although it was depleted at that time. However it has shown recovery since, because of restoration of natural conditions. In that case a more recent population level should be set as FRP such as current value $(\mathrm{CV})$ or use an operator and wait till population size has been stabilized.

\footnotetext{
7 by Rhys Green, Jerry Wilson, Gillian Gilbert (RSPB) and Tom Mason, Steve Willis, Phillip Stevens (Durham University).
} 
3. A species' population size can have increased after the BD came into force not as a consequence of restoration/improvement of natural conditions but due to unnatural human influences. In this case, we suggest to set FRP equal to DV (if DV exceeds upscaled MVP), despite a higher current value.

The reference-based approach can be used for setting FRR as well in most cases after an analysis of trends in range size and configuration (part of the stepwise process, see Figure 3.1). In a few cases (species breeding clustered in colonies) changes in numbers and range might differ. Note that a lack of historical distribution data might constrain setting FRRs. Basically "The EBCC Atlas of the European Breeding Birds" (Hagemeijer \& Blair, 1997) reflecting the period around 1980, is the only historical source for distribution overviews on a European scale.

\subsubsection{The potential range method in setting FRVs for reproductive populations}

The LIPU (Lega Italiana Protezione Uccelli)/BirdLife Cyprus-method is a model-based approach for setting FRVs for common, widespread breeding bird species (more than 2500 pairs). The method works by identifying favourable reference densities in 'optimal' and 'average' habitats within a potential range. Whenever possible, the availability and relative suitability of a species' habitat is modelled. A FRP is derived by applying habitat-density relationships. When feasible a future vision is then developed, which results in estimates of future habitat extent and suitability including restoration opportunities, which in turn can contribute to defining the favourable reference value for population. The resulting FRP value should be definitely higher than the (upscaled) MVP.

The method was developed and applied by Brambilla et al. (2011, 2014) and Tye et al. (2014). In summary the method includes the following steps:

1. Define a favourable density

a. Assess what constitutes 'optimal' and 'average' habitats or mosaics of these for the species at relevant spatial levels (local to landscape level).

b. Identify favourable reference densities in 'optimal' and 'average' habitats or mosaics.

2. Assess the FRP based on current habitat

c. Whenever possible, assess the potential and current spatial distribution of habitat extent and suitability (e.g. by species distribution or habitat suitability modelling).

d. Derive a FRP based on habitat extent and suitability and density values previously obtained.

e. Check whether the FRP is higher than the (upscaled) MVP (see § 4.3.2). If not, the upscaled MVP must be used.

f. Adjust the FRP on the basis of the habitat extent and quality resulting from a future vision on restoration opportunities and foreseen macro-habitat changes (e.g. due to climate change, land abandonment, habitat restoration, etc.) and potential conflicts between and within macro-habitats/habitat types, taking into account ecological requirements of the different species and whether this prevents reaching favourable reference densities.

For uncommon breeding bird species Brambilla et al. (2011) used a PVA-appoach.

\subsubsection{Migratory birds and setting FRVs for the staging and wintering populations}

\section{Why a special approach for migratory birds?}

In migratory birds the conservation status (population size, trend, range, distribution) will be the combined result of conditions during breeding, migration and wintering and the interactions between these annual cycle phases. In many migratory birds these phases occur large distances apart often in different countries or even continents with rather contrasting environments. Bottlenecks in population development can be caused by factors in one or a combination of these annual cycle phases. Many examples exist of causes of unfavourable conservation status connected to either breeding, migration or wintering without evidence that one of these phases is more dominant in causing population limitation than the other (Newton, 2008). On the other hand evidence exist that migratory bird populations have in general a less favourable conservation status than resident populations and requires extra conservation effort (Vickery et al., 2014). 
Table A2.5 in Appendix 2 lists all European (partially) migratory birds with indications whether species breed or winter in Europe.

\section{FRVs for the breeding, staging and wintering phases of migratory birds}

Given the framework of favourable reference values under the Birds Directive these references must be defined for all phases of the annual migratory cycle i.e. the reproductive and wintering phase. See also guidance on the interpretation of Favourable Conservation Status under AEWA (AEWA Technical Committee, 2017). The conservation status of the migratory population is considered favourable only when all phases are in good condition.

As a consequence the evaluation of the conservation status of migratory species needs FRVs for the staging and wintering annual phases besides FRVs for the breeding phase. Important steps in setting these FRVs are similar to the general stepwise approach but require additional considerations:

A. agree on the definition and delineation of flyway populations of migratory species;

B. define the breeding, staging and wintering ranges within the flyway;

C. gather information about the population status of these flyway populations;

D. assess the FRP and FRR for components of the flyway population: breeding, staging during migration and wintering phase.

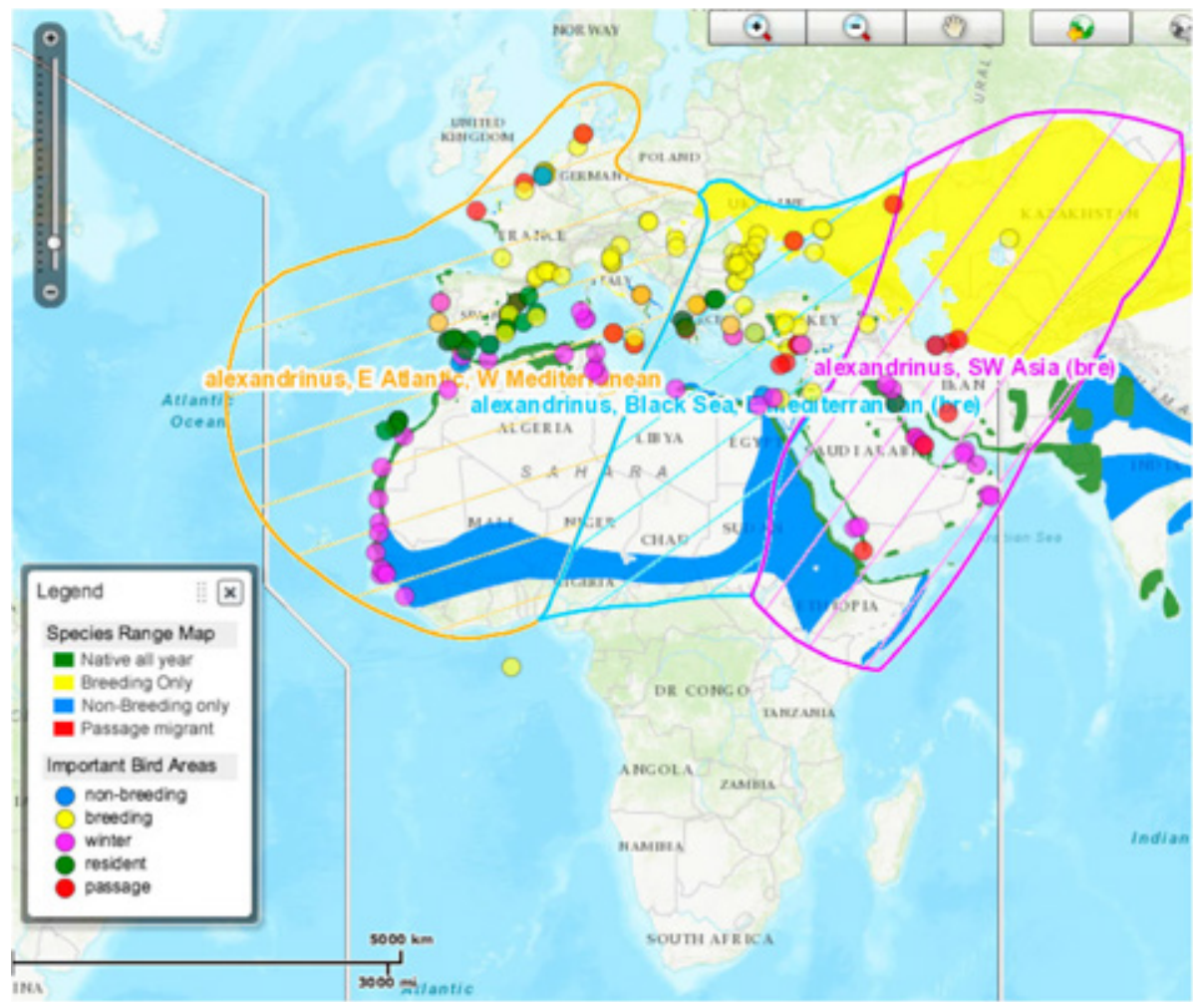

Figure 4.3.2 Waterbird example showing distinct flyways. Delineation of flyway populations of Kentish Plover (Charadrius alexandrinus) in the African-Eurasian region (http://csntool.wingsoverwetlands.org) 


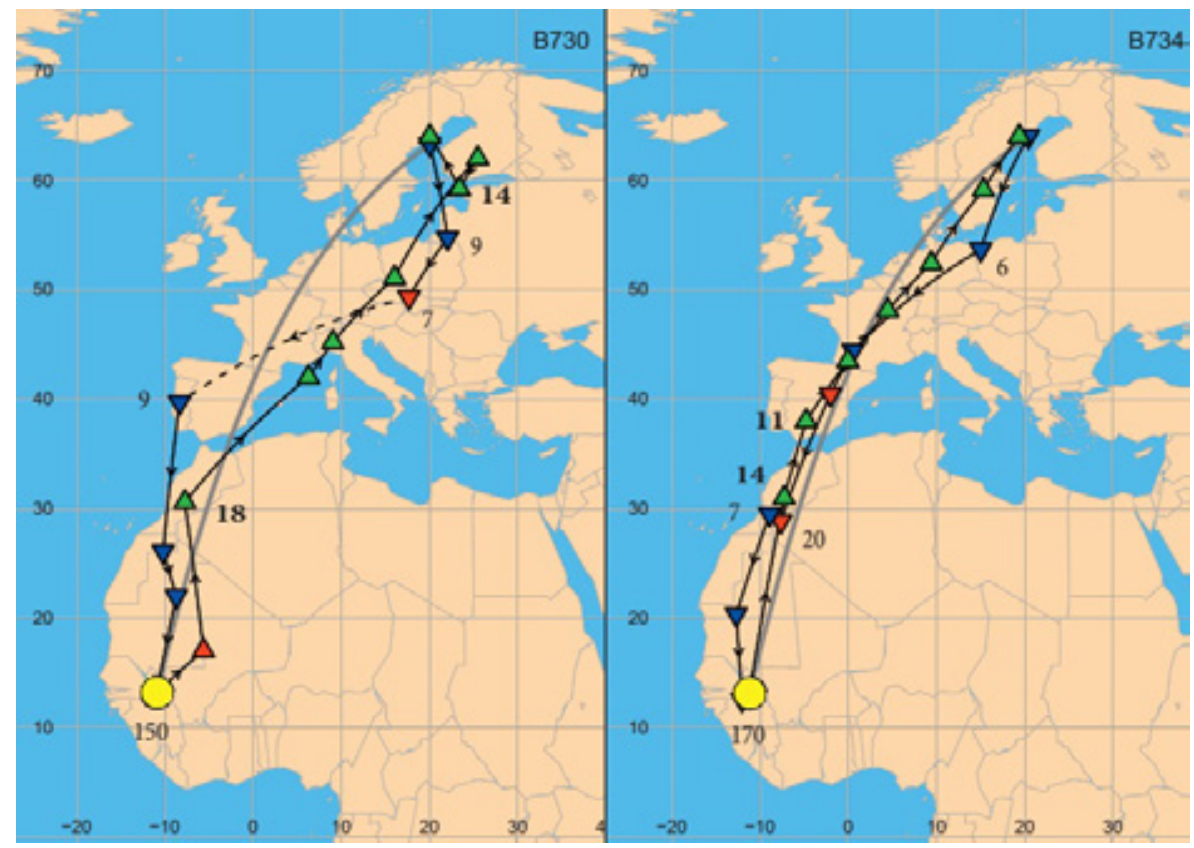

Figure 4.3.3 Passerine example showing distinct flyways. Migration routes for Ortolan Buntings (Emberiza hortulana) between Sweden and sub-Saharan Africa. Longer stays are indicated with numbers (equaling the number of days spent there). Figures given with regular font represent autumn; bold figures represent spring periods (based on Selstam et al., 2015)

Step A. Define and delineate flyway populations

A flyway population is a distinct population of a migratory species. A flyway is the entire range through which the population moves on an annual basis including the breeding grounds and wintering grounds and the area in between used for feeding, resting and migration (Boere \& Stroud, 2006). A distinct flyway population can be the entire population of a monotypic species or the entire population of a subspecies.

In most cases more than one flyway-population within monotypic species or even subspecies are present.

Generally, flyways are defined by knowledge of connectivity between breeding, staging and wintering ranges in a rather crude way and on a relatively large geographical scale (Figure 4.3.2 and 4.3.3). Within the breeding, staging and wintering ranges of a species, more or less discrete geographical units can be distinguished. Examples within the European-African migration system are: East Canada and Greenland, Iceland, Scandinavia, West Russia, Siberia, Britain \& Ireland, West continental Europe and East Europe for the breeding range and NW Europe, West Mediterranean, East Europe, EastMediterranean, West Africa, East Africa, South Africa for the staging and wintering range. Between the breeding, staging and wintering geographical units connectivity is investigated using information from ringing of individual birds or other marking and tracking data or based on biometrics, isotopes and DNA signature. Patterns in connectivity between breeding, staging and wintering units reveal boundaries between flyway populations. If such patterns are not found, mostly the entire population in the African-Palearctic region is considered as one flyway population, which in itself can be a subdivision of a more worldwide occurrence of the species.

Within a flyway and therefore within a flyway population of a migratory bird species, truly migratory individuals breeding in the northern parts may mix during migration and or wintering with more sedentary individuals in the southern part of the breeding range. Both kinds of individuals are considered part of the same flyway population and are taken together for the FRV- assessment during breeding, staging or wintering.

This concept of flyway populations is at present well developed for waterbirds (Scott \& Rose, 1996; Delany et al., 2009; Critical Sites Network tool - http://csntool.wingsoverwetlands.org) but can also 
be applied to seabirds (Brooke, 1990; Nelson, 1997) and passerines (Zwarts et al., 2009). As a further underpinning of these flyways a summary of connectivity information should be made. Many references with data from individual countries (ringing atlases) exist already and tracking data of individual birds are collected (www.movebank.org). An European/African integration should be made to use this data to its full extent to define flyway populations.

Step B. Define the breeding, staging and wintering ranges within the flyway Defining the breeding ranges requires information available from breeding bird atlases and other information about evidence of breeding (Hagemeijer \& Blair, 1997; Lappo et al., 2012). Up to date breeding ranges are also indicated in recent field guides and handbooks (Svensson et al., 1999; del Hoyo et al., 1999-2011). The wintering range can be loosely defined as the geographical range where the population stays between the end of their autumn migration and the start of their spring migration. In practice population specific choices need to be made based on knowledge of behaviour and timing of movements. Wintering ranges can also be found in del Hoyo et al. (1999-2011). The staging range is the geographical area where migratory birds make stop-overs for some days or weeks to restore energy reserves. This range is part of the overall migration range. The direct use (staging) at sites and habitats during migration is most appropriate for defining FRVs. Sometimes the difference between wintering and staging range is less clear and the two are better taken together.

\section{Step C. Gather information about the population status of the flyway population}

In this step information is gathered about size and trend of population numbers and range of the flyway population, preferably including historical data in connection with major factors that (have) affected population size. Estimates of flyway population size are mostly based on either wintering or breeding phase or sometimes migration, using the best estimate available, but should be cross checked if estimates from more than one phase are available. Estimates can be the result of a more or less complete surveys or combinations of surveys and extrapolations. Trends should be based on monitoring programmes. Information about ranges needs to be based on atlases and records of occurrence. Regular occurrence (on a yearly basis in a certain minimum number during breeding, staging and wintering) should be considered as part of the range contrary to irregular or vagrant occurrences.

Step D. Assess the FRP and FRR for components of the flyway population

For a given flyway population, assessment of the conservation status must be based on the population size of the breeding phase (relative to the reproductive FRP) and wintering and or staging phases (relative to corresponding non-reproductive FRPs). Corresponding FRRs can be derived by following the general stepwise approach (see § 3.2).

D.1. Breeding populations (reproductive FRPS)

Paragraph 4.3.2 or 4.3.3 addresses how FRPs for breeding bird populations can be defined and this applies to the breeding phase of flyway populations as well.

\section{D.2. Wintering and/or staging populations (non-reproductive FRPS)}

Population numbers in wintering and staging areas can not be assessed by a MVP-based method but must of course be consistent with estimates of breeding populations. For wintering or staging 'populations' four non-reproductive population categories have been established: MNR1 - MNR4 (see Table 3.1). The method used is mostly reference-based and targets for wintering or staging must consider the carrying capacity of the (national or supranational) areas using time series over several years from which average numbers during favourable periods can be used as a proxy for the non-reproductive FRP. The FRP should not be lower than the population size in 1980 (DV).

\section{References}

AEWA Technical Committee. 2017. Guidance on the Interpretation of Favourable Conservation Status in the context of setting population targets for AEWA international species action and management plans. Doc AEWA/GGMPWS Inf. 1.3, Adopted March 2017, AEWA, Bonn Germany.

Boere, G.C. \& D.A. Stroud. 2006. The flyway concept: what it is and what it isn't. Waterbirds around the world. Eds. G.C. Boere, C.A. Galbraith \& D.A. Stroud. The Stationery Office, Edinburgh, UK. pp. 40-47. 
Brambilla, M., Gustin, M. \& Celada, C. 2011. Defining Favourable Reference Values for bird populations in Italy: setting long-term conservation targets for priority species. Bird Conservation International 21, 107-118.

Brambilla M., Gustin, M. \& Celada, C. 2014. Setting Favourable Habitat Reference Values for breeding birds: general principles and examples for passerine birds. Bird Conservation International 24: 263-271.

Brooke M. 1990. The Manx Shearwater. T \& A.D. Poyser. London. http://csntool.wingsoverwetlands.org

Delany. S, Scott D., Dodman. \& Stroud, D (eds) 2009. An Atlas of Wader Populations in Africa and Western Eurasia. Wetlands International, Wageningen, The Netherlands.

Hagemeijer, E.J.M. \& M.J. Blair (Editors). 1997. The EBCC Atlas of European Breeding Birds: Their Distribution and Abundance. T. \& A. D. Poyser, London.

Del Hoyo et al. 1992-2011. Handbook of the Birds of the World. Vol 1-16. Lynx Edicions, Barcelona. Hilbers, J.P., L. Santini, P. Visconti, A.M. Schipper, C. Pinto, C. Rondinini \& M.A.J. Huijbregts. 2016 b. Setting population targets for mammals using body mass as a predictor of population persistence. Conservation Biology DOI: 10.1111/cobi.12846.

Lappo EG, Tomkovich PS, Syroechkovskiy EE. 2012. Atlas of Breeding Waders in the Russian Arctic. Publishing House OOO UF Ofsetnaya Pechat, Moscow, Russia.

Nelson B. 1997. Morus bassanus Northern Gannet. BWP Update 1: 131-143.

Newton I. 2008. The migration ecology of birds. Elsevier, London.

Scott D.A. \& Rose P.M. 1996. Atlas of Anatidae Populations in Africa and Western Eurasia. Wetlands International, Wageningen.

Selstam, G., Sondell, J. \& Olsson, P. 2015. Wintering area and migration routes for Ortolan Buntings Emberiza hortulana from Sweden determined with light-geologgers. Ornis Svecica 25: 3-14.

Svensson L., Mullarny K., Zetterström \& P. Grant 1999. Collins Bird Guide. Collins, UK.

Teunissen, W., C. Kampichler, M. Roodbergen \& R. Vogel. 2015. Beoordeling van de staat van instandhouding van de Kievit (Ljip) Vanellus vanellus als broedvogel in de provincie Fryslân. Sovon-rapport 2015/56, Sovon Vogelonderzoek Nederland, Nijmegen.

Traill, L.W., C.J.A. Bradshaw \& B.W. Brook. 2007. Minimum viable population size: A meta-analysis of 30 years of published estimates, Biological Conservation 139(1-2): 159-166.

Tye, A., C. Christodoulou-Davies, C. Papazoglou \& M. Apostolidou. 2014. Setting Favourable Reference Values for Annex I bird species at Oroklini marsh as part of the LIFE project: "Restoration and Management of Oroklini Lake SPA in Larnaca, Cyprus".

Vickery, J.A., Ewing, S.R., Smith, K.W., Pain, D.J., Bairlein, F., Skorpilova, J. \& Gregory, R. 2014. The decline of Afro-Palaearctic migrants and an assessment of potential causes. Ibis 158(1): 1-22.

Zwarts L., Bijlsma R.G., van der Kamp J \& Wymenga E. 2009. Living on the edge: Wetlands and birds in a changing Sahel. KNNV Publishing, Zeist, The Netherlands. 


\subsection{Migratory fish}

\subsubsection{General remarks}

Migratory fish species that are using large areas comprising both freshwater and marine habitats to complete their life cycles are referred to as 'diadromous' species. They need not only both freshwater and marine habitats but also corridors in between making them vulnerable to multiple human pressures such as overfishing, pollution, habitat loss and migratory barriers. Within the diadromous fish species different life history traits are present. An often used division is between catadromous species spawning at sea and realising growth in freshwater (such as European eel Anguilla anguilla) and anadromous species spawning in freshwater and realising their main growth in marine habitats (such as Atlantic salmon Salmo salar, European sturgeon Acipenser sturio, North Sea Houting Coregonus oxyrhinchus, shads and lampreys).

The Habitats Directive lists 12 migratory species of fish and lamprey, the latter belonging to the order of Cyclostomata or jawless fishes (see Annex 2, Table A2.4). All of these migratory species are anadromous and many are endangered or locally extinct. The European sturgeon that used to be present in a large part of Europe now only occurs in the Gironde basin of France. The North Sea Houting that was endemic to the River delta of the Scheldt, Meuse and Rhine and the rivers entering the Wadden Sea, was close to global extinction. In both cases rearing in captivity was developed, followed by reintroduction programs using reared individuals.

Table 4.4.1 Spatial scales of different life stages/habitats occupied by migratory fishes and lampreys listed on the Habitats Directive Annex II, IV and V

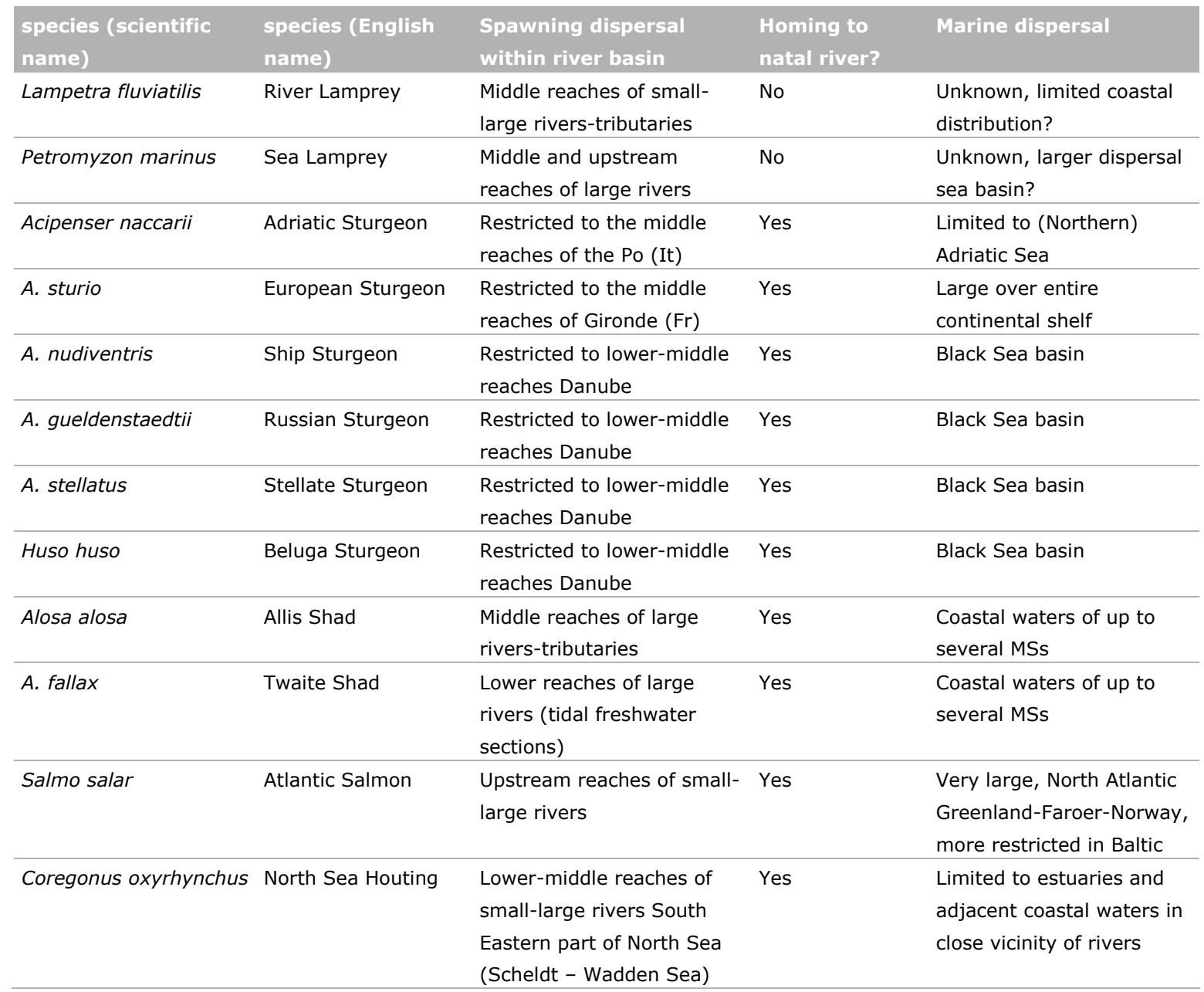


The catadromous European eel is considered critically endangered by the IUCN but not listed on Annex II, IV, V of the habitat Directive. This species spawns in the Sargasso Sea in the Atlantic and realises most of its growth in freshwater on the European continent (individual life span range of $\sim 6000 \mathrm{~km}$ ) and is dealt with within a separate EU trajectory (Council Regulation (EC) 1100/2007, 'establishing measures for the recovery of the stock of European eel').

\subsubsection{Spatial scale of functioning}

The spatial scale of the ranges that individuals use to complete their life cycle, varies highly among and within these species, both during their freshwater and marine phases (Table 4.4.1).

Most anadromous species perform strong natal homing to the rivers they were born and therefore populations in rivers are reproductively isolated with limited gene flow between populations. The lampreys form an exception to this, with much more mixing between populations in adjacent rivers as a consequence (Bergstedt et al., 1995). Lampreys use pheromones excreted by larvae ('ammocoetes') that live in the middle and upstream sections for spawning, not necessarily the river they were born. The pheromones are an important cue to select spawning rivers and therefore go to rivers proved suitable for the species rather than returning to where they were born (Buchinger et al., 2015). As a result, the migratory fish species have fairly separated spawning populations per river basin, whereas lampreys show more mixing between river basins and thus form larger regional populations at a larger scale than individual river basins.

When combining the freshwater and marine phase, individuals for most migratory fish species use spatial scales that encompass more than one MS. When considering only the freshwater stages of river basin populations, most are confined to a single $M S$, except for some large river basins like the Rhine (NL, DE, FR, Switzerland), Meuse (NL, BE-WAL, LU, FR, DE) and Danube (DE, AT, CZ, SK, HU, BU, RO) or rivers forming borders like the Oder (DE, $\mathrm{PL})$.

Potentially, species that complete their life cycle within large river basins like the Rhine, Meuse or Danube can have individuals with home ranges that encompass several MS's. Even though data and knowledge on the scale of movement patterns of most freshwater species is limited, there are examples of individuals may move over several hundreds of kilometres within a river basin. However, these appear to encompass only a smaller proportion of the populations. As of yet, no species are known where the majority of the population has home ranges that exceed MS scales.

For some endangered marine fish species this is different, e.g. different shark species or Bluefin tuna, where the majority of individuals of a population may perform movement patterns at scales of several $1000 \mathrm{~s} \mathrm{~km}$. However, no marine species are included in the Habitat Directive Annexes and therefore not considered here.

\subsubsection{Setting FRPs}

\section{Minimum viable populations}

For fish, minimum viable population size can vary between species and depending on the different life history traits and degree of mixing between populations. Thompson (1991) reviewed the various methods available, to determine the MVP for fish stock. Depending on the degree of precision desired, the conclusion of the analysis was that most rules of thumb (including 'genetic MVPs' derived from the $\mathrm{N}_{\mathrm{e}}>500$ rule; see $\S 2.2 .2$ ) fall within an order of magnitude of each other, giving a generic MVP of 1,000 to 10,000 adults. Also Traill et al. (2007) list much higher numbers for MVP for fish than for other taxa. PVAs are possible, e.g. Wildhaber et al. (2017) for pallid sturgeon in the Mississippi, but they require extensive datasets on parameters that are rarely available for endangered fish species and often very hard to measure in practice.

\section{Population trends and management units}

For most species river basins are the appropriate 'population' scales and/or management units. Especially for the diadromous fishes that show strong homing to natal rivers. Because diadromous fish populations rely on very different habitat types ranging from freshwater to marine, are highly 
dependent on corridors linking these habitats (estuaries and mainstream rivers) that are often densely populated and used by humans, they are highly vulnerable to anthropogenic impact. Diadromous fish populations have decreased dramatically in most of the river basins throughout Europe (Limburg \& Waldman, 2009) due to a combination of severe overfishing, migratory barriers like dams and weirs, water pollution and habitat loss. This lead to many local extinctions or strong decreases in population numbers in river basins in the course of the $19^{\text {th }}$ and first half of the $20^{\text {th }}$ century. European Sturgeon, Adriatic Sturgeon and North Sea Houting were close to global extinction (hence the priority status for these species within the Habitat Directive). Due to captive breeding programs these species were safe guarded against extinction, though for European Sturgeon and Adriatic Sturgeon natural reproduction in the wild has been lacking for tens of years. North Sea Houting has been successfully reintroduced in different Danish, German and Dutch rivers and nowadays forms self-sustaining populations that do not rely on stocking anymore. The Atlantic Sturgeon (Acipenser oxyrhinchus) that historically occupied the Baltic, and there is growing evidence that it also lived in sympatry with the European sturgeon along the Atlantic and North Sea coasts of western Europe, became extinct in Europe in the 19th and first half of the 20th century and is now only found in the western Atlantic in North America.

\subsubsection{Setting FRRs}

\section{Present range}

Some migratory species have very restricted ranges of occurrence during their freshwater stages due to extensive local extinctions well before 1992. European sturgeon is now only limited to the Gironde basin. Beluga, Ship and Stellate Sturgeons are confined to the lower reaches of the Danube. The Adriatic Sturgeon is confined to the Po. North Sea Houting was confined to a single small river in southern Denmark, the Vida Aa, in 1992. After successful reintroduction programs they re-occurred in the lower reaches of the Elbe and the Rhine. Other species, namely Atlantic Salmon, Allis and Twaite Shad maintained a wide distribution with some local extinctions in some river basins (mainly in western Europe, e.g. Seine, Thames, Meuse, Rhine), where several reintroduction efforts are being carried out especially for Atlantic salmon (Thames, Seine, Meuse, Rhine) and to a lesser extent Allis shad (Rhine). The range of the River and Sea Lamprey has maintained comparable to historical times.

\section{Historical range $\left(19^{\text {th }}\right.$-early $20^{\text {th }}$ century)}

For many species, historical ranges were substantially larger than the present ranges, both in terms of river basins occupied as well as the range occupied within a river basin. $M$ barriers like dams and weirs often restricted the range of occurrence, especially for species that used the upstream reaches and tributaries for spawning, such as Atlantic Salmon and the different sturgeon species in the Danube. The most dramatic decrease in range took place for the European sturgeon that was distributed throughout Europe ranging from river basins around the Black Sea, Mediterranean, Atlantic coasts, North Sea and Baltic Sea, whereas nowadays it is confined to the Gironde in France. The Adriatic Sturgeon was present throughout the Adriatic Sea, and is now confined to the Po and northern part of the Adriatic Sea. The North Sea Houting already had a limited historical distribution ranging from the lower reaches of the Scheldt, the Meuse, Rhine up to the the small Danish rivers discharging into the Wadden Sea (SouthEastern North Sea endemic), but became extinct in all but one small Danish river (Vida Aa).

\section{References}

Bergstedt RA, Seelye JG (1995). Evidence for a lack of homing by sea lampreys. Trans. Am. Fish. Soc. 124:235-239.

Buchinger TJ, Siefkes MJ, Zielinski BS, Brant CO, Weiming Li W, (2015). Chemical cues and pheromones in the sea lamprey (Petromyzon marinus). Frontiers in Zoology 2015:12-32.

Limburg KE, Waldman JR (2009). Dramatic declines in North Atlantic diadromous fishes. Bioscience 59(11): 955-965.

Thompson GG (1991). Determining minimum viable populations under the endangered species act. NOAA Technical Memorandum NMFS F/NWC-198.

Traill LW, Bradshaw CJA, Brook BW (2007). Minimum viable population size: a meta-analysis of 30 years of published estimates. Biol Conserv 139:159-166.

Wildhaber ML, Albers, JL, Green NS, Moran EH (2017). A fully-stochasticized, age-structured population model for population viability analysis of fish: Lower Missouri River endangered pallid sturgeon example. Ecological Modelling 359: 434-448. 


\subsection{Invertebrates}

\subsubsection{General remarks}

All invertebrate species together cover a tremendous diversity in size, life history and habitats. With respect to setting FRPs, some of the larger species, like octopuses, may be comparable with mammals in methodology. Large as a reproductive unit are wood ant colonies, which may be treated in the same way. At the other end of the size spectrum, the very small individuals may be assessed by an areabased approach as a proxy. The challenge is to tackle the large group in between: the small and mobile species. Migrating dragonflies, butterflies and moths may be treated like migrating birds, as distances are often comparable as in the butterflies Vanessa cardui and Vanessa atalanta and the dragon flies Anax parthenope and Sympetrum fonscolombei. Species migrating or commuting on smaller scales require larger areas than just the area where they forage. Ground breeding bees such as Andrena vaga, require open soil and their main food source, flowering willows, in short distances (less than a couple of $100 \mathrm{~m}$, for smaller species even closer). Dragonflies and damselflies develop in fresh water and forage as an adult in sometimes extended landscapes: Sympetrum sanguineum develops in soft water lakes, where eggs are deposited on the banks and rain in the water next season, whereas the emerged adults use the vast heathland landscape to hunt. These are just a few examples of many species that require more than one habitat type in close range.

A number of species appear to need much larger areas than previously understood: ground beetle species such as Poecilus versicolor at the Dwingelderveld and Brachinus crepitans at the Wrakelberg (both in the Netherlands) occupy as a moving population a much larger area than the few acres around fixed pitfall traps, resulting in an apparently fluctuating number in the traps, while the population is fairly constant in sizes but moves around in the area. This makes the area to conserve thus bigger than presumed. In another example, a butterfly Melitaea cinxia at the Bemelerberg (the Netherlands), the area needs to cover larger differences in moisture gradients, as the population moved in a very dry year to the extended part (reclaimed from agriculture just a few years before) of the area (which was moister) and recolonized the original reserve the year after again. A nice example of metapopulation movement; without the reclaimed extension of the original reserve, the reintroduced species would have been gone extinct again (see also Van Noordwijk et al., 2012).

Another problem to tackle, typically in invertebrates, is that of the very vast fluctuations in numbers. However, in most species numbers are fairly high, thus no extinction problems are to be expected in terms of loss of genetic variation. Loss of habitat will usually be the largest threat. Nevertheless, some species occurring in lower densities may show these high fluctuations, for instance in the butterfly Callophrys rubi: in transect studies annual densities vary from 10-350. In PVA studies this variance is used to estimate the chance of extinction (less than once in 100 generations). In this methodology one assumes a mirroring of fluctuations downward and upward, while from ecological literature it is known that downward fluctuations are much lower in magnitude than the upward ones. Even several kinds of life history features exist to cope with detrimental seasons, such as prolonged diapause, resting eggs, etc. Taking the log of the numbers before calculating the PVA may help here to prevent overestimates of required surfaces to keep a population in a sustainable state.

So, in summary, for larger invertebrates methodology as proposed for mammals may be used, for the vast majority of the small and less mobile ones, habitat preservation is of most importance, thus following an area-based approach. Only the small and mobile species require extra attention in terms of metapopulation dynamics, combination of habitats were required, and rescaling the fluctuations in numbers when PVA are to be calculated.

\subsubsection{Population categories for species groups}

As argued above, for invertebrates as a group one may need several methodologies to proper estimate a FRP. We will start with a short key based on just mobility, body size and density of the species: 
1. a. Larger species, usually in low density with a high to moderate mobility (e.g. octopuses, colonies of carpenter bees and larger ants, N.B. the colony here is the unit of reproduction, not the individual, so mobility, size and density refers here to colonies): GROUP I

b. smaller species, or having higher mobility and/or density

2. a. Species less mobile in most of their life stages, usually in high densities in the habitat they live in, size is mostly small (e.g. soil inhabiting mites and springtails, plant specific herbivores as aphids, all kinds of leaf mining insects, etc.): GROUP II

b. Species having a higher mobility and sometimes a lower density

3. a. Species using several types of habitats during their life span, these types of habitat lie within the mobility range of the species during one generation, or species having a higher mobility that allows for fast (re)colonization of new spots ---

b. Species being much more mobile, with individuals dispersing over large distances, even crossing MS borders (e.g. migrating butterflies and dragonflies): GROUP III

4. a. Species having a high mobility that allows for fast (re)colonization of new spots: GROUP IV b. Species using several types of habitats during their life span, these types of habitat lie within the mobility range of the species during one generation: GROUP $\mathbf{V}$

These groups are described in more detail below in relation to the population categories defined in Table 3.1.

Group I: Species having a moderate to high mobility, large size and usually lower densities. FRPs for these species may follow the methodology for vertebrates (mammals, birds, fish etc.) with population category S1.

Group II: Species in this group have small-sized individuals, usually in high densities and with a limited mobility (population category S6). Populations are not often subject to extinction threats, nevertheless, if the local habitat becomes too small or deteriorated, recolonization may be very difficult due to local adaptations of these species. Local adaptation can be seen as a trade-off to mobility: either a species is more mobile and hence less adapted to specific local environmental conditions, or a species is very well adapted and is consequently less mobile (higher mobility and colonization would give rise to a higher mortality rate, due to experienced less favourable conditions elsewhere).

Group III: For species in this group the same methodology as in birds may be followed (mostly population category S1 or MR1 for truly migratory species). However, for calculating growth rates of populations a log transformation on numbers may be used as argued above.

Group IV: Species having a higher mobility that allow for fast (re)colonization of new spots are typically the species with metapopulation dynamics (population category S5). This concept was introduced in a study of an endangered butterfly, the Glanville fritillary (Melitaea cinxia) (Hanski et al., 1995). In setting FRPs not only the number of individuals per site is important, but also the number of potentially suitable sites and their connection. Based on the metapopulation dynamics (frequency of (re)colonisations and local extinctions) one can calculate the number of sites needed for a sustainable metapopulation (see Mills, 2007 Chapter 10).

Group V: Species using several types of habitats during their life span require that these types of habitat lie within the mobility range of the species during one generation. Population can mov around in vast areas, e.g. for Poecilus versicolor, a ground beetle. Sampling these populations on fixed spots (for instance with pitfall traps) may give rise to fluctuating numbers on such a spot, whilst the population as such has much less fluctuation. This kind of dynamics is included in population category S5 as well.

\section{References}

Hanski, I, T. Pakkala, M. Kuussaari and G. Lei, 1995. Metapopulation persistence of an endangered butterfly in a fragmented landscape. Oikos 72: 21-28.

Mills, L.S., 2007. Conservation of wildlife populations. Blackwell Publishing, 407 pp.

Van Noordwijk, C.G.E., D.E. Flierman, E. Remke, M.F. Wallis De Vries \& M.P. Berg, 2012. Impact of grazing management on hibernating caterpillars of the butterfly Melitaea cinxia in calcareous grasslands. Journal of Insect Conservation 16: 909-920. 


\subsection{Marine habitats}

\subsubsection{General remarks}

Nine habitat types on Annex I are included under marine reporting requirements of the Habitats Directive (Table 4.6.1). With the exception of Posidonia beds, they are all physiographic features, albeit at various scales. Estuaries and inlets and bays can extend over many square kilometres for example, while sea caves and submarine structures made by leaking gases are typically much smaller features. Reporting on the status of coastal lagoons (habitat code 1150) is usually grouped with terrestrial habitat types.

Most of the habitat types occur in many coastal Member States and are present across all the marine biogeographical regions. The main exception is Boreal Baltic narrow inlets, which only occurs in the Baltic biogeographical marine region. Posidonia beds, a priority marine habitat type, also has a more limited distribution, only being found in the Mediterranean.

Table 4.6.1 Marine habitat types

\begin{tabular}{ll} 
Habitat code & Habitat Type \\
\hline 1110 & Sandbanks which are slightly covered by sea water all the time \\
\hline 1120 & Posidonia beds (Posidonion oceanicae) \\
\hline 1130 & Estuaries \\
\hline 1140 & Mudflats and sandflats not covered by seawater at low tide \\
\hline 1160 & Large shallow inlets and bays \\
\hline 1180 & Reefs \\
\hline 8830 & Submarine structures made by leaking gasses \\
\hline
\end{tabular}

The Interpretation Manual of EU habitats describes some of the variability within these habitat types. Some of the descriptions have been modified (cf. sandbanks) and additional changes made for accession countries since the first version of the Manual was published (EC, 1995; EC, 2007; EC, 2013) and consequently shifted potential values of FRV and FRA between the first and subsequent reporting periods

The list of marine habitat types is far less comprehensive than that for the terrestrial environment, particularly in relation to shelf and open ocean ecosystems (e.g. EEA, 2015). Guidance on determining FRVs could therefore usefully be framed with a potentially expanded Annex 1 list of marine habitats in mind.

\subsubsection{Setting FRR and FRA for marine habitats}

Current range. The current range of what are often large intertidal/coastal marine habitat types $(1130,1140,1160$ and 1650) is generally well known across the marine biogeographical regions. The situation is less clear for permanently submerged/offshore features primarily due to lack of information or mapping on a detailed enough scale to distinguish such habitat types. This is being addressed through marine survey work and inventories frequently driven by the requirements of the Habitats Directive (e.g. Barratt et al., 2014) and supported by INTERREG projects (e.g. MESH, and PANACHE). A recent 'Red List' assessment, using a network of marine scientists, has also brought together information to provide an overview of the character, extent and status of benthic marine habitats across the European Union (Gubbay et al., 2016). The knowledge base for determining current range of marine habitats, including Annex I habitat types is therefore improving and consequently the baseline, even working on $10 \times 10 \mathrm{~km}$ grid squares (reported at $50 \times 50 \mathrm{~km}$ ), is likely to change for these lesser known habitat types at least over the next reporting period. 
Potential extent of range. Given that the majority of Annex I marine habitats are physiographic features, the underlying geological, physical and oceanographic processes are especially important influences on their potential range. Understanding and mapping these influences has been used to scope the potential range of some offshore habitat types (e.g. sandbanks and reefs). The use of proxies is a reasonable and realistic approach to determining potential range of such marine habitat types and therefore also informative where there is an absence of current range data. Indeed, in the absence of historical data and current range information, this is potentially the most significant factor to focus on when setting FRR.

A valuable source in this regard at European level is EUSeaMap, although working at a more detailed level than Annex 1 habitat types (see Figure 4.6.1). A combination of survey data and predictive modelling is being undertaken in phases by the European Marine Observation and Data Network (EMODnet). Work to date has provided benthic habitat layers across the Celtic Seas, Greater North Sea and Baltic Sea, as well as undertaking broad-scale mapping of the western Mediterranean for the first time. The coverage of the maps is currently being extended to all European seas.

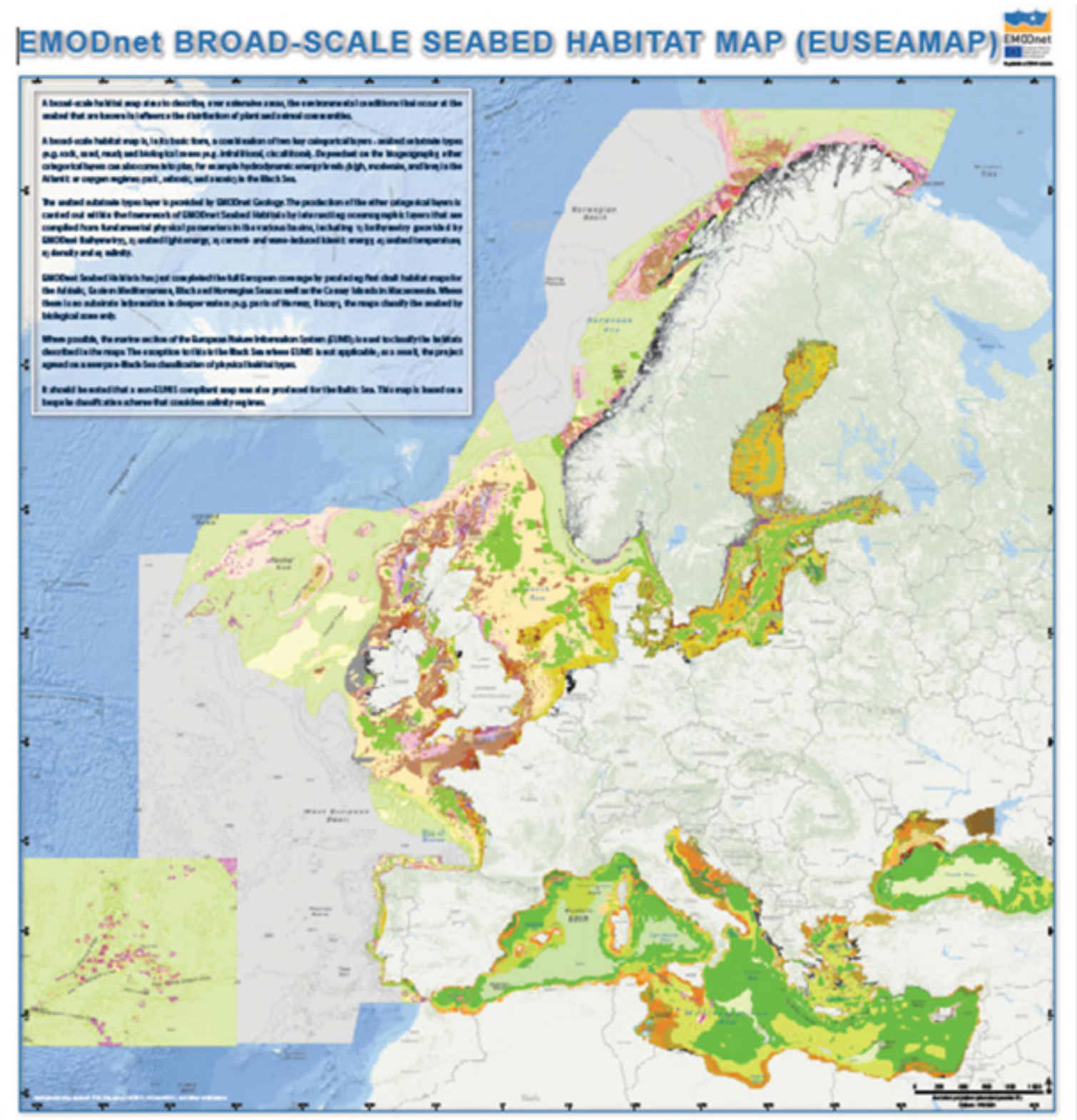

Figure 4.6.1 EUSeaMap 
Historical range. The timescale over which historical range is considered will determine the potential for FRR to be informed by this parameter. For example, there is good historical information on changes in the extent of the some of the Annex 1 habitat types. This is most likely the case for 1130 and 1140 but with the most substantial changes in extent having taking place in the 18th and $19^{\text {th }}$ centuries. More recent (decadal) changes have been reported for Posidonia beds (1120) based on species distribution (e.g. RAC/SPA, 2014), while for physiographic features such as 1160 and 1650 historical range may be similar to current range, as substantive changes may take place over geological time scales. There is unlikely to be detailed historical mapping of the extent of habitat types where they occur far from the coast or in deeper waters, although some point source data and small scale maps are available, for example from 19th century scientific surveys, fishing logbooks and historical charts.

Area required for variability of the habitat. For Annex 1 marine habitat types that are physical features, such as Boreal Baltic inlets and estuaries, their variability is usually known and described in general terms. Despite this the associated biotopes/marine communities may not be known and even where this is the case, they may be poorly understood. This precludes a good understanding of whether the full variability of the habitats is present within the FRR. It is also the case that such variation is unlikely to be 'captured' at a national scale (e.g. submerged and semi-submerge caves which support different characteristic communities depending on the predominant rock time). Nevertheless, if the variability is accounted for within each Member State, then when taken in combination, this factor should be adequately addressed.

\section{References}

Barratt, L., Houston, J., Rose, C. \& Mitchell, D. 2014. Marine Thematic Report. The future of Europe's seas - contribution of the LIFE programme to protecting and improving the marine environment. Astrale 'gamma-Contract'. 67pp.

European Commission 1995 Interpretation Manual of European Union Habitats - EUR12. European Commission Directorate-General XI. Environment, Nuclear Safety and Civil Protection.

European Commission 2007. Interpretation Manual of European Union Habitats - EUR27. European Commission DG Environment. Nature and biodiversity.

European Commission 2013. Interpretation Manual of European Union Habitats - EUR28. European Commission DG Environment. Nature and biodiversity.

European Environment Agency 2015. State of nature in EU. Results from reporting under the nature directives 2007 - 2012. EEA Technical Report No.2/2015.

Gubbay, S. et al., 2016. European Red List of Habitats. Part 1. Marine habitats. 52pp. http://ec.europa.eu/environment/nature/knowledge/pdf/Marine_EU_red_list_report.pdf

RAC/SPA - UNEP/MAP, 2014. Monitoring protocol for Posidonia oceanica beds. By Guala I, Nikolic V, Ivesa L, Di Carlo G, Rajkovic Z, Rodic P, Jelic K. Ed. RAC/SPA - MedMPAnet Project, Tunis. 37 pages + annexes. 


\section{General references}

Agrillo, E., N. Alessi, B. Jiménez-Alfaro, L. Casella, P. Angelini, O. Argagnon, G. Crespo, F. FernándezGonzález, T. Monteiro-Henriques, C. Silva Neto \& F. Attorre. 2018. The use of large databases to characterize habitat types: the case of Quercus suber woodlands in Europe. Rendiconti dei Lincei (accepted)

Álvarez-Martínez, J.M., B. Jiménez-Alfaro, J. Barquín, B. Ondiviela, M. Recio, A. Silió-Calzada \& J.A. Juanes. 2017. Modelling the area of occupancy of habitat types with remote sensing. Methods Ecol. Evol., doi: 10.1111/2041-210X.12925.

Angelstam, P. \& T. Kuuluvainen. 2005. Boreal forest disturbance regimes, successional dynamics and landscape structures - a European perspective. Ecological Bulletins 51: 117-136.

Beissinger S.R. \& D.R. McCullough (eds.) 2002. Population Viability Analysis. University of Chicago Press.

Bensettiti, F., R. Puissauve, F. Lepareur, J. Touroult \& L. Maciejewski. 2012. Evaluation de l'état de conservation des habitats et des espèces d'intérêt communautaire. Guide méthodologique - DHFF article 17, 2007-2012. Version 1. Rapport SPN 2012-27, Service du patrimoine naturel, Muséum National d'Histoire Naturelle, Paris.

Berg, L.J.L. van den, E. Dorland, Ph. Vergeer, M.A.C. Hart, R. Bobbink \& J.G.M. Roelofs. 2005. Decline of acid-sensitive plant species in heathland can be attributed to ammonium toxicity in combination with low pH. New Phytologist 166: 551-564.

Bijlsma R.J., J.A.M. Janssen, E.J. Weeda \& J.H.J. Schaminée. 2014. Gunstige referentiewaarden voor oppervlakte en verspreidingsgebied van Natura 2000-habitattypen in Nederland. Wageningen, Wettelijke Onderzoekstaken Natuur \& Milieu, WOt-rapport 125 / Favourable reference values for area and range of Natura 2000 habitat types in the Netherlands. Wageningen, Statutory Research Tasks Unit for Nature and the Environment, Wageningen UR. WOt-report 125.

Bonelli, S., F. Barbero, A. Zampollo, C. Cerrato \& V. La Morgia. 2018. Apollo (Parnassius apollo) in Italy - Alpine biogeographical region.

http://biodiversity.eionet.europa.eu/activities/Reporting/Article_17/Reports_2019/Files_2019/Fav ourable\%20reference\%20values.zip

Bragina, E.V., A.R. Ives, A.M. Pidgeon, T. Kuemmerle, L.M. Baskin, Y.P. Gubar, M. Piquer-Rodríguez, N.S. Keuler, V.G. Petrosyan \& V.C. Radeloff. 2015. Rapid declines of large mammal populations after the collapse of the Soviet Union. Conservation Biology 29: 844-853.

Brambilla, M., M. Gustin \& C. Celada. 2011. Defining Favourable Reference Values for bird populations in Italy: setting long-term conservation targets for priority species. Bird Conservation International 21: 107-118.

Brambilla M., M. Gustin \& C. Celada. 2014. Setting Favourable Habitat Reference Values for breeding birds: general principles and examples for passerine birds. Bird Conservation International 24: 263-271.

Brigham, C.A. \& M.W. Schwartz (eds.) 2003. Population viability in plants. Conservation, management, and modeling of rare plants. Ecological Studies 165. Springer.

Brook, B.W., C.J.A. Bradshaw, L.W. Traill \& R. Frankham. 2011. Minimum viable population size: not magic, but necessary. Trends in Ecology and Evolution December 26(12): 619-620.

Bruford, M.W. 2015. Additional Population Viability Analysis of the Scandinavian wolf population. Report 6639. Swedish Environmental Protection Agency.

Bücking, W. 2003. Are there threshold numbers for protected forests? Journal of Environmental Management 67: 37-45.

Busing, R.T. \& P.S. White (1993). Effects of area on old-growth forest attributes: implications for the equilibrium landscape concept. Landscape Ecology 8(2): 119-126.

Comte, L. \& G. Grenouillet. 2013. Species distribution modelling and imperfect detection: comparing occupancy versus consensus methods. Diversity Distrib. 19, 996-1007.

Cousins, S.A.O., H. Ohlson \& O. Eriksson. 2007. Effects of historical and present fragmentation on plant species diversity in semi-natural grasslands in Swedish rural landscapes. Landscape Ecology 22: 723-730. 
Cousins, S.A.O. \& D. Vanhoenacker. 2011. Detection of extinction debt depends on scale and specialisation. Biological Conservation 144: 782-787.

DG Environment. 2017. Reporting under Article 17 of the Habitats Directive: Explanatory notes and guidelines for the period 2013-2018. Brussels.

Di Marco M., L. Santini, P. Visconti., A. Mortelliti, L. Boitani \& C. Rondinini. 2016. Using habitat suitability models to scale up population persistence targets. Hystrix, the Italian Journal of Mammalogy 27(1). http://www.italian-journal-of-mammalogy.it/article/view/11660/pdf.

Dodman, T. \& G.C. Boere (eds.) 2010. The Flyway Approach to the conservation and wise use of waterbirds and wetlands: A Training Kit. Wings Over Wetlands Project, Wetlands International and BirdLife International, Ede, The Netherlands.

Dullinger, S., F. Essl, W. Rabitsch, K.H. Erb, S. Gingrich, H. Haberl, K. Hülber, V. Jarošík, F. Krausmann, I. Kühn, J. Pergl, P. Pyšek \& Ph.E. Hulme. 2013. Europe's other debt crisis caused by the long legacy of future extinctions. Proceedings of the National Academy of Sciences of the United States of America 110(18): 7342-7347.

European Commission. 2005. Assessment, monitoring and reporting of conservation status Preparing the 2001-2007 report under Article 17 of the Habitats Directive (DocHab-04-03/03 rev.3). European Commission, DG Environment, Brussels.

European Commission. 2013. Interpretation manual of European Union habitats. EUR 28. European Commission, DG Environment, Brussels.

Evans, D. \& M. Arvela. 2011. Assessment and reporting under Article 17 of the Habitats Directive. Explanatory Notes \& Guidelines for the period 2007-2012. Final Draft, July 2011. European Topic Centre on Biological Diversity, Paris.

Evans, P.G.H. \& Teilmann, J. (eds.) 2009. Report of ASCOBANS/HELCOM Small Cetacean Population Structure Workshop. ASCOBANS/UNEP Secretariat, Bonn, Germany. 140pp.

Frankham, R., C.J.A. Bradshaw \& B.W. Brook. 2014. Genetics in conservation management: Revised recommendations for the 50/500 rules, Red List criteria and population viability analyses. Biological Conservation 170: 56-63.

Franklin, J. 2010. Mapping species distributions. Spatial inference and prediction. Cambridge University Press, Cambridge.

Fuller, R.M. 1987. The changing extent and conservation interest of lowland grasslands in England and Wales: A review of grassland surveys 1930-84. Biological Conservation 40: 281-300.

Hahn, K., J. Emborg, L. Vesterdal, S. Christensen, R.H.W. Bradshaw, K. Raulund-Rasmussen \& J.B. Larsen. 2007. Natural forest stand dynamics in time and space - synthesis of research in Suserup Skov, Denmark and perspectives for forest management. Ecological Bulletins 52: 183194.

Harrison, S. \& C. Ray. 2002. Plant population viability and metapopulation-level processes. Pages 109122 in S.R. Beissinger \& D.R. McCullough (eds.) Population viability analysis. Chicago Univ. Press.

Hilbers, J.P., A.M. Schipper, A.J. Hendriks, F. Verones, H.M. Pereira \& M.A.J. Huijbregts. 2016a. An allometric approach to quantify the extinction vulnerability of birds and mammals. Ecology $97(3)$ : 615-626.

Hilbers, J.P., L. Santini, P. Visconti, A.M. Schipper, C. Pinto, C. Rondinini \& M.A.J. Huijbregts. 2016 b. Setting population targets for mammals using body mass as a predictor of population persistence. Conservation Biology DOI: 10.1111/cobi.12846.

Jamieson, I.G. \& F.W. Allendorf. 2012. How does the 50/500 rule apply to MVPs? Trends in Ecology and Evolution 27(10): 578-584.

Jefferson, T.A., M.A. Webber\& R.L. Pitman. 2008. Marine Mammals of the World. Academic Press/Elsevier, Amsterdam, London and New York.

Joint Nature Conservation Committee. 2007. Second Report by the UK under Article 17 on the implementation of the Habitats Directive from January 2001 to December 2006. Peterborough: JNCC.

Jones, K.E., J. Bielby, M. Cardillo, S.A. Fritz, J. O’Dell, C.D.L. Orme, K. Safi, W. Sechrest, E.H. Boakes, Ch. Carbone, Ch. Connolly, M.J. Cutts, J.K. Foster, R. Grenyer, M. Habib, Ch.A. Plaster, S.A. Price, E.A. Rigby, J. Rist, A. Teacher, O.R.P. Bininda-Emonds, J.L. Gittleman, G.M. Mace \& A. Purvis. 2009. PanTHERIA: a species-level database of life history, ecology, and geography of extant and recently extinct mammals. Ecology 90: 2648.

Kaplan, J.O., K.M. Krumhardt \& N. Zimmermann. 2009. The prehistoric and preindustrial deforestation of Europe. Quaternary Science Reviews 28: 3016-3034. 
Kim, E.S., D.N. Zaya, J.B. Fant \& M.V. Ashley. 2015. Genetic factors accelerate demographic decline in rare Asclepias species. Conserv.Genet. 16:359-369.

Laikre, L., F. Olsson, E. Jansson, O. Hössjer \& N. Ryman. 2016. Metapopulation effective size and conservation genetic goals for the Fennoscandian wolf (Canis lupus) population. Heredity 117: 279-289.

Linnell, J., V. Salvatori \& L. Boitani. 2008. Guidelines for population level management plans for large carnivores in Europe. A Large Carnivore Initiative for Europe report prepared for the European Commission (contract 070501/2005/424162/MAR/B2).

Louette, G., D. Adriaens, P. Adriaens, A. Anselin, K. Devos, K. Sannen, W. Van Landuyt, D. Paelinckx \& M. Hoffmann. 2011. Bridging the gap between the Natura 2000 regional conservation status and local conservation objectives. Journal for Nature Conservation 19: 224-235.

Louette, G., D. Adriaens, G. De Knijf \& D. Paelinckx. 2013. Staat van instandhouding (status en trends) habitattypen en soorten van de Habitatrichtlijn (rapportageperiode 2007-2012). Rapport INBO.R.2013.23. Instituut voor Natuur- en Bosonderzoek, Brussel.

McConville, A.J. \& G.M. Tucker. 2015. Review of Favourable Conservation Status and Birds Directive Article 2 interpretation within the European Union. Natural England Commissioned Reports, Number 176. http://publications.naturalengland.org.uk/publication/4852573913743360

McGuire, L.P. \& J.M. Ratcliffe. 2011. Light enough to travel: migratory bats have smaller brains, but not larger hippocampi, than sedentary species. Biol Lett. 7(2): 233-236.

Mergeay, J. 2012. Afwegingskader voor de versterking van populaties van Europees beschermde soorten. INBO.A.2012.141. Instituut voor Natuur- en Bosonderzoek, Brussel.

Nilsson, T. 2013. Population viability analyses of the Scandinavian populations of bear (Ursus arctos), Iynx (Lynx lynx) and wolverine (Gulo gulo). Report 6549. Swedish Environmental Protection Agency.

Olea, P.P. \& P. Mateo-Tomás. 2014. Living in risky landscapes: delineating management units in multithreat environments for effective species conservation. Journal of Applied Ecology 51: 42-52.

Olsen, M.T., L.W. Andersen, R. Dietz, J. Teilmann, T.H. Härkönen \& H.R. Siegismund. 2014. Integrating genetic data and population viability analyses for the identification of harbour seal (Phoca vitulina) populations and management units. Molecular Ecology 23: 815-831.

Ottburg, F.G.W.A. \& C.A.M. van Swaay (red.) 2014. Gunstige referentiewaarden voor populatieomvang en verspreidingsgebied van soorten van bijlage II, IV en $\mathrm{V}$ van de Habitatrichtlijn. Wageningen, Wettelijke Onderzoekstaken Natuur \& Milieu, WOt-rapport 124.

Palsbøll, P.J., Bérubé, M., and Allendorf F.W. (2007) Identification of management units using population genetic data. Trends in Ecology \& Evolution 22: 11-16.

Palstra, F.P. \& D.J. Fraser. 2012. Effective/census population size ratio estimation: a compendium and appraisal. Ecology and Evolution 2(9): 2357-2365.

Parviainen, J. 2005. Virgin and natural forests in the temperate zone of Europe. For.Snow Landsc. Res. 79(1/2): 9-18.

Poiani, K.A., B.D. Richter, M.G. Anderson \& H.E. Richter. 2000. Biodiversity conservation at multiple scales: Functional sites, landscapes, and networks. BioScience 50(2): 133-146.

Puranen-Li, H., C. Sollevi \& P. Sjögren-Gulve. 2014. Complementary analyses of genetic Minimum Viable Population size of Scandinavian bears (Ursus arctos). Swedish Environmental Protection Agency Report 6644.

Piessens, K. \& M. Hermy. 2006. Does the heathland flora in north-western Belgium show an extinction debt? Biological Conservation 132: 382-394.

Radchuk, V., S. Oppel, J. Groeneveld, V. Grimm \& N. Schtickzelle. 2016. Simple or complex: Relative impact of data availability and model purpose on the choice of model types for population viability analyses. Ecological Modelling 323: 87-95.

Ridding, L.E., J.W. Redhead \& R.F. Pywell. 2015. Fate of semi-natural grassland in England between 1960 and 2013: A test of national conservation policy. Global Ecology and Conservation 4: 516525.

Rodríguez, J.P, K. Rodríguez-Clark, J.E.M. Baillie, N. Ash, J. Benson, T. Boucher, C. Brown, N.D. Burgess, B. Collen, M. Jennings, D.A. Keith, E. Nicholson, C. Revenga, B. Reyers, M. Rouget, T. Smith, M. Spalding, A. Taber, M. Walpole, I. Zager \& T. Zamin. 2010. Establishing IUCN Red List criteria for threatened ecosystems. Conservation Biology 25(1): 21-29.

Sanderson, E.W. 2006. How many animals do we want to save? The many ways of setting population target levels for conservation. BioScience 56(11): 911-922. 
Santini L., M. Di Marco, P. Visconti, D. Baisero, L. Boitani \& C. Rondinini C. 2013. Ecological correlates of dispersal distance in terrestrial mammals. Hystrix 24, 181-186.

Sjögren-Gulve, P. \& T. Ebenhard (eds). 2001. The use of population viability analysis in conservation planning. Ecological Bulletins, vol. 48.

Sutherland, G.D., A.S. Harestad, K. Price \& K.P. Lertzman. 2000. Scaling of natal dispersal distances in terrestrial birds and mammals. Conservation Ecology 4: 16.

Sveegaard, S., A. Galatius, R. Dietz, L. Kyhna, J.C. Koblitz, M. Amundinc, J. Nabe-Nielsen, M.-H.S. Sinding, L.W. Andersen \& J. Teilmann. 2015. Defining management units for cetaceans by combining genetics, morphology, acoustics and satellite tracking. Global Ecology and Conservation 3: 839-850.

Traill, L.W., C.J.A. Bradshaw \& B.W. Brook. 2007. Minimum viable population size: A meta-analysis of 30 years of published estimates. Biological Conservation 139: 159-166.

Traill, L.W., B.W. Brook, R.R. Frankham \& C.J.A. Bradshaw. 2010. Pragmatic population viability targets in a rapidly changing world. Biological Conservation 143: 28-34.

Tye, A., C. Christodoulou-Davies, C. Papazoglou. \& M. Apostolidou. 2014. Setting Favourable Reference Values for Annex I bird species at Oroklini marsh as part of the LIFE project: "Restoration and Management of Oroklini Lake SPA in Larnaca, Cyprus".

Voigt, Ch.C., L.S. Lehnert, G. Petersons, F. Adorf \& L. Bach. 2015. Wildlife and renewable energy: German politics cross migratory bats. European Journal of Wildlife Research DOI: 10.1007/s10344-015-0903-y.

Wallace, B.P. et al. 2010. Regional Management Units for marine turtles: a novel framework for prioritizing conservation and research across multiple scales. PLoS ONE 5(12): e15465. doi: $10.1371 /$ journal.pone. 0015465.

Wang, J., E. Santiago \& A. Caballero. 2016. Prediction and estimation of effective population size. Heredity 117: 193-206.

Waring, G.T., D.B. Palka \& P.G.H. Evans. 2009. North Atlantic Marine Mammals. Pp. 763-771. In: Encyclopedia of Marine Mammals (Editors W.F. Perrin, B. Würsig and J.G.M. Thewissen). 2nd edition. Academic Press, San Diego.

Whitmee, S. \& C.D.L. Orme. 2013. Predicting dispersal distance in mammals: a trait-based approach. Journal of Ecology 82: 211-221.

Yackulic, C.B. \& J.R. Ginsberg. 2016. The scaling of geographic ranges: implications for species distribution models. Landscape Ecol. 31:1195-1208.

Zeigler, S.L., J.P. Che-Castaldo \& M.C. Neel. 2013. Actual and potential use of population viability analyses in recovery of plant species listed under the U.S. endangered species act. Conservation Biology 27(6): 1265-1278. 


\section{Annex 1 Questionnaire sent to Member States}

\section{QUESTIONNAIRE ON SETTING REFERENCE VALUES}

This inquiry results from a service contract by the European Commission for Defining and applying reference values for species and habitats under the EU birds and habitats directive

(ENV.B.3./SER/2015/0009). The contracting authority works closely together with the EEA and its ETC-BD who are leading on the whole review process.

The questionnaire has been sent to all Member State representatives involved in Article 12 and 17 reporting. The results of this inquiry will become available spring 2016 in the CIRCABC-website on Favourable Reference Values (https://circabc.europa.eu/w/browse/951a6763-c409-4f66-9fcec7e9b6ed80c2).

The deadline for filling in the questionnaire is 31 December 2015. Please send the completed document to Angelika.Rubin@ec.europa.eu with copies to rienkjan.bijlsma@wur.nl and Carlos.Romao@eea.europa.eu.

\begin{tabular}{|c|c|c|c|}
\hline \multicolumn{4}{|l|}{ General } \\
\hline \multicolumn{4}{|l|}{ Member State: } \\
\hline $\begin{array}{l}\text { Contact details of persons involved in } \\
\text { setting Favourable Reference Values } \\
\text { (FRVs) }\end{array}$ & name* & e-mail* & FRR/ FRA/ FRP** \\
\hline $\begin{array}{l}\text { Documentation of methods used to } \\
\text { set FRVs }\end{array}$ & reference* & link* & language* \\
\hline $\begin{array}{l}\text { Documentation of definitions for } \\
\text { habitat types including typical species }\end{array}$ & reference* & link* & language* \\
\hline $\begin{array}{l}\text { Did you set reference values for bird } \\
\text { populations under the Birds Directive? }\end{array}$ & \multicolumn{3}{|c|}{ no/ yes**; if yes: please give name and e-mail address of contact person $* * *$ : } \\
\hline \multicolumn{4}{|c|}{ Methods for features of the Habitats Directive only } \\
\hline $\begin{array}{l}\text { When did you report reference values } \\
\text { as unknown }(x) \text { ? }\end{array}$ & \multicolumn{3}{|c|}{$\begin{array}{l}\text { lack of actual distribution data/ lack of historic distribution data/ lack of trend } \\
\text { data**/ other reasons:*** }\end{array}$} \\
\hline $\begin{array}{l}\text { When did you report operators instead } \\
\text { of real values? }\end{array}$ & \multicolumn{3}{|c|}{ *** } \\
\hline $\begin{array}{l}\text { How did you decide whether FRVs are } \\
\text { different from levels when the HD } \\
\text { came into force? }\end{array}$ & \multicolumn{3}{|l|}{$* * *$} \\
\hline \multirow[t]{3}{*}{$\begin{array}{l}\text { Which factors did you consider in } \\
\text { setting FRVs? } \\
\text { From: Evans \& Arvela 2011, } \\
\text { Explanatory Notes \& Guidelines for } \\
\text { reporting under Article } 17 \text { for the } \\
\text { period } 2007-2012\end{array}$} & $\begin{array}{l}\text { FRR** } \\
\text { - current r } \\
\text { - potential } \\
\text { - historic } r \\
\text { - area requ } \\
\text { - variability } \\
\text { other: } * * *\end{array}$ & $\begin{array}{l}\text { taking int } \\
\text { of chang } \\
\text { of habita } \\
\text { tics }\end{array}$ & $\begin{array}{l}\text { cal and ecological conditions } \\
\text { Ad migration use }\end{array}$ \\
\hline & \multicolumn{3}{|c|}{$\begin{array}{l}\text { FRA** } \\
\text { - historic distribution } \\
\text { - potential natural vegetation } \\
\text { - natural variation } \\
\text { - actual distribution and variation (including quality of habitat) } \\
\text { - dynamics of the habitat type } \\
\text { - requirements of typical species (including gene flow) } \\
\text { other: } * * *\end{array}$} \\
\hline & \multicolumn{3}{|c|}{$\begin{array}{l}\text { FRP** } \\
\text { - historic distribution and abundances and causes of change } \\
\text { - potential range }\end{array}$} \\
\hline
\end{tabular}


- biological and ecological conditions

- migration routes and dispersal ways

- gene flow or genetic variation including clines

- populations should be sufficiently large to accomodate natural fluctuations and allow a healthy population structure

other: $* * *$

What method(s) did you use in the assessment of connectivity aspects of FRP and/or FRR? none/ GIS analysis of habitat coverage in the landscape/ ecological dispersal studies (marked animals)/ direct genetic method (unique markers for individuals or subpopulations)/ indirect genetic method (e.g. Fst analysis, BayesAss, Assignment test)**/ other:***

Methods for HD features and birds with reference values Did you use historic references for setting reference values? Did you use trend data for setting reference values?

For FRP/birds: did you use or include estimates of minimum viable population size? Did you consider feasibility in setting reference values?

How did you assess references values for mobile species with dynamic ranges crossing national boundaries or going beyond EU territories? Did you otherwise differentiate in methods between groups of species or habitats?

Which species or habitat types are good illustrative examples for the methods used?

Application/translation Are your current conservation targets based on reference values?

Are you defining milestones in reaching the set values?

Problems, suggestions

Which (kind of) species or habitats require biogeographic or population based reference values and why? Which species (groups) or habitat types were otherwise problematic and why?

Do you have suggestions to improve the process of setting reference values?

* expand/repeat when necessary; $* *$ delete/strike out options, *** add free text no/ fixed general baseline e.g. a particular year as used in red lists/ species or habitat specific reference e.g.a year when a feature was supposed to have FCS** no/ habitat types/ HD species/ birds**

no/ yes: based on literature/ yes: based on specific analyses**

no/ technical/ financial/ social**

$* * *$

standardized approaches for species and for habitats/ marine versus terrestrial incl. aquatic/ migrating versus non-migrating species/ central versus peripheral position in range**/ other groupings: *** ***

\begin{tabular}{|l|l|}
\hline$* * *$ \\
\hline$* * *$ \\
\hline$* * *$ \\
\hline
\end{tabular}




\section{Annex 2 Lists of migratory species and species with large home ranges}

Table A2.1 Terrestrial mammals

Michela Pacifici, Carlo Rondinini \& Luigi Boitani

References: Bats (Chiroptera) with disjunct breeding and wintering ranges: McGuire \& Ratcliffe (2011), Voigt et al. (2015). Other terrestrial mammals (Cetartiodactyla, Carnivora): Jones et al. (2009).

\begin{tabular}{lllll} 
Taxonomic group & Scientific name & English name & HD Annex Functional units* \\
Chiroptera & Barbastella barbastellus & Barbastelle & II, IV & B, W \\
\hline Chiroptera & Miniopterus schreibersii & Common Bentwing bat & II, IV & B, W \\
\hline Chiroptera & Myotis dasycneme & Pond bat & II, IV & B, W \\
\hline Chiroptera & Myotis & Greater mouse-eared bat & II, IV & B, W \\
\hline Chiroptera & Myotis daubentonii & Daubenton's bat & IV & B, W \\
\hline Chiroptera & Nyctalus leisleri & Leisler's bat & IV & B, W \\
\hline Chiroptera & Nyctalus noctula & Noctule & IV & B, W \\
\hline Chiroptera & Pipistrellus nathusii & Nathusius' pipistrelle & IV & B, W \\
\hline Chiroptera & Pipistrellus pygmaeus & Pygmy Pipistrelle & IV & B, W \\
\hline Chiroptera & Vespertilio murinus & Particoloured bat & IV & B, W \\
\hline Cetartiodactyla & Rangifer tarandus fennicus & Finnish forest reindeer & II & B, W \\
\hline Carnivora & Canis lupus & Wolf & II, IV, V & B \\
\hline Carnivora & Ursus arctos & Brown bear & II, IV & B \\
\hline Carnivora & Gulo gulo & Wolverine & II & B \\
\hline Carnivora & Eynx & II, IV & B
\end{tabular}

* Functional units: B (breeding) population, W (wintering) population. 
Table A2.2 Seals and turtles

\section{Susan Gubbay}

Reference: IUCN Red List of threatened species (http://www.iucnredlist.org/search)

\begin{tabular}{lllll} 
Taxonomic group & Scientific name & English name & HD Annex Functional units* \\
Pinniped & Cystophora cristata & Hooded seal & V & NB -vagrant \\
\hline Pinniped & Erignathus barbatus & Bearded seal & V & NB -vagrant \\
\hline Pinniped & Halichoerus grypus & Grey seal & II, V & B, NB \\
\hline Pinniped & Monachus monachus & Mediterranean monk seal & II, IV & B, NB \\
\hline Pinniped & Phoca (Pagophilus) groenlandica & Harp seal & V & NB -vagrant \\
\hline Pinniped & Phoca (Pusa) hispida botnica & Ringed Seal & II, V & B,NB \\
\hline Pinniped & Phoca vitulina & Harbour seal & II, V & B,NB \\
\hline Reptile & Caretta caretta & Loggerhead turtle & II, IV & B,NB \\
\hline Reptile & Chelonia mydas & Green turtle & II, IV & B,NB \\
\hline Reptile & Dermochelys coriacea & Leatherback turtle & IV & NB \\
\hline Reptile & Eretmochelys imbricata & Hawksbill turtle & IV & NB \\
\hline Reptile & Lepdochelys kempii & Kemps's Ridley turtle & IV & NB -vagrant \\
\hline
\end{tabular}

* Functional units: B (breeding) population, NB (non-breeding) population 
Table A2.3 Cetaceans

Peter Evans

References: Jefferson et al. (2008), Waring et al. (2009).

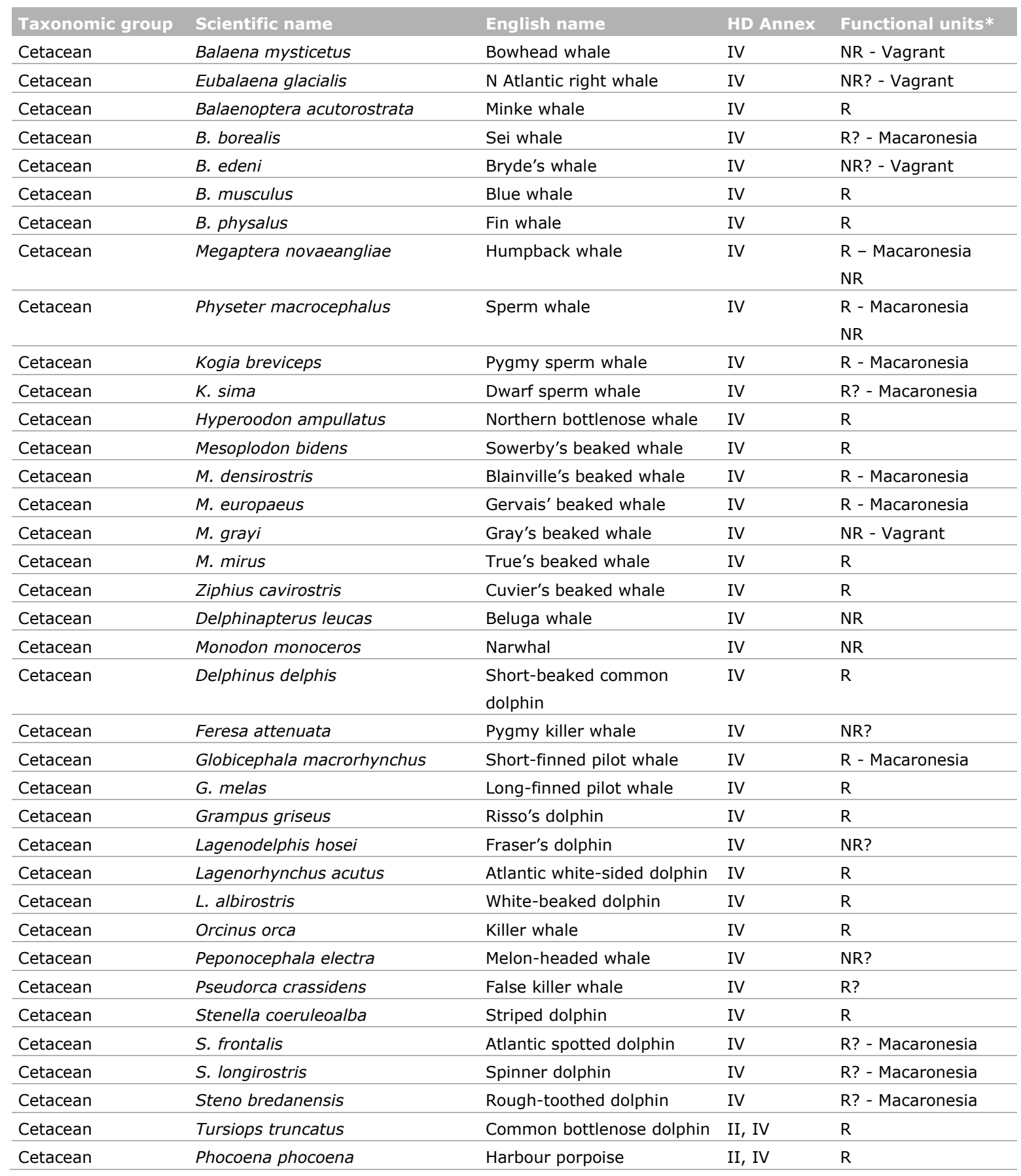

* Functional units: R (reproductive) population, NR (non-reproductive) population 
Table A2.4 Fishes and lampreys

Erwin Winter

\begin{tabular}{llllc} 
Taxonomic group & Species (scientific name) & Species (English name) & HD Annex Functional units* \\
Petromyzonidae & Lampetra fluviatilis & River Lamprey & II, V & S \\
\hline Petromyzonidae & Petromyzon marinus & Sea Lamprey & II & S \\
\hline Acipenseridae & Acipenser naccarii & Adriatic Sturgeon & II, IV & S \\
\hline Acipenseridae & Acipenser sturio & European Sturgeon & II, IV & S \\
\hline Acipenseridae & Huso huso & Beluga Sturgeon & V & S \\
\hline Acipenseridae & Acipenser nudiventris & Ship Sturgeon & S & S \\
\hline Acipenseridae & Acipenser gueldenstaedtii & Russian Sturgeon & V & S \\
\hline Acipenseridae & Acipenser stellatus & Stellate Sturgeon & II, V & S \\
\hline Clupeidae & Alosa alosa & Allis Shad & Twaite Shad V & S \\
\hline Clupeidae & Salosa fallax & Atlantic Salmon & II, V & S \\
\hline Salmonidae & Coregonus oxyrhynchus & North Sea Houting & II, IV & S
\end{tabular}

* Functional units: $\mathrm{S}$ (pawning) population in river basin 
Table A2.5 Birds

André van Kleunen, Marc van Roomen \& Ruud Foppen

The table lists the EU (partially) migratory bird species. Scientific and English names according to 2014 BirdLife/Handbook of the Birds of the World/IUCN.

M/PM: Migratory (M), partially migratory (PM); NotW: species not wintering in Europe; NotB: species not breeding in Europe.

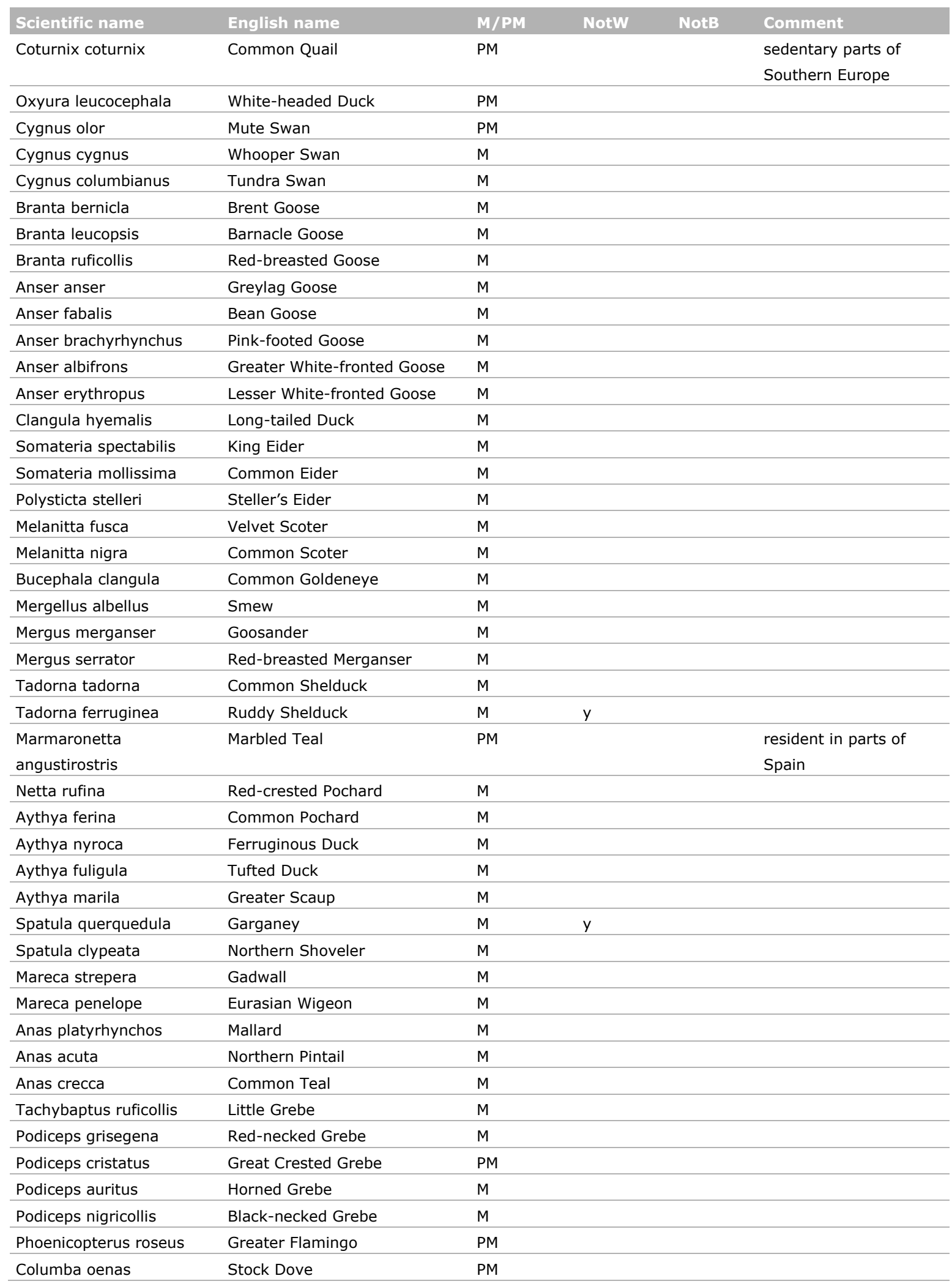




\begin{tabular}{|c|c|c|c|c|c|}
\hline Scientific name & English name & M/PM & Notw & NotB & Comment \\
\hline Columba palumbus & Common Woodpigeon & PM & & & \\
\hline Streptopelia turtur & European Turtle-dove & M & y & & \\
\hline Streptopelia decaocto & Eurasian Collared-dove & PM & & & \\
\hline Spilopelia senegalensis & Laughing Dove & PM & & & \\
\hline Pterocles orientalis & Black-bellied Sandgrouse & PM & & & \\
\hline Pterocles alchata & Pin-tailed Sandgrouse & PM & & & \\
\hline Caprimulgus ruficollis & Red-necked Nightjar & $M$ & y & & \\
\hline Caprimulgus europaeus & European Nightjar & M & y & & \\
\hline Tachymarptis melba & Alpine Swift & $M$ & $y$ & & \\
\hline Apus caffer & White-rumped Swift & M & y & & \\
\hline Apus affinis & Little Swift & M & y & & \\
\hline Apus pallidus & Pallid Swift & $M$ & $y$ & & \\
\hline Apus apus & Common Swift & M & y & & \\
\hline Clamator glandarius & Great Spotted Cuckoo & M & $y$ & & \\
\hline Cuculus canorus & Common Cuckoo & M & $y$ & & \\
\hline Rallus aquaticus & Western Water Rail & M & & & \\
\hline Crex crex & Corncrake & M & y & & \\
\hline Porzana porzana & Spotted Crake & M & y & & \\
\hline Zapornia parva & Little Crake & M & y & & \\
\hline Zapornia pusilla & Baillon's Crake & M & y & & \\
\hline Gallinula chloropus & Common Moorhen & PM & & & \\
\hline Fulica atra & Common Coot & PM & & & \\
\hline Anthropoides virgo & Demoiselle Crane & M & y & & \\
\hline Grus grus & Common Crane & M & & & \\
\hline Tetrax tetrax & Little Bustard & PM & & & \\
\hline Otis tarda & Great Bustard & PM & & & \\
\hline Gavia stellata & Red-throated Loon & M & & & \\
\hline Gavia arctica & Arctic Loon & M & & & \\
\hline Gavia immer & Common Loon & $M$ & & & \\
\hline Gavia adamsii & Yellow-billed Loon & M & & & \\
\hline Oceanites oceanicus & Wilson's Storm-petrel & M & & & \\
\hline Pelagodroma marina & White-faced Storm-petrel & $M$ & & & \\
\hline Hydrobates pelagicus & European Storm-petrel & M & & & \\
\hline Hydrobates castro & Band-rumped Storm-petrel & M & & & \\
\hline Hydrobates leucorhous & Leach's Storm-petrel & M & & & \\
\hline Fulmarus glacialis & Northern Fulmar & M & & & \\
\hline Pterodroma deserta & Desertas Petrel & M & & & \\
\hline Pterodroma madeira & Zino's Petrel & $M$ & & & \\
\hline Ardenna grisea & Sooty Shearwater & M & & & \\
\hline Ardenna gravis & Great Shearwater & M & & & \\
\hline Calonectris diomedea & Scopoli's Shearwater & $M$ & & & \\
\hline Calonectris borealis & Cory's Shearwater & M & & & \\
\hline Puffinus puffinus & Manx Shearwater & M & & & \\
\hline Puffinus yelkouan & Yelkouan Shearwater & $M$ & & & \\
\hline Puffinus mauretanicus & Balearic Shearwater & M & & & \\
\hline Puffinus Iherminieri & Audubon's Shearwater & M & & & \\
\hline Bulweria bulwerii & Bulwer's Petrel & $M$ & & & \\
\hline Ciconia nigra & Black Stork & PM & & & \\
\hline Ciconia ciconia & White Stork & PM & & & \\
\hline Platalea leucorodia & Eurasian Spoonbill & PM & & & \\
\hline Geronticus eremita & Northern Bald Ibis & M & $y$ & & \\
\hline Plegadis falcinellus & Glossy Ibis & $M$ & & & \\
\hline Botaurus stellaris & Eurasian Bittern & PM & & & \\
\hline Ixobrychus minutus & Common Little Bittern & M & $y$ & & \\
\hline Nycticorax nycticorax & Black-crowned Night-heron & PM & & & \\
\hline Ardeola ralloides & Squacco Heron & $M$ & y & & \\
\hline Bubulcus ibis & Cattle Egret & M & & & \\
\hline Ardea cinerea & Grey Heron & PM & & & \\
\hline
\end{tabular}




\begin{tabular}{|c|c|c|c|c|c|}
\hline Scientific name & English name & M/PM & NotW & NotB & Comment \\
\hline Ardea purpurea & Purple Heron & M & y & & \\
\hline Ardea alba & Great White Egret & M & & & \\
\hline Egretta garzetta & Little Egret & M & & & \\
\hline Pelecanus crispus & Dalmatian Pelican & M & y & & \\
\hline Pelecanus onocrotalus & Great White Pelican & M & y & & \\
\hline Morus bassanus & Northern Gannet & M & & & \\
\hline Microcarbo pygmaeus & Pygmy Cormorant & PM & & & \\
\hline Phalacrocorax carbo & Great Cormorant & $M$ & & & \\
\hline Burhinus oedicnemus & Eurasian Thick-knee & PM & & & \\
\hline Haematopus ostralegus & Eurasian Oystercatcher & M & & & \\
\hline Recurvirostra avosetta & Pied Avocet & M & & & \\
\hline Himantopus himantopus & Black-winged Stilt & PM & & & \\
\hline Pluvialis squatarola & Grey Plover & M & & & \\
\hline Pluvialis apricaria & Eurasian Golden Plover & M & & & \\
\hline Eudromias morinellus & Eurasian Dotterel & M & & & $\begin{array}{l}\text { tiny wintering area in } \\
\text { southern Spain }\end{array}$ \\
\hline Charadrius hiaticula & Common Ringed Plover & M & & & \\
\hline Charadrius dubius & Little Ringed Plover & PM & & & \\
\hline Charadrius alexandrinus & Kentish Plover & PM & & & \\
\hline Charadrius leschenaultii & Greater Sandplover & M & y & y & $\begin{array}{l}\text { not a European } \\
\text { breeding bird }\end{array}$ \\
\hline Vanellus vanellus & Northern Lapwing & M & & & \\
\hline Vanellus spinosus & Spur-winged Lapwing & M & y & & \\
\hline Numenius phaeopus & Whimbrel & M & & & \\
\hline Numenius tenuirostris & Slender-billed Curlew & M & y & & \\
\hline Numenius arquata & Eurasian Curlew & M & & & \\
\hline Limosa lapponica & Bar-tailed Godwit & M & & & \\
\hline Limosa limosa & Black-tailed Godwit & M & & & \\
\hline Arenaria interpres & Ruddy Turnstone & M & & & \\
\hline Calidris canutus & Red Knot & $M$ & & & \\
\hline Calidris pugnax & Ruff & M & & & \\
\hline Calidris falcinellus & Broad-billed Sandpiper & M & y & & \\
\hline Calidris ferruginea & Curlew Sandpiper & M & & & \\
\hline Calidris temminckii & Temminck's Stint & M & & & \\
\hline Calidris alba & Sanderling & M & & & \\
\hline Calidris alpina & Dunlin & M & & & \\
\hline Calidris maritima & Purple Sandpiper & M & & & \\
\hline Calidris minuta & Little Stint & M & & & \\
\hline Scolopax rusticola & Eurasian Woodcock & M & & & \\
\hline Gallinago media & Great Snipe & M & $y$ & & \\
\hline Gallinago gallinago & Common Snipe & M & & & \\
\hline Lymnocryptes minimus & Jack Snipe & M & & & \\
\hline Phalaropus lobatus & Red-necked Phalarope & M & y & & \\
\hline Phalaropus fulicarius & Red Phalarope & M & y & & \\
\hline Xenus cinereus & Terek Sandpiper & M & $y$ & & \\
\hline Actitis hypoleucos & Common Sandpiper & M & & & \\
\hline Tringa ochropus & Green Sandpiper & M & & & \\
\hline Tringa erythropus & Spotted Redshank & M & & & \\
\hline Tringa nebularia & Common Greenshank & M & & & \\
\hline Tringa totanus & Common Redshank & M & & & \\
\hline Tringa glareola & Wood Sandpiper & M & & & \\
\hline Tringa stagnatilis & Marsh Sandpiper & M & & & \\
\hline Cursorius cursor & Cream-coloured Courser & $?$ & $?$ & & \\
\hline Glareola pratincola & Collared Pratincole & M & y & & \\
\hline Glareola nordmanni & Black-winged Pratincole & M & y & & \\
\hline Hydrocoloeus minutus & Little Gull & M & & & \\
\hline Xema sabini & Sabine's Gull & M & y & & \\
\hline Rissa tridactyla & Black-legged Kittiwake & M & & & \\
\hline Larus genei & Slender-billed Gull & $M$ & & & \\
\hline
\end{tabular}




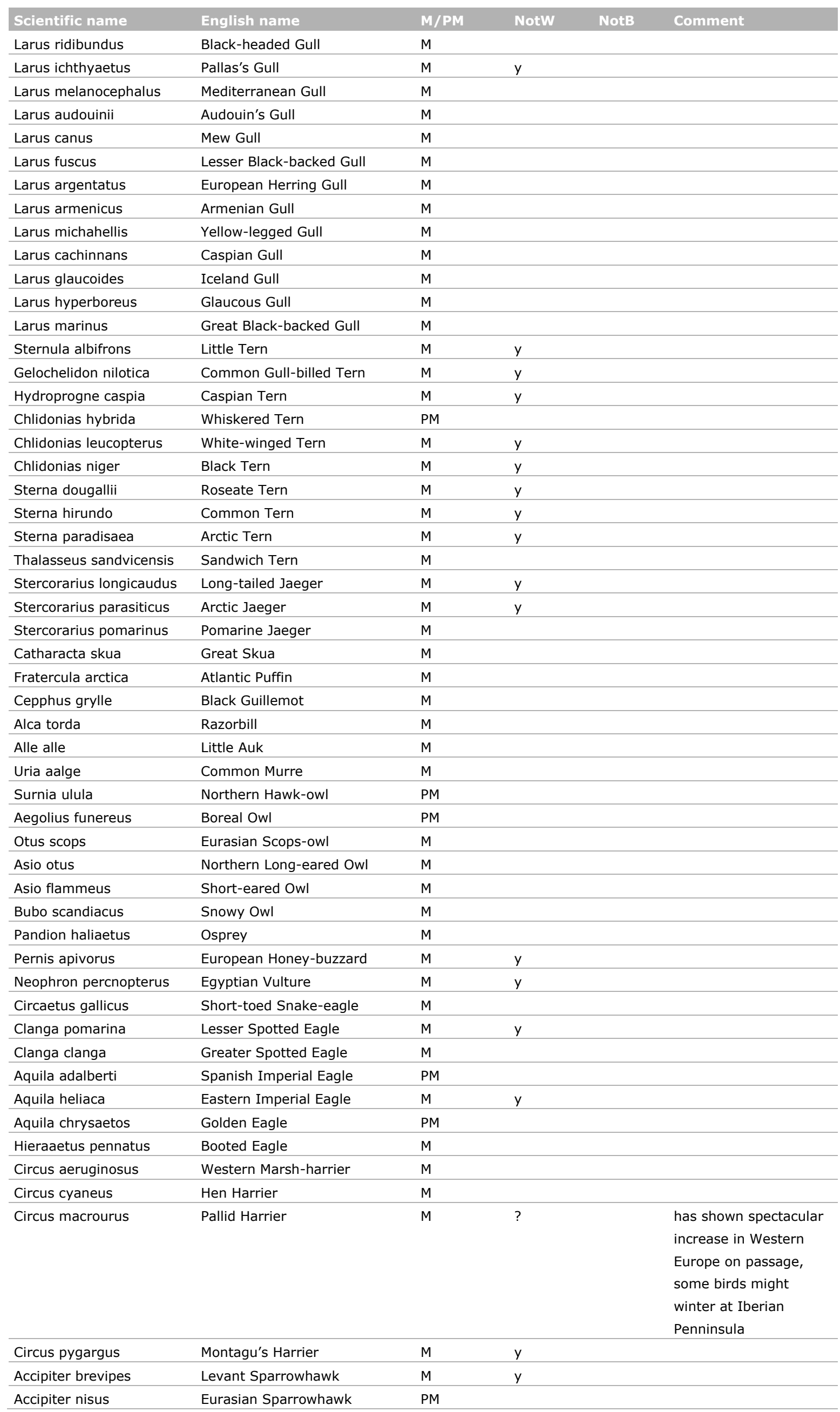




\begin{tabular}{|c|c|c|c|c|c|}
\hline Scientific name & English name & M/PM & NotW & NotB & Comment \\
\hline Accipiter gentilis & Northern Goshawk & PM & & & \\
\hline Haliaeetus albicilla & White-tailed Sea-eagle & M & & & \\
\hline Milvus milvus & Red Kite & M & & & \\
\hline Milvus migrans & Black Kite & M & & & \\
\hline Buteo lagopus & Rough-legged Buzzard & M & & & \\
\hline Buteo buteo & Eurasian Buzzard & PM & & & \\
\hline Buteo rufinus & Long-legged Buzzard & M & & & \\
\hline Upupa epops & Common Hoopoe & M & & & \\
\hline Merops apiaster & European Bee-eater & M & $y$ & & \\
\hline Coracias garrulus & European Roller & M & y & & \\
\hline Alcedo atthis & Common Kingfisher & PM & & & \\
\hline Jynx torquilla & Eurasian Wryneck & M & & & \\
\hline Dryocopus martius & Black Woodpecker & PM & & & \\
\hline Picoides tridactylus & Three-toed Woodpecker & PM & & & \\
\hline Dryobates minor & Lesser Spotted Woodpecker & PM & & & \\
\hline Dendrocopos major & Great Spotted Woodpecker & PM & & & \\
\hline Falco naumanni & Lesser Kestrel & M & & & \\
\hline Falco tinnunculus & Common Kestrel & PM & & & \\
\hline Falco vespertinus & Red-footed Falcon & M & $y$ & & \\
\hline Falco eleonorae & Eleonora's Falcon & M & $y$ & & \\
\hline Falco columbarius & Merlin & M & & & \\
\hline Falco subbuteo & Eurasian Hobby & M & $\mathrm{y}$ & & \\
\hline Falco biarmicus & Lanner Falcon & M & & & \\
\hline Falco cherrug & Saker Falcon & M & & & \\
\hline Falco rusticolus & Gyrfalcon & M & & & \\
\hline Falco peregrinus & Peregrine Falcon & M & & & \\
\hline Lanius collurio & Red-backed Shrike & M & $y$ & & \\
\hline Lanius minor & Lesser Grey Shrike & M & y & & \\
\hline Lanius excubitor & Great Grey Shrike & M & & & \\
\hline Lanius senator & Woodchat Shrike & M & $y$ & & \\
\hline Lanius nubicus & Masked Shrike & M & $y$ & & \\
\hline Oriolus oriolus & Eurasian Golden Oriole & M & $y$ & & \\
\hline Garrulus glandarius & Eurasian Jay & PM & & & \\
\hline Pica pica & Black-billed Magpie & PM & & & \\
\hline Corvus monedula & Eurasian Jackdaw & PM & & & \\
\hline Corvus frugilegus & Rook & PM & & & \\
\hline Corvus corone & Carrion Crow & PM & & & \\
\hline Corvus corax & Common Raven & PM & & & \\
\hline Bombycilla garrulus & Bohemian Waxwing & M & & & \\
\hline Parus ater & Coal Tit & PM & & & \\
\hline Parus major & Great Tit & PM & & & \\
\hline Parus caeruleus & Blue Tit & PM & & & \\
\hline Remiz pendulinus & Eurasian Penduline-tit & M & & & \\
\hline Riparia riparia & Sand Martin & M & $y$ & & \\
\hline Hirundo rupestris & Eurasian Crag-martin & M & & & \\
\hline Hirundo rustica & Barn Swallow & M & $y$ & & \\
\hline Hirundo daurica & Red-rumped Swallow & M & $y$ & & \\
\hline Delichon urbicum & Northern House-martin & M & y & & \\
\hline Aegithalos caudatus & Long-tailed Tit & PM & & & \\
\hline Melanocorypha calandra & Calandra Lark & M & & & \\
\hline Calandrella brachydactyla & Greater Short-toed Lark & M & $\mathrm{y}$ & & \\
\hline Calandrella rufescens & Lesser Short-toed Lark & M & & & \\
\hline Galerida cristata & Crested Lark & PM & & & \\
\hline Lullula arborea & Wood Lark & M & & & \\
\hline Alauda arvensis & Eurasian Skylark & M & & & \\
\hline Eremophila alpestris & Horned Lark & M & & & \\
\hline Cisticola juncidis & Zitting Cisticola & M & & & \\
\hline Cettia cetti & Cetti's Warbler & M & & & \\
\hline
\end{tabular}




\begin{tabular}{|c|c|c|c|c|c|}
\hline Scientific name & English name & M/PM & Notw & NotB & Comment \\
\hline Locustella naevia & Common Grasshopper-warbler & M & y & & \\
\hline Locustella fluviatilis & Eurasian River Warbler & M & y & & \\
\hline Locustella luscinioides & Savi's Warbler & M & y & & \\
\hline $\begin{array}{l}\text { Acrocephalus } \\
\text { melanopogon }\end{array}$ & Moustached Warbler & M & & & \\
\hline Acrocephalus paludicola & Aquatic Warbler & M & y & & \\
\hline $\begin{array}{l}\text { Acrocephalus } \\
\text { schoenobaenus }\end{array}$ & Sedge Warbler & M & y & & \\
\hline Acrocephalus agricola & Paddyfield Warbler & M & y & & \\
\hline Acrocephalus scirpaceus & Eurasian Reed-warbler & M & y & & \\
\hline Acrocephalus dumetorum & Blyth's Reed-warbler & M & y & & \\
\hline Acrocephalus palustris & Marsh Warbler & M & y & & \\
\hline $\begin{array}{l}\text { Acrocephalus } \\
\text { arundinaceus }\end{array}$ & Great Reed-warbler & M & y & & \\
\hline Hippolais caligata & Booted Warbler & M & y & & \\
\hline Hippolais pallida & Eastern Olivaceous Warbler & M & y & & \\
\hline Hippolais opaca & Western Olivaceous Warbler & M & y & & \\
\hline Hippolais olivetorum & Olive-tree Warbler & M & y & & \\
\hline Hippolais polyglotta & Melodious Warbler & M & y & & \\
\hline Hippolais icterina & Icterine Warbler & M & y & & \\
\hline Phylloscopus trochilus & Willow Warbler & M & y & & \\
\hline Phylloscopus collybita & Common Chiffchaff & M & & & \\
\hline Phylloscopus ibericus & Iberian Chiffchaff & M & y & & \\
\hline Phylloscopus bonelli & Bonelli's Warbler & M & y & & \\
\hline Phylloscopus sibilatrix & Wood Warbler & M & y & & \\
\hline Phylloscopus inornatus & Inornate Warbler & M & y & & \\
\hline Phylloscopus borealis & Arctic Warbler & M & y & & \\
\hline Phylloscopus trochiloides & Greenish Warbler & M & y & & \\
\hline Sylvia atricapilla & Blackcap & M & & & \\
\hline Sylvia borin & Garden Warbler & M & y & & \\
\hline Sylvia communis & Common Whitethroat & M & y & & \\
\hline Sylvia curruca & Lesser Whitethroat & M & y & & \\
\hline Sylvia nisoria & Barred Warbler & M & y & & \\
\hline Sylvia hortensis & Orphean Warbler & M & y & & \\
\hline Sylvia rueppelli & Rueppell's Warbler & M & y & & \\
\hline Sylvia melanocephala & Sardinian Warbler & M & & & \\
\hline Sylvia melanothorax & Cyprus Warbler & M & y & & \\
\hline Sylvia cantillans & Subalpine Warbler & M & y & & \\
\hline Sylvia subalpina & Moltoni's Warbler & M & y & & \\
\hline Sylvia conspicillata & Spectacled Warbler & M & & & \\
\hline Sylvia sarda & Marmora's Warbler & M & y & & \\
\hline Panurus biarmicus & Bearded Parrotbill & PM & & & \\
\hline Regulus regulus & Goldcrest & PM & & & \\
\hline Regulus ignicapilla & Firecrest & M & & & \\
\hline Troglodytes troglodytes & Winter Wren & PM & & & \\
\hline Tichodroma muraria & Wallcreeper & M & & & \\
\hline Certhia familiaris & Eurasian Treecreeper & M & & & \\
\hline Sturnus roseus & Rosy Starling & M & & & \\
\hline Sturnus vulgaris & Common Starling & M & & & \\
\hline Turdus torquatus & Ring Ouzel & M & & & \\
\hline Turdus merula & Eurasian Blackbird & PM & & & \\
\hline Turdus pilaris & Fieldfare & M & & & \\
\hline Turdus iliacus & Redwing & M & & & \\
\hline Turdus philomelos & Song Thrush & M & & & \\
\hline Turdus viscivorus & Mistle Thrush & M & & & \\
\hline Erithacus rubecula & European Robin & PM & & & \\
\hline Luscinia luscinia & Thrush Nightingale & M & & & \\
\hline Luscinia megarhynchos & Common Nightingale & $M$ & & & \\
\hline Luscinia svecica & Bluethroat & $M$ & & & \\
\hline
\end{tabular}




\begin{tabular}{|c|c|c|c|c|c|}
\hline Scientific name & English name & $M / P M$ & NotW & NotB & Comment \\
\hline Tarsiger cyanurus & Orange-flanked Bush-robin & M & y & & \\
\hline Erythropygia galactotes & Rufous-tailed Scrub-robin & M & y & & \\
\hline Phoenicurus ochruros & Black Redstart & M & & & \\
\hline Phoenicurus phoenicurus & Common Redstart & M & y & & \\
\hline Saxicola rubetra & Whinchat & M & y & & \\
\hline Saxicola torquatus & Common Stonechat & M & & & \\
\hline Oenanthe oenanthe & Northern Wheatear & M & y & & \\
\hline Oenanthe finschii & Finsch's Wheatear & M & & & Breeds in Caucasus \\
\hline Oenanthe hispanica & Black-eared Wheatear & M & & & \\
\hline Oenanthe pleschanka & Pied Wheatear & M & y & & \\
\hline Oenanthe cypriaca & Cyprus Wheatear & M & y & & \\
\hline Oenanthe isabellina & Isabelline Wheatear & M & y & & \\
\hline Monticola saxatilis & Rufous-tailed Rock-thrush & M & y & & \\
\hline Monticola solitarius & Blue Rock-thrush & M & & & \\
\hline Muscicapa striata & Spotted Flycatcher & M & y & & \\
\hline Ficedula hypoleuca & European Pied Flycatcher & M & y & & \\
\hline Ficedula albicollis & Collared Flycatcher & M & y & & \\
\hline Ficedula semitorquata & Semi-collared Flycatcher & M & y & & \\
\hline Ficedula parva & Red-breasted Flycatcher & M & y & & \\
\hline Cinclus cinclus & White-throated Dipper & M & & & \\
\hline Passer hispaniolensis & Spanish Sparrow & M & & & \\
\hline Passer moabiticus & Dead Sea Sparrow & $M$ & y & $?$ & $\begin{array}{l}\text { Breeds in Asian part of } \\
\text { Turkey }\end{array}$ \\
\hline Passer montanus & Eurasian Tree Sparrow & M & & & \\
\hline Montifringilla nivalis & White-winged Snowfinch & PM & & & \\
\hline Prunella collaris & Alpine Accentor & M & & & \\
\hline Prunella modularis & Hedge Accentor & M & & & \\
\hline Motacilla alba & White Wagtail & M & & & \\
\hline Motacilla citreola & Citrine Wagtail & M & y & & \\
\hline Motacilla flava & Yellow Wagtail & M & y & & \\
\hline Motacilla cinerea & Grey Wagtail & M & & & \\
\hline Anthus richardi & Richard's Pipit & M & y & y & \\
\hline Anthus campestris & Tawny Pipit & M & y & & \\
\hline Anthus trivialis & Tree Pipit & M & $y$ & & \\
\hline Anthus pratensis & Meadow Pipit & M & & & \\
\hline Anthus cervinus & Red-throated Pipit & M & $\mathrm{y}$ & & \\
\hline Anthus petrosus & Rock Pipit & M & & & \\
\hline Anthus spinoletta & Water Pipit & M & & & \\
\hline Fringilla coelebs & Eurasian Chaffinch & M & & & \\
\hline Fringilla montifringilla & Brambling & M & & & \\
\hline Serinus serinus & European Serin & M & & & \\
\hline Carduelis chloris & European Greenfinch & PM & & & \\
\hline Carduelis spinus & Eurasian Siskin & M & & & \\
\hline Carduelis carduelis & European Goldfinch & PM & & & \\
\hline Carduelis flammea & Common Redpoll & M & & & \\
\hline Carduelis flavirostris & Twite & M & & & \\
\hline Carduelis cannabina & Eurasian Linnet & M & & & \\
\hline Carpodacus erythrinus & Common Rosefinch & M & y & & \\
\hline Pinicola enucleator & Pine Grosbeak & M & & & \\
\hline Loxia pytyopsittacus & Parrot Crossbill & M & & & \\
\hline Loxia scotica & Scottish Crossbill & M & & & \\
\hline Loxia curvirostra & Red Crossbill & M & & & \\
\hline Loxia leucoptera & White-winged Crossbill & M & & & \\
\hline Pyrrhula pyrrhula & Eurasian Bullfinch & PM & & & \\
\hline $\begin{array}{l}\text { Coccothraustes } \\
\text { coccothraustes }\end{array}$ & Hawfinch & PM & & & \\
\hline Miliaria calandra & Corn Bunting & M & & & \\
\hline Emberiza citrinella & Yellowhammer & PM & & & \\
\hline Emberiza leucocephalos & Pine Bunting & $M$ & & & \\
\hline
\end{tabular}




\begin{tabular}{|c|c|c|c|c|c|}
\hline Scientific name & English name & M/PM & Notw & NotB & Comment \\
\hline Emberiza cia & Rock Bunting & M & & & \\
\hline Emberiza cineracea & Cinereous Bunting & M & y & & \\
\hline Emberiza hortulana & Ortolan Bunting & M & y & & \\
\hline Emberiza caesia & Cretzschmar's Bunting & $M$ & $y$ & & \\
\hline Emberiza pusilla & Little Bunting & M & y & & \\
\hline Emberiza rustica & Rustic Bunting & M & y & & \\
\hline Emberiza aureola & Yellow-breasted Bunting & $M$ & $y$ & & \\
\hline Emberiza melanocephala & Black-headed Bunting & M & y & & \\
\hline Emberiza schoeniclus & Reed Bunting & M & & & \\
\hline Calcarius lapponicus & Lapland Longspur & M & & & \\
\hline Plectrophenax nivalis & Snow Bunting & M & & & \\
\hline
\end{tabular}


Wageningen Environmental Research P.O. Box 47

6700 AA Wageningen

The Netherlands

T +31 (0)317480700

www.wur.nl/environmental-research

Wageningen Environmental Research Report 2928

ISSN 1566-7197
The mission of Wageningen University \& Research is "To explore the potential of nature to improve the quality of life". Under the banner Wageningen University \& Research, Wageningen University and the specialised research institutes of the Wageningen Research Foundation have joined forces in contributing to finding solutions to important questions in the domain of healthy food and living environment. With its roughly 30 branches, 5,000 employees and 10,000 students, Wageningen University \& Research is one of the leading organisations in its domain. The unique Wageningen approach lies in its integrated approach to issues and the collaboration between different disciplines.

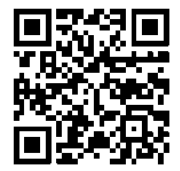





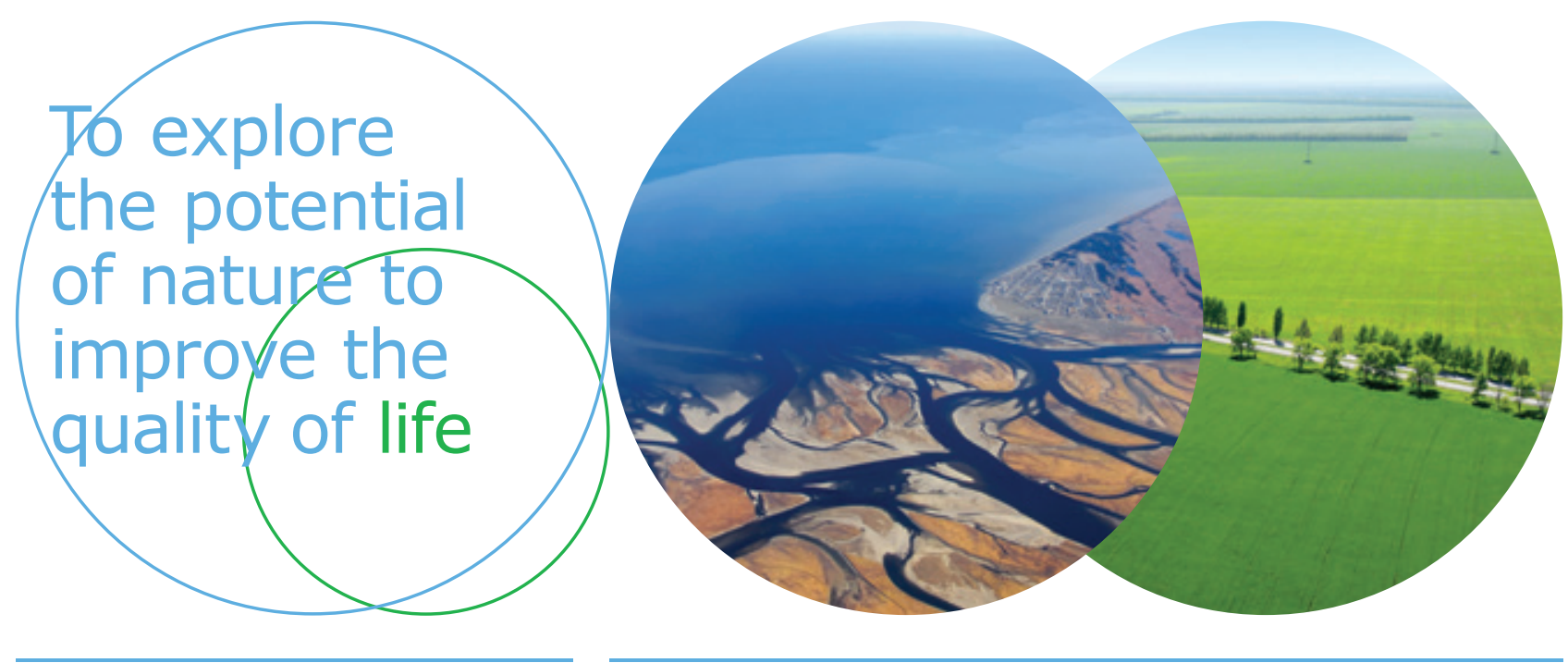

Wageningen Environmental Research P.O. Box 47

$6700 \mathrm{AB}$ Wageningen

The Netherlands

$T+31(0) 317480700$

www.wur.eu/environmental-research

Report 2928

ISSN 1566-7197
The mission of Wageningen University \& Research is "To explore the potential of nature to improve the quality of life". Under the banner Wageningen University \& Research, Wageningen University and the specialised research institutes of the Wageningen Research Foundation have joined forces in contributing to inding solutions to important questions in the domain of healthy food and living environment. With its roughly 30 branches, 5,000 employees and 10,000 students, Wageningen University \& Research is one of the leading organisations in its domain. The unique Wageningen approach lies in its integrated approach to issues and the collaboration between different disciplines. 